\title{
Electromyography of the sphincter of Oddi and gastrointestinal tract : experimental studies in the Opossum
}

Citation for published version (APA):

Coelho, J. C. U. (1985). Electromyography of the sphincter of Oddi and gastrointestinal tract: experimental studies in the Opossum. [Doctoral Thesis, Maastricht University]. Rijksuniversiteit Limburg. https://doi.org/10.26481/dis.19850101jc

Document status and date:

Published: 01/01/1985

DOI:

10.26481/dis.19850101jc

Document Version:

Publisher's PDF, also known as Version of record

\section{Please check the document version of this publication:}

- A submitted manuscript is the version of the article upon submission and before peer-review. There can be important differences between the submitted version and the official published version of record.

People interested in the research are advised to contact the author for the final version of the publication, or visit the DOI to the publisher's website.

- The final author version and the galley proof are versions of the publication after peer review.

- The final published version features the final layout of the paper including the volume, issue and page numbers.

Link to publication

\footnotetext{
General rights rights.

- You may freely distribute the URL identifying the publication in the public portal. please follow below link for the End User Agreement:

www.umlib.nl/taverne-license

Take down policy

If you believe that this document breaches copyright please contact us at:

repository@maastrichtuniversity.nl

providing details and we will investigate your claim.
}

Copyright and moral rights for the publications made accessible in the public portal are retained by the authors and/or other copyright owners and it is a condition of accessing publications that users recognise and abide by the legal requirements associated with these

- Users may download and print one copy of any publication from the public portal for the purpose of private study or research.

- You may not further distribute the material or use it for any profit-making activity or commercial gain

If the publication is distributed under the terms of Article 25fa of the Dutch Copyright Act, indicated by the "Taverne" license above, 
Promotores: Prof. Dr.J.M. Greep, Mastricht

Prof. Dr. F.G. Moody, Houston, USA

Referenten: Prof: Dr. J.A. Flendrig, Maastricht

Prof. Dr. G.N. Tytgat, Amsterdam

Prof. Dr. P.J. Klopper, Amsterdam

The experimental studies reported in this thesis were performed at the Department of Surgery of the University of Texas Medical School at Houston, Texas, USA. 
This thesis is dedicated with love to my wife, Celit Regina, and my two daughters, Caroline and Christine. 



\section{ACKNOWLEDGEMENTS}

I wish to express my sincere apprectation to prof. Dr. J.M. Greep for his kind hospitality and the opportunity to defend this thesis at his department. I feel deeply grateful for this privilege. I have also appreciated very much his valuable suggestions and comments.

I am very grateful to Prof. Dr. F.G. Moody for his assistance, encouragement, guidance and above all friendship. HIs tremendous medical knowledge and interest $1 \mathrm{n}$ me and in my family were constant stimuli.

I wish to thank Prof. Dr. G.A. Flendrig, Prof. Dr. G.N. Tytgat, and Prof. Dr. P.J. Klopper, for their critical reviewing of this thesis and very helpful comments.

My special gratittude to my friend Dr. Dirk J. Gouma for his valuable collaboration in the experiments and in the organdzation of this thesis. He has not only a pleasant personality, but also proved to be an excellent friend.

I also would like to thank Dr. Norman W. Welsbrodt and Mr. Jerry $F$. Schelegel for their teaching and collaboration.

My eternal appreciation to my old surgical profesars, Prof. Dr. Giocondo V. Artigas, Prof. Dr. Bernard sigel, and Prof. Dr. Lloyd $M$. Nyhus, who have contributed so much for my medical education.

I also thank Ms. Sandra Zeekaf for her secretariaj work. 



\section{CONTENTS}

Chapter 1. GENERAL INTRODUCTION

1.1. Historical background

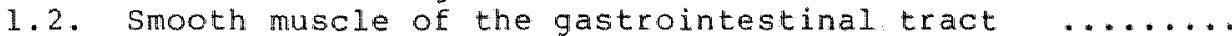

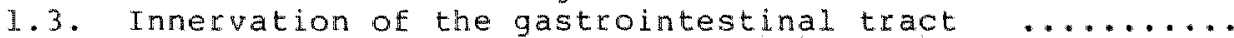

1.4. Neuromuscular junction of the gastrointestinal tract

1.5. Anatony and innervation of the sphincter of oddi ....

1.6. Motility of the gastrointestinal tract and sphincter

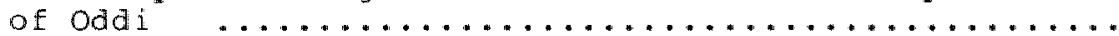

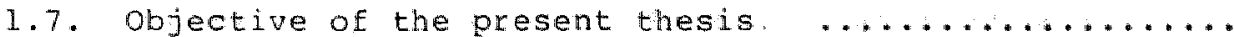

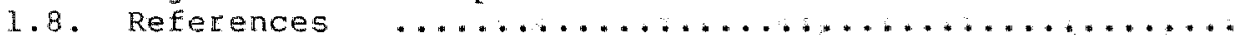

Chapter 2. A NEW METHOD FOR CORRELATING PANCREATIC AND DUCT PRESSURES AND SPHINCTER OF ODDI ELECTROMYOGRAPHY

2.1. Introduction

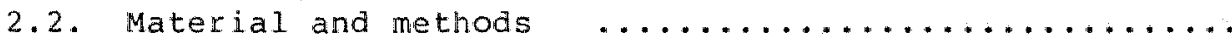

2.3. Results

2.4 .

Discussion

2.5 .

Summary

2. 5 . References

Chapter 3. THE EFFECT OF FEEDING ON MYOELECTRIC ACTIVITY OF THE SPHINCTER OF ODDI AND GASTROINTESTINAI TRACT IN THE OPOSSUM

3.1.

Introduction

3.2 .

Material and methods

3.3.

Results

3. 4 .

Discussion

3.5 .

Surmary

3.6. References

Chapter 4. EFFECT OF GASTROINTESTINAL HORMONES ON THE SPHINCTER OF ODDI AND DUODENUM MYOELECTRIC ACTIVITY AND ON PANCREATIC AND BILIARY PRESSURES IN THE OPOSSUM

4.1. Introduction

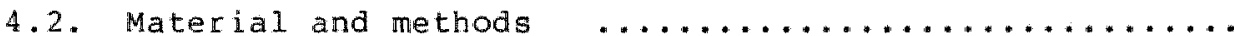

4.3. Results

4.4. Discussion

4. 5 .

Summary

4.6. References

Chapter 5. GASTROINTESTINAL MYOELCTRIC ACTIVITY FOLLOWING

\section{ABDOMINAL OPERATIONS IN THE OPOSSUM}

5.1. Introduction

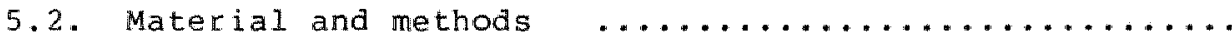

5.3. Results

5.4. Discussion 
Chapter 6. EPFECT OF ALCOHOL UPON MYOELECTRIC ACTIVITY OF THE GASTROINTESTINAL TRACT AND PANCREATIC AND BILIARY DUCT PRESSURES

6.1. Introduction

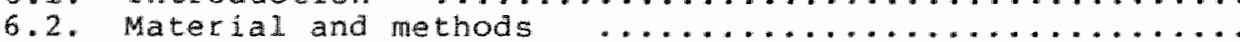

6.3.

Results

115

6. 4.

Discussion

118

6.5 .

Summaxy

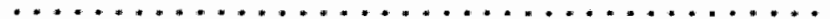

124

6.6.

References

Chapter 7. SPHINCTER OF ODDI AND GASTROINTESTINAL MOTILITY DISTURBANCES FOLLONING ALCOHOL ADMINISTRATION IN THE OPOSSUM

7. 1. Introduction

7.2. Material and

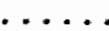

7.3. Results

7.4. Discussion

7.5. Summary

136

142

145

7.6. References

146

Chapter 8. EFFECT OF 16,16 DIMETHYL PROSTAGLANDIN E ON THE MYOELECTRIC ACTIVTTY OF" THE GASTROINTESTINAL "TRAC' OF THE OPOSSUM

8.1 .

Introduction

8.2 .

Material and

$\ldots \ldots$

149

8.3 .

Results

a. 4 .

Discussion

8.5 .

Summary

8.6 .

References

me thods

150

152

157

161

162

Chapter 9. SEROTONIN INCREASES THE VELOCITY OF PROPAGATION AND FREQUENCY OF THE MIGRATING MYOELECTRIC COMPLEXES

9.1. Introduction

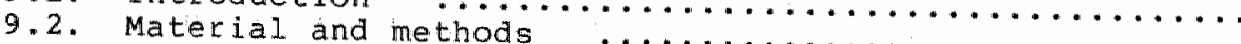

9.3. Results

9.4. Discussion

9.5 .

Summary

9.6. References

Chapter 10. GENERAL DISCUSSION

Summary

Samenvatting

Publications of the studies presented in this thesis 


\section{CHAPTER 1}

\section{GENERAL INTRODUCTION}

The gastrointestinal tract has the important function of converting food into smaller constituents and absorbing them. In order for these events to be achieved, food must be mixed with digestive juices and transported along the alifuentay tract at an approppriate rate.

\section{1. HISTORICAL BACKGROUND}

Motility of the gastrointestinal tract has fascinated man for centuries. The earliest description of movements of the stomach was made by HaIler in 1764, who observed that contraction of the stomach alternated with relaxation in vilisected wolves, dogs, and cats (1). In 1833, Beaumont observed movements of the stomach directiy through an accidentally created gastrostomy in a man who had been wounded in the epigastrium by the accidental discharge of a musket (2). He described the important functions of the pylorus in regulating the passage of gastric contents from the stomach into the duodenum as well as impending the regurgitation of duodenal secretion. several other 
1.nvestgators, including Friedtan, Bassow, Blondlot, Quincke, and Pawlow, also made faportant contributions to our knowledge of gastulc physiology astig gastric fistulas and pouches $(3)$.

Contraction of the small bowel was studied by exteriorizing the gut or placing it in the subcutaneous tis sue. Some of these methods are still employed $(4-6)$. In the Thiry-vella technique, the stomas of a sectioned segment of the small bowel are exteriorized through the abdominal wall. The continuity of the remaining small bowel is re-established. This enables the placement of a small recording balloon into the gut. The small bowel can algo remalin in continuity ard be placed within a tube of skin (Biebl loop) or on the top of the skin.

Motility of the gut has also been studied in vitro. In 1854, Haffer appears to have been the first to thave evaluated perlstalsis in excised segments of the small bowel in a warm wher bath with oxygenated Locke solution (3). In 1904, Magnus ovaluad the effect of pharmacologic substances on resectid gut (3). This eliminated the action of the extrinsic nerves an the bowel.

From 1898 to 1914, Cannon made many contributions to the knowledge of gastrointestinal motility employing the thew discovered $x-r a y$ to study the peristalsis of the esophagus, stomach, and bowel (7-9). He described peristalic contraction rings pressing the gastric contents through the pylorus. Radiographic techniques had the 
advantage that movement of radiopaque substances within the gastrointestinal tract could be evaluated in conscious animals. However, overlying loops of the intestine was a drawback of this technique.

In 1920, Wheelon and Thomas concluded that the pyloric sphincter was not an independent musclar structure but contracted rhythmically in coordination with the antrum of the stomach (10). In 1921, Alvarez performed the first electromyography of a human stomach by placing the electrodes on the skin of a patient with a large ventral hernia in the left upper quadrant of the abdomen $(3,11)$. In 1922 Alvarez demonstrated in dogs and in rabbits that a slow wave precedes each contraction and that not all slow waves were accompanied by contractions (12). Wth the improvement of electronic recorders in the following years, many aninals studies followed Alvarez's marvelous work.

The relationship between slow waves, splke potentials, and contractions is now well established. In 1969, Szurszewsit deronstrated inthe fasted dog a secific myoelectric migrating complex (MMC) which migrated down the gastrolntestinal tract cyclically from the stomach to the terminal lieum (13). In 1975, Code and Marlett divided the MMC into four phases (14). During phase $I$, occacional or mo spike potentials are observed. In phase II, splke potentials are superimposed on the slow waves in a random fashlon. Phase III consists of splke potentials of high ampltude on each slow wave. During phase IV, the frequency and amplitude 
of sike potentila dectease rapidiy to begin a new MMc. Feeding laterrupts the MMC and results in a noncycical patern of intermitent gike potentials that persists for the duration of the postprandial period. Following these intial deseriptions of the MMC, numerous studies have been performed to evaluate the myoelectric activity of the gastrointestinal tract under several conditions and in several species. The MMC is further discussed in section 6 of this chapter.

A great deal of our knowledge about the motor activity of the alimentary tract is founded on interpretation of the structure of the musulature and its nerves. The musculature, innervation, and neuromuscular junction of the gastrointestinal tract is also reviewed in this introduction.

\subsection{SMOOTH MUSCLE OF THE GASTROINTESTINAL TRACT}

The muscle coat of the gastrointestinal tract is a continuous structure made of smooth muscle and exterding from the esophagus to the anal canal. Except in the stomach, the muscle cells of the gastrointestinal tract are grouped In two layers termed outer longitudinal layer and inner circular layer. The wall of the stomach is composed of three muscular layers, inner oblique, middle circular, and outer 
longltudinal layer. Although the circular and the longitudinal layers are separated by the myoenteric plexus, they are linked to each other by connective tissue bridges (15). These bridges have been implicated as the means of commulcation between the two layers.

At the connection between different segments, a sphincter may be formed by the locallzed thickening of the circular layer, such as the pylorus and the sphincter of Oddi. Occasionally, the sphincteric function of a segment $1 \mathrm{~s}$ not due to the thickening of the muscular layer, but is due to the fine structural features of the finervation and pharmacological characteristics of the musculature of that portion of the gastrointestinal tract. This peculiar segment Is observed at the esophagogastric junction and is termed a physiologic sphincter. The sphincters $\mathbb{1}$. The alimentary tract have two important functions; to regulate the velocity of emptying of the proximal segment into the distal as well as to impede the regurgitation of contents from the distal seguent.

The muscle cells of the gastrointestinal tract are uninucleated, splndle-shaped, and measure 500 to 700 Hin $\mathbb{1}$ length and 2 to $10 \mu \mathrm{m}$ in thickness at rest (16). During contraction, the muscle cells can shorten to les than one-fourth of their inteld size. They have a high surface/volume ratio and they form a network th Intermeshed collagen fibers. The surface of the cells contains several specialized structures that establish 
junctions between adjacent cells and junctions between a cell and the surcounding comnective tissue stroma (17). These junctlons are of paramount importance for transmission and propagation of action potentials between the cells. Since the myosin and actin filaments are not regularly arranged, smooth muscle cells lack the striation typical of cardiac and skeletal musle.

The suoth muscle celis contract by siding of wyofllaments toward and over one another, i.e., the actin fulanents are pulled inward anong the myosin filaments so that they overlap each other to a major extent (18).

Initiation of muscle contraction starts with action potentials in the muscle fibers. These potentials of action spread to the interior of the fiber where they cause release of calcium lons from the sarcoplasmic reticulum. Ther the calcium long initiate the chemical events of the contractile process. Finaly, contraction occurs after depolarization of the membrane and tops after repolarization.

The wooth muscle of the gastrolntestinal tract exhlots two types of myoelectric activity, referred to as slow waves and action potentials (19). Slow waves are myogenic, pontaneous, and secondary to regular depolarization ( 10 to 15 mV) and repolarization of the smooth muscle cells. They are gemerated in the langitudinal muscle layer and posslbly spread to the circular layer ( 20 . All polnts in a cross-section of the gastrointestinal tract are in phase and each segment of the gastrointestinal tract 
generates a slow wawe frequency typical of that segment. In the opossum small intestine, for example, the slow wave frequency decreases Iinearly from the duodenum, where the Exequency is about 19 cycles/min, to about 14 cycle/min in the terminal ileum. This phenomenon is called the slow wave Erequency gradient ( 21 ). The slow wave frequency is $3.5 / \mathrm{m} 1 \mathrm{~m}$ in the stomach and $19 / m i n$ in the sphincter of oddi of the o possum.

The cause of the slow wawe rhythm is as yet unknown. It has been suggested that it may be caused by rhythmic activity of an electrogenic sodium pump (18). The slow waves are always present and they determine the timing and maxtmal frequency of contractions. Therefore, the slow waves are frequently called pacemaker waves. They do not cause mucle contraction, but: when the potential of the slow waves rises above the level of approximately -35 m, an action potential develops and contraction ensues. Such action potentialo can be elicited in many was, such as by electrical stimulation, action of hormones, neurotransmissors, or by spontaneous generation in the muscle fiber.

Unlike slow waves, action potentials do not usually accur continuously. They can occur alone or in bursts and are followed by a weak or strong contraction of the circular and longitudinal muscles $(22,23)$. Since action potentials are superimposed on the depolarization of the alow waves, the slow wave frequency determines the maximum frequency of contraction. For example, in the opossum stomach, four 
contraction: per minute is the maximum, while in the duodenum and shincter of oddi, the maximum frequency of contractions is 19 per minute.

Once an action potential starts, it spreads through the entire muscle mass. This creates a constrictive ring in the gastrointestinal wall which moves and propels the intestinal contents downard. This process is called peristalsis. The sow wave propagation velocity determines the velocity of peritalte contraction (24).

Although the contractile process in smooth muscle is sindiar to that in skeletal muscle, some important differences extst. The contraction and relaxation time of smooth muscle is longer than in skeletal muscle (18). For this reason, smooth muscles are especially well suited for maintaling prolonged contraction without fatigue and with litte energy consumption.

Another special characteristic of the smooth muscle is its ability to whorten a fat greater percentage of its Length than can skeletal muscle (18). This allows the gastrolntestimal tract to change 1 ts lumen diameter several times. Due to the random arrangement of the actin and myosin filaments in smooth muscle, it has the ability co greatly change its length with ninfmal wariation of the cension. This feature is of special importance in the stomach, whose lumen may change dramatically after a meal. 


\subsection{INNERVATION OF THE GASTROINTESTINAL TRACT}

The alimentary tract is innervated by both the parasympathetic and sympathetic nervous systems that are capable of changing the activity of specific segments or the entire alimentary tract.

The parasymathetic fibers that supply the gut originate from the vagal motor nucleus in the medulla oblongata (cranial division) and from the second, third, and fourth sacral segments of the spinal cord (sactal division) (25). The cranial parasymathetic division is transmitted by the vagus nerves and inmervates the gut from the esophagus to the right colon, including the galibladder. The sacral division passes through the pelvic nerves to the left colon, rectum, and internal anal sphincter and has an essential role during defection.

The symathetic fibers to the allinemtary tract originate in the spinal cord between the gegments $\mathrm{T}-8$ and L-3 and, after passing the celiac, superior megentertc, inferlor mesenteric, or pelvie ganglia, they are distributed Wth the blood vessels to the gut (25).

The great majority of neurones and fibers to the gastrointestinal tract are grouped in two plexuses nated myenteric or Auerbach's plexus and submucosal or Melsiner plexus $(26,27)$. They extend along the entre letigth of the smooth muscle wall from the esophagus to the anus. The myenteric plexus is mainly motor in function and lies 
between the Longitudinal and circular mocular layers. Most wenteric fibers are stimulatory (cholinergic) but some are probably: inhibltory (adrenergic).

The submucosal plexus, which is localized in the submcosa, has the laportant function of receiving stimulus from the gut mucosa and from stretch receptors in the gut wall (28). These stimuli are conveyed by sympathetic and paragapathetic nerves. Painful stimuli are cransmitted to the spinal cord by sympathetic fibers while signals that intiated several gastrolntestinal reflexes are propagated to the medulla oblongata la the vagus nerve.

The dominat effect of the stimulation of the vagus nerve on the muscle of the small intestine and proximal colon is excitatory $(29,30)$. If the intestine 1 s quiescent, rhythic contractions are indtated, and if the gut is in contraction, the existing contraction fucreases in amplitude. The excitatory effects of the pelvic nerves are more prominent in the distal colon and rectum, but the proximal colon and even the distal ileum may also respond Wh some dalay. Therefore, there is an overlapping of Innervation of the vagus and pelvic nerves. The pelvic merves contract both the circular and longitudinal muscle layers of the colon and rectum that are involved wth defection $(31)$.

The action of the sympathetic pathways on the movements of noushincterlc paxts of the intestine is inhibitory, While the sympathetic innervation of the sphincters is 
excitatory. It is also important to note that the presence of a few sympathetic excitatory as well as inhibitory vagal fibers to the nonsphincteric parts of the intestine have been dacumented by several authors ( 31 ).

\subsection{NEUROMUSCULAR JUNCTION OF THE GASTROINTESTINAL TRACT}

Although there is no specialized neuromuscular junction in the gut, transmision from intrinsic excitatory and inhibitory neurons is very effective and even a single nerve pulse elicits either transient depolarizations or hyperpolarizations of the muscle cells $(31,32)$. Bundles of axons with dilations or varicosities lie within the muscular layers of the gut. These varicose axons release transmitters when stimulated at many points adjacent to different macle cells. These cells may also transmit the gtimulus to several other muscle cells that are interconnected both electrlcally and mechantcally.

\subsection{ANATOMY AND INNERVATION OF THE SPHINCTER OF ODDI}

According to Boyden, G11s8on was the flrst to observe the "locking mechanism" of the sphincter of oddit that 
consists of "ringlike fibers which occupy not only the openting (of the comon channel) itself but also the whole ablique tract (through the incestinal wall)" (33). Gage was the fixst to examine the sphincter of oddi ricroscopicaldy (34). This sphincter was named after the italian oddi, who was the first to demonstrate it in several anfmals, to measure its resistance, to postulate that lts dysfunction might cause elinical symptoms, and to show that remoral of the galladaer caused marked dilatation of the blle ducts $(33,35)$

The distal common bille duct passes downard behind the first part of the duodenum and within the head of the pancreas. The duct then curves to the right to course obliquely through the duodenal wall for a distance of 8 to $22 \mathrm{~mm}(36)$. In approximately $80 \%$ of the instances, the main pancreatic duct joins the posteromedial aspect of the comon bll duct to form a camon chanmel, which is referred to as the amplia of Vater, although there Is no dilatation of the channel (37). The common bile duct and the main pancreatc duct, elther together or separately, pierce the second portion of the duodenum at a smooth elevation of the mucosa, named major pap111a.

Boyden has demonstrated that the sphincter of oddi in humans is formed by the sphincter choledochus and the sphimcter ampuliae that encircles the distal common bile duct and the ampulla of vater, respectively (33). In some human specimens, a band of thickened muscle, the sphincter 
parceaticus, surrounds the end of the pancreatic duct (33).

only a few studies have been reported on the innervation of the sphincter of oddi. Kyosola has demonstrated, in cats and dogs, that the ganglia of the myenteric and submucosal plexuses in the sphincter of odd are rich in cholinergic fibers (38). Adrenerglc fibers may also innervate the sphincter of oddi (39). Tooull et al. showed that the density of ganglia is larger at the proximal segment of the sphincter of odd1 of the opossum (40). They suggest that the higher density of ganglion cella in the proximal portion of the sphincter may constitute a center of neural modulation of sphincter function.

\subsection{MOTILITY OF THE GASTROINTESTINAL TRACT AND SPHINCTER OF ODDI}

The progression of food from the stomach to the rectum 1s complex and involves secretion and mixing of digegtive julce wth nutriente and absorption and transporting of the gut contents at an appropriate rate. The luminal contents undergo dramatic changes in volume, in physical state, and in chemical composition as they progress through the digestive tube. Therefore, it is not surprising that the pattern of motility of the gut varies with feeding habit, volume and composition of the diet, the fasted or fed 
stats, the different parts of the intestine, and with different species.

The generally recognized mowements of the gut are pertstals, segmentation, and pendular movement ( 18 . Peristaltic waves may occur 1 n any part of the intestine and consiste of one or more contractions of the circular muscle that are propagated along the bowel. This provides a constrictig ring that propels the content analward along the gut. This movement is mainly propulsive, although some content ming may also occur.

Segmentation movements consist of two or more simutaneous concentric contractions of small segments of the gut. The segmentation contractions have a brief duration and as one set of contractions relaxes, a new set begins. In this wy, the segments are constantly divided and subdivided. This results in progressive mixing of food particles whth digestive juice.

Pendular movements consist of contrations and relaxtions of the longitudinal muscle of the gut that result in shorteniag and lengthening of intestinal gegments 1. a pendular fashion. These movements are poorly understood since they cannot be adequately evaluated by electromyography, pressure change within the bowel 1 umen, or by deformation of strain gauge transducers attached to the gut wall (41). Peristalsis and segmentation are movements of clrcular muscles and are effectively studied with methods mentoned above. 
Change in contractions of the muscularis mucosae can cause shortening or lengthening of the latestinal mucosa folds which decreases or increases the exposed mucosa to the chyme and the rate of nutrilent absorption (18).

Early investigators were concerned malnil with the type and frequency of gut contractions that occurred over short periods of time. However, it was known at that time that the activity of the bowel was not unform over long periods. Boldyreff was the first authar to document that the motility of the gut was cyclic in the dog (42). He recogilzed that it was organized in brief bursts of activity which recurred at regular intervals of approximately 90 minutes and was interrupted by feeding.

In 1969, Szurszewski further characterized this recurrent pattern of gastrointestinal activity in dogs using an electromyographic technique (13). He described a sequence of myoelectric activities in which a perfod of approximtely 60 inlutes of no splke potentials was followed by a period of 15 to 40 minutes of Irregular splke activity $1 n$ the gut. This was followed by a four- to elght-minute period of intense spike activity. This sequence of activities started In the duodenum and migrated distally to the terminal lleum every 115 to 183 minutes.

Code and Marlett called this activity pattera the igrating myoelectric complex (MC) and divided each complex into four phases (14). In phase $I$, occasional or no splke potentials occurred. During phase II, the splke potentials 
mere lreguar and increased in frequency and intensity throughout the phase. Phase III was characterized by action potentials of high amplitude that were superimposed on 90 to $100 \%$ of the slow waves. During phase IV, the frequency and Intensity decreased quickly to start a new cycle.

The MC has been recorded only durling the fasting state 1n some specles and during fasting and fed states in others. Man, dog, cat, rat, and opossum are lneluded in the first group $(40,43,44)$, and sheep, cattie, rabbits, and pigs in the second group $(45,46)$. Feeding interrupts the MMC in the first group of animals and results in a noncycilcal pattern of Intermittent spike potentials that persists for the duration of the postprandial period.

The correlation between the MMC phases and mowements of intraluminal contents has been the objective of several studies. Code and schlegel have demonstrated by combined. cineradigraphic and electromyographic recordings that the actulty front of each complex (phase III) is assoclated wth propagated contractions whose function is propulsion of gastrolntestinal content between meals (47). They observed that any material injected into the lumen of a bowel loop during phase III was immediately propelied distally. The materlal was stetonary when administered during phase I. Bueno et al. obtained similar results when nonaborbable markers were radiascoplically followed through the intestine of dogs and sheep (46).

It has alsa been suggested that the MMC is important 
during the fasting state to prevent bacterial overgrowth of the small bowel. Vantrappen et a1. reported that af 12 patients with possible bacterial overgrowth of the suld intestine, five had gross disorders of the MMC patterns (48). In fact, disorders assoclated with abnormalities of the intestinal transit, such as difarhea and intestinal pseudo-obstruction, present with changes of the gut myoelectric activity pattern (49).

Several studies have been conducted to describe the dynamics of the sphincter of odd1. The methods most commony employed are cholanglography, cineradiography, measurement of bile duct flow, choledochal pressure profllometry and manometry of the sphincter of oddi and pancreatic and bl11ary ducts $(50-54)$. Nuboer suggested in 1928 that the sphincter of oddi presents peristaltic contractions and acts as an ejaculation apparatus (55). This hypothesis was supported by choledochal pressure profilometry atudes performed by Bruijnes and Klopper In dogs (56).

Recently, electromyography has been employed to evaluate the motility of the sphincter of odd1. This method is advantageous over other studes because it can be employed in chronic studies on conscious animals. In addition, administration of flulds or placement of catheters in the pancreatic and blliary ducts is not necesary. Ishioka demonstrated in 1959 that the rabbit phincter of oddi generates spontaneous rhythmic bursts of sike potentials (57). In 1968, Ono detected periodic bursts of 
splke potentials in the human sphincter of oddi at laparoton (58). Myolectrie recordings performed by Becker et a . and Honda et al. In 1982 revealed that the opossum sphincter of odd exhlbits spontaneaus spike potentials which propagated from the proximal to the distal portion of the shincter $(59,60)$.

opossums are mamals of the family Didelphidae and superorder Marsupialia (Figure 1). They are omnivorous and usually live in hollow trees. The opossum was selected for the studies reported in this thesis because its sphincter of odd is mostly extraduodenal and measures 2 to 3 cm in length and, therefore, dissection of the pancreas and duodenum is not necessary to implant electrodes along the sphincter of oddi. In addition, $\mathbb{1}$. the opossum, as in the human, the main pancreatic duct joins the common duct at the praximal portion of the spinincter of oddi. The motility of the gastrointestinal tract is similar in the opossum and in the human. These andigls a lso lie quietiy for many hours whout the need of drug administration or use of costatist.

\subsection{OBJECTIVE OF THE PRESENT THESIS}

This thesis consists of ten chapters. In Chapter 1 , General. Introduction, an historical background of the 


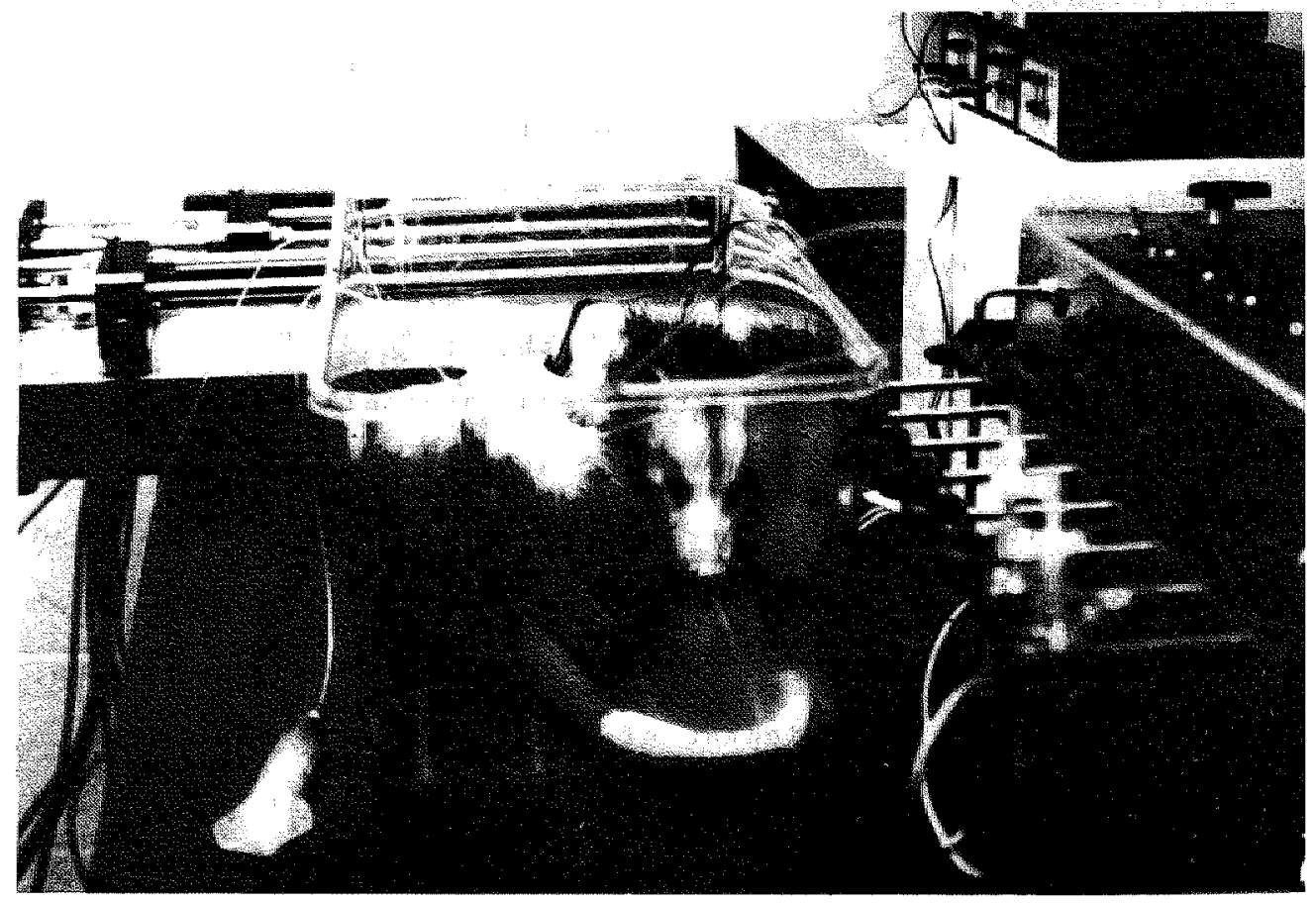

Figure 1. opossum during a recording session. 
development of the motility of the gastrointestinal tract, a review of the anatomy and physiology of the smooth muscle, In nexation, and neuromuscular junction of the gastrolntestinal tract, anatomy and innervation of the sphlacter of oddi, wotility of the gastrointestinal tract and ophincter of odd, and the objective of the present thes 18 are presented.

Efght experimental studies are described 1 n Chapter 2 through 9. InIt1al1y, the normal electromyographic activity of the gastrofntestinal tract and sphincter of oddt $1 \mathrm{~s}$ presented in chapter 2. In this study, a new experimental mode1 is a 1 so reported to measure the pancreatle duct and the common bile duct pressures under clrcumstances which minimally disturb the normal phystology of the pancreas, b111ary tree, and sphincter of odd1. In addition, the data obtalned are used to correlate the pancreatic duct and b1l1ary duct pressures ith the sphlncter of odd myoelectric activity, both in fasting and fed states.

The effect of different foods on the myoelectric activity of the sphincter of oddi and gastrointestinal tract is evaluated in Chapter 3. Sinultaneous gallbladder pressure recordings were also abtalned in this study.

The effect of gastrolntestinal hormones and acetylcholine on the sphincter of oddi and duodenum moelectric activity on pancreatic duct and common bile duct presauresis studied in chapter 4.

Following studies of the electromyography of the 
gastrointestinal tract and sphincter of odd under physiological conditions, the effect of abdominal operations and substances known to cause disturbances in the motility of the alimentary tract are evaluated. In Chapter 5 , the motility of the gastrointestinal tract and sphincter of Oddi, both in the fasting and fed states, is studied following several abdominal operations.

The effect of alcohol on gastrointestinal and sphincter of oddi myoelectric activity and on pancreatic and billary duct pressures is described in chapter 6. The mechanism by which ethanol stimulates the motility of the sphincter of oddi and gastrointestinal tract is evaluated in chapter 7 .

The effect of two substances known to cause diarrhea is also studied. 16,16 dimethyl prostaglandin $\mathbb{E}_{2}$, a aubtance employed experimentally in the treatment of peptic ulcer disease, Is evaluated in Chapter 8, and serotonin, a substance possibly responsible for the diarrhea in patients with carcinoid tumors, is studied in chapter 9.

The final discussion is presented in Chapter 10.

The objective of this thesis is to study the motility of the sphincter of oddi and gastrointestinal tract in consclous, nonmedicated opossums under phystological conditions and following several timuli that cause gastrointestinal disturbances. The electromyographic activity of the sphincter of oddi and gatrointestinal tract is correlated with the biliary and pancreatic duct presures both in the fasting and fed states. The motility of the 
sphincter of odd and gastrointestinal tract is evaluated following abdominal operations and following administration of different foods, gastrotntestinal hormones, acetylcholine and substances known to cause duarhea (prostaglandin and aerotonin) and pancreatis (alcohol). The raechanisin of alcohol-related myoelectric activity disturbances of the sphincter of odd is a 1 so assessed.

\subsection{REFERENCES}

1. Code CF, Carlson HC. Motor activity of the stonach. In Code CF, editor. Handbook of Physiology. Baltimore, Waverly Press, Inc., 1968, Pp. 1903-1915.

2. Beaumont W. Experiments and observations on the gastric Julce and the physilology of digestion. New York, Dover, 1959.

3. Alvarez WC. Early sudies of the movements of the stomach and bowel. In Code CF, editor. Handbook of physiology. Baltimore, Waverly Press, Inc., 1968, pp. $1573-1578$

4. Carlson GM, Bedi BS, Code CF. Mechanism of propagation of Intestinal myoelectric complex. Am J Physiol $222: 1027-1030,1972$.

5. Bass P, Wiley JN. Effects of ligation and morphine on electric and motor activity of dog duodenum. Am J Physiol 208:908-913, 1965 .

6. Sumbers RW, Helm $J$, Christensen J. Intestinal 
propulsion in the dog* Its relation to food intake and migratory myolectric complex. Gastroenterology $70: 753-758,1976$.

7. Cannon WB. The movements of the stomach studled by means of the roentgen rays. Am J Physio1 $1: 359-382$, 1898.

8. Cannon WB, Lieb CW. The receptive relaxation of the stomach. Am J Physiol 29:267-273, 19⿺1.

9. Cannon WB, Wastourn AL. An explanation of hunger. Am J Physio1 29:441-454, 1912 .

10. Wheton $\mathbb{H}$, Thomas JE. Observations on the motility of the antrum and the relation of rhythic activity of the pyloric sphincter to that of the antrum. J Lab C1In Med $6: 124-143,1920$.

11. Alvarez WC. The electrogastrogram and what 1 t shows. JAMA $78: 1116-1119,1922$.

12. Alvarez WC, Mahoney LJ. Action currents 1 n stomach and intestine. Am J Physio1 $58: 476-493,1922$.

13. Szurszewski. JH. A ingrating electrical complex of the canine small intestine. Am J Physio1 217:1757-1763, 1969.

14. Code CF, Marlett JA. The Interdigestive myolectric complex of the stomach and small bowel of dogs. J Physiol (London) $246: 289-309,1975$.

15. Taylor AB, Kreulen D, Prosser CL. Electron microscopy of the connective tissues between longtudinal and circular muscle of smali intestine of cat. Am J Anat 
$150: 427-442,1977$

16. Gabe1la G. Structure of mucles and nerves in the gastrolntestinal tract. In Johrson LR, editor. Physiology of the Gastrofinestinal Tract. New York, Raven Press, 1981, pp. 197-241.

17. Schottelius BA, Schottelius DD. Muscle physiology contractility. In Schottelius BA, sehotcelius DD, editors. Textbook of Physiology, St. Lauis, Mosby, $1978, \mathrm{pp} .79-117$.

18. Guyton AC. Nerve and muscle. In Guyton AC, editor. Textbook of Medical. Physiology. Philadelphia, WB Saunders Co., 1981, p. 104-146.

19. Welsbrodt $\mathbb{N}$. Motility of the smali intestine. In Johnson LR, editor. Physiology af the Gastrolntestinal Tract. Wew York, Raven Press, 1981, Pp. 411-443.

20. Bortoff A. Electrical transmission of slow waves from longitudinal to circular intestinal muscle. Am J Phys lol 209:1254-1260, 1965 .

21. Diamant NE, Bortofi A. Nature of the intestinal slow wave frequenoy gradient. Arm J Physiol 216:301-307, 1969.

22. Daniel $E \mathrm{E}$, Sarna $S$. The generation and conduction of activity in smooth muscle. Annu Rev Pharmacol Toxicol $18: 145-166,1978$.

23. Tomita T. Electrophysilology of mamalian smooth muscle. Prog Blophys Mol Bio1, 30:185-203, 1975.

24. Grivel M-L, Ruckebush. $Y$. The propagation of segmental 
contractions along the small intestine. J Physlol (London) $227: 611-625,1972$.

25. Davison JS. Innervation of the gastrolntestimal tract. In Christensen J, Wingate DL, editors. A Gulde to Gastraintestinal Motility. Bristol, John Wright \& Sons, Ltd., 1983, p p $1-47$.

26. Wood JD. Neurophyslology of Auerbach's plexus and control of intestinal motility. Physlol Rev 55:307-324, 1975

27. Wood JD. Neurophysiology of the enteric nervous system. In Brooks CMC, editor. Integrative Functions of the Autonomic Nervous System. Tokyo, University of Tokyo Press, 1979, PP. 177-193:

28. Guyton AC. Movement of food through the allmentary tract. In Guyton AC, editor. Textbook of Medical Physlology. Philadelphia, WB Saunders Co, 1981, pp. $784-800$

29. Kewenter J. The vagal control of the jejunal and 11 eal motilly and blood flow. Acta Physlal scand (Suppl) $251: 3-68,1965$.

30. Kosterlitz HW. Intrinsic and extrinste nervous control of motility of the stomach and the intertine. In code CF, editor. Handbook of Physiology. Baltimore, Willias and W11kins, 1968, pp. 2147-2171.

31. Costa M, Furness JB. Nervous control of intestinal motility. In Bertaccini G, editor. Mediatori and Drugg in Gastrolntestinal Motility. Berlin, Springer-verlag, 
$1982, \mathbb{P P} \cdot 279-382$

32. Furness JB, Costa M. Types of nerve in the enteric nervous system. Neurosclence 1-20, 1980.

33. Boyden EA. The sptincter of oddi in man and certain representative mamals. Surgery $1: 25-37,1937$.

34. Gage 5 4 . The ampulla of vater and the pancreatic ducts 1n the domestic cat. An Quart. Micr J $1: 1-12,1879$.

35. Oddi R. D'une disposition a sphlincter speciale de l'ouverture du canal choledoque. Arch Ital Biol $8: 317-322, \quad 1887$

36. Kune GA. Surgical anatomy of the common bile duct. Arch Surg $89: 995-1004,1964$.

37. Hand BH. An anatomical study of the choledochoduodenal area. Br J Surg $1: 486-494,1963$.

38. Kyosola $K$. Cholinesterase histochemistry of the innervation of the smooth muscle sphincter around the terminal intranual part of the ductus choledochus in the cat and the dog. Acta physiol Scand 90:278-280, 1974.

39. Kyosola K. sympatho-adrenergic neural comtrol of the sphincter of oddi of the cat and the dog. Tohoku I Exp Med $127: 113-117,1979$.

40. Tooul1 J, Dodds WJ, Honda $R$, Sarna $S$, Hogan WJ, Komarowsk RA, Lineban, JH, Arndorfer RC. Motor function of the opossum sphincter of oddi. J ciln Invest $71: 208-220,1983$.

41. Wingate DL. The small intestine. In Christensen J, 
Wingate DL, editors. A Guide to Gastrointestinal Motility. Bristol, John Wright \& Sons Ltd., 1983, pp. $128-156$.

42. Boldyroff. W. Einige heue seiten der tatigkeit des pandreas * Ergeb der Phys101 11:121-217, 1911.

43. Weisbrodt NW. Electrical and contractile activities of the small intestine of the cat. Am J Dig Dis 19:93-99, 1974.

44. Weisbrodt NW, Badial-Aceves F, Copeland EM, Dudrick SJ, Castra GA. Smali intestinal transit during total parenteral nutrition in the rat. Am J Dig Dis $23: 363-369,1978$.

45. Ruckebusch Y, Bueno $L$. The effect of feeding on the motility of the stomach and small intestine in the pig. Bir J Nutr. 35:397-405, 1976 .

46. Bueno I, Firoamonti J, Ruckebusch $\mathrm{Y}$. Rate of flow of digesta and electrical activity of the small intestine In dogs and sheep. J Physiol (London) 249:69-85, 1975.

47. Code CF, Schlegel JF. The gastrointegtinal housekeper. In Daniel EE, editor. Gagtrointegtinal, Motility. Vancouver, Mitche11. Press, 1974, pp. 631-633.

48. Vantrappen $G$, Janssens $J$, Ghoos $Y$. The interdigestive motor complex of normal subjects and patients with bacterial overgrowth of the mall intestine. J ciln Invest $59: 1158-1166,1977$

49. Kumpuris DD, Brannan PG, Goyal RK. Characterization of motor activity in the jejunum of normal subjects and 
two patients th ldopathic intestinal

pseudo-abstruction syndrome (IIPS). Gastroenterology $76: 1177,1979$.

50. Menguy $\mathbb{R B}$, Hallenbeck GA, Bollman JL, Grindlay JH. Intraductal pressures and sphincterif cesistance in cantne pancreatic and blliary ducts after various stimuli. Surg Gynecol obstet 106:306-320, 1958 .

51. Geenen JE, Hogan WJ, Dodds WJ, Stewart ET, Arndorfer Rco. Intralumal pressure recording from the human spincter of Odd $i$. Gastroenterology $78: 317-324,1980$.

52. Nebel oT. Manometric evaluation of the papilia of Vater. Gastro1ntest Endose 21:126-128, 1975 .

53. Caroll J, Porcher P, Pequignot G. Contribution of cineradiography study of the function of the human biliary tract. An J Dig Dis $5: 677-696,1960$.

54. Bruljnes E, Klopper PJ. The pressure profile of the common bile duct. An experimental study in 15 mongrel. dogs. Acte Hepato-Gastroenterol 25:308-312, 1978 .

55. Nuboer $J \mathbb{F}$. Onderzoekingen over den boum en de verrichtingen van het extrahepatische galwegenstelsel onder normalle en ziekelijke onstandigheden. Thesis, Utrecht 1928

56. Brulfnes $\mathbb{E}$, Klopper PJ. Choledochal pressure profilometry following dilatation, sphincterotomy, sphincteroplasty or diathermic sphincterotomy. Hepato-gastroenterol $28: 327-332,1981$.

57. Ishioka T. Electromyographic study of the 
choledochoduodenal junction and duodenal wall muscle. Tohuku J Exp Med 70:73-84, 1959.

58. Ono $K$, Watanabe $N$, Suzuki $K$. Bile flow mechantsms in man. Arch Surg. $96: 869-874,1968$.

59. Becker JM, Moody FG, Zinsmeister AR. Effect of gastrointestinal hormones on the biliary sphincter of the opossum. Gastroenterology 82:1300-1307, 1982 .

60. Honda $R$, Toouli J, Dodds WJ, Sarna $S$, Hogan WJ, Itoh Z. Relationship of sphincter of oddi spike bursts to gastrointestinal myolectric activity in conscious. opossums. J Cin Invest $69: 770-778,1982$. 


\section{A NEW METHOD FOR CORRELATING PANCREATIC AND BILIARY DUCT PRESSURES AND SPHINCTER OF ODDI ELECTROMYOGRAPHY}

\subsection{INTRODUCTION}

physilogle pancreatic and blitary duct pressures thave been difficult to measure. Most commony used methods of recording pressure produce elther fistula, occlusion of a major duct by the recording catheter, or interference with the sphincteric mecharisa $(1,2,3)$. Recent developments in electrophyslologic techniques have allowed a more direct evaluation of the sphincter of oddi (4). Howewer, the corelation between electromyographic actulty of the splncter of oddl and pancreatic and billary duct pressures has not yet been evaluated.

A new experitantal nodel has been developed to measure the pancreatic duct and comon bile duct pressures under cincumstances that minimally disturb the normal phystology of the pancreas, biliary tree and sphincter of oddi. In add thion, the data obtalmed was used to correlate parcreatic and biliary duct pressures with the sphincter of odd 
myolectric activity in conscious opossums, in both fasting and feeding states.

\subsection{MATERIAL AND METHODS}

Eight healthy, opossums of elther sex welghing 3.0 to 4.5 $\mathrm{kg}$ were studied. After an overnight fast, the animals were anesthetized with intraperitoned administration of 25 mg/kg of sodium pentobarbital. The abdomen was entered through an upper midine incision.

The main pancreatic duct and the common blle duct were catheterized for pressure recording. A PE-50 polyethylene T tube was placed in the main pancreatic duct, $3 \mathrm{~cm}$ distal to i.ts junction with the duodemum (Figure 1). The bile duct, which connects the right laterallobule of the liver to the common duct below the cystic duct, was cannulated with PE- 50 polyethylene tube.

Four bipolar extracelilular electrode padrs were placed in the sphincter of oddi and duodenum. Two pairs of electrodes were placed in the sphincter of oddi: one palr was Implanted 1 cm proximal to the sphincter of oddi-duodenal junction and the second palr was placed 1 cm more distaly. The third and fourth pairs of electrodes were placed in the duodenum, $2 \mathrm{~cm}$ proxtmal and $2 \mathrm{~cm} d 1 \mathrm{stal}$ to the sphincter of oddi-duadenal junction, respectively. The electrodes consisted of stranded silver-plated copper wire With teflon insulation of 36 AWG size. The biliary and 


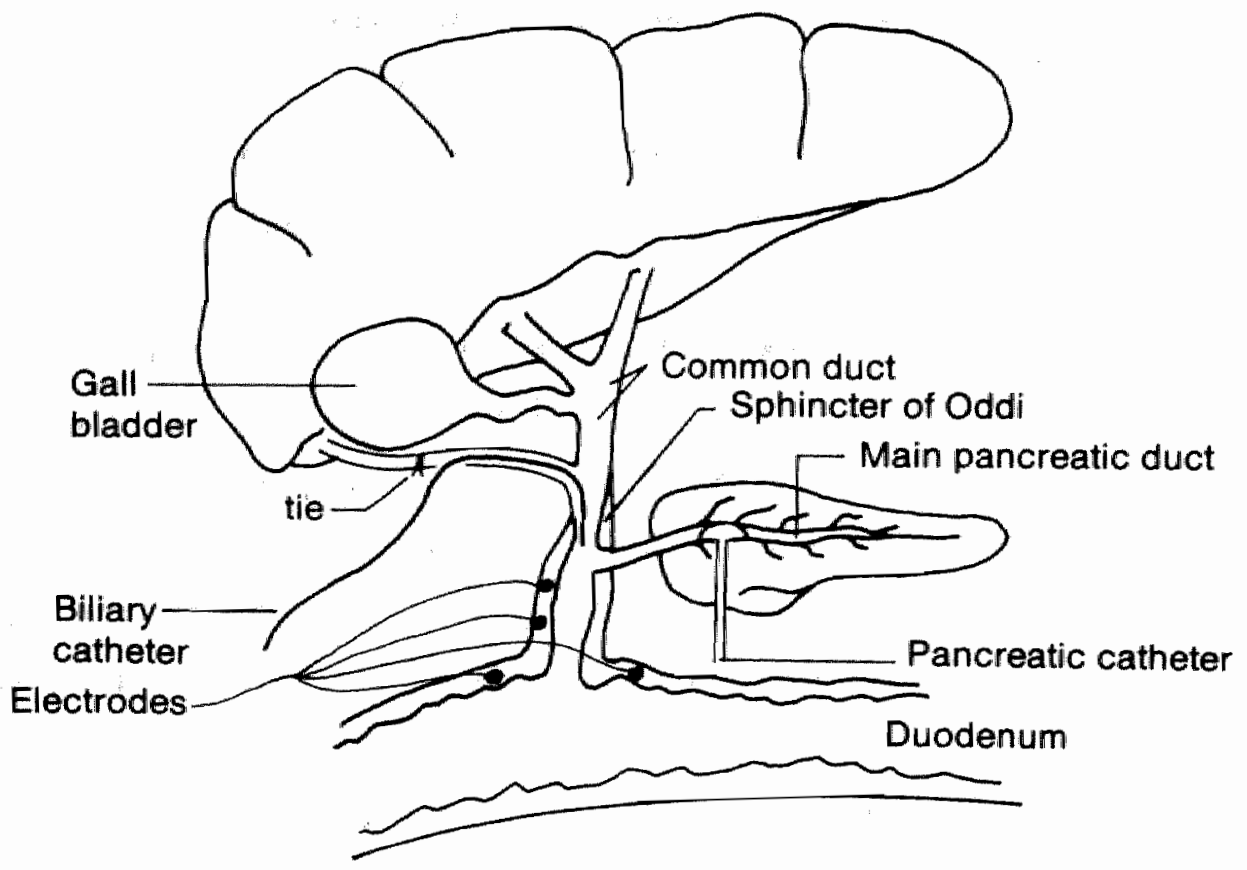

Figure 1. Schematic diagram of the opossum preparation shows the sphincter of oddi and duodenum electrodes and the pancreatic and biliary catheters. 
pancreatic catheters and the wiles were passed through a subcutaneous tunnel to the animal's back and sitched to the skin. The wires were previously soldered to a female socket. Recordings were begun 7 to 10 days after the operation. A male plug was inserted 1 nto the female socket, thereby conducting electromographic potentils through isolation preamplifiers to an eight-channel Gould 2800 s Instrument (Gould Inc., Recording Systems DIvision, Cleveland, ohio). Recordings were made by a paper speed of 1 $\mathrm{mm} / \mathrm{sec}$, low-frequency cutoff filter of $1 \mathrm{~Hz}$, high-frequency cutoff fiter of $10 \mathrm{~Hz}$, and overall sensteivity of $100 \mathrm{rV}$.

The pancreatic and bliliar catheters were attached directly to Gould P23 pressure transducers (Gould Statham Instruments, Inc., Hato Rey, Puerto Rico), which were connected to the Gould recorder. An Arndorfer hydraulic cap111ary Infusion system (Arndorfer Medical Spectalties, Inc., Greendale, Wisconsin) was used to administer water in the pancreatic and biliary ducts at a constant rate of 0.04 mituln. The high-frequency cutoff fllter was positioned at direct-couple offet.

Catheters equal to those placed in the pancreatic and billary ducts were infused with water at a flow rate of 0.04 milmin to determine the baseline pressure. The tip of each catheter was positioned externaliy at the same helght as the internal catheters. while the opossum s lying on 1 ts abdomen. To verify the sensitivity of the pressure system, the tip of each catheter was occluded for 2 seconds. This 
cased an Herease in pressure of at least 20 min $\mathrm{Hg}$.

Recording sessions of 5 to 8 hours were obtalned in each antmal for a period of 1 to 4 months, with an average of 10 recording sessions per opossum. The animals were studled fin both the fasted and fed states. Ten to $20 \mathrm{~g}$ of commerctal Purina cat chow, consisting of protein 30\%, fat $8 \%$, flber $4.5 \%$, molsture $12 \%$, calcium $1.2 \%$, phosphorus $1 \%$, and NaCl $1.5 \%$, were given before the sessions began or after recording two migrating myoelectric complexes.

For analyols of the myoelectric recordings, the migrating myoelectric complex in the duodenum was divided Into four sequential phases, as suggested by code and Marlett $(5,6)$ and Carlson et al. (7). Phase I 1 . the quiescent phase in which occasional or no splke potentials are observed: Phase II consists of irregular spike potentials that increase in frequency and intensity throughout the phase. Phase III 1 s sudden in appearance and 1s characterized by regular splke potentilals of high amplitude that accompanded 90 to $100 \%$ of the slow waves. During phase LV the frequency and amplitude of action potentils rapidiy decrease to start a new myoelectric complex. The average number of spike potentials and the duration of each phase were determined. For recordings obtalned after feeding, the average number of spike potentials in the sphincter of odd and duodenum was also calculated. 


\subsection{RESULTS}

\section{Myoelectric activity}

Slow waves were easily ldentifled in both the sphincter of oddi and duodenum in most of the recordings. The frequency of slow waves was the same in the sphincter of odd and duodenum, and it varied from 17 to 20 per minute, with an average of 19 per minute. Inspection of the recordings revealed that the variation in the frequency of spike potentials $1 \mathrm{n}$ the sphincter of oddi correlated to that of the migrating myoelectric complex in the duodenum, and therefore myoelectric activity of the sphincter of oddi was also divided in phases I, II, III, and IV (FIgure 2). The phases of the migrating myoelectric complex were determined by inspection of the recordings.

Usually there was no difference in the amplitude ( 4 to $10 \mathrm{mV}$ ) of sphincter of oddi spike potentials in the same experiment, and $95 \%$ of the splke potentials or 1 ginated $1 \mathrm{n}$ the proximal portion of the sphincter propagated distally. Some splke potentials had less amplitude and did not propagate from the proximal to the distal segment of the sphincter of oddi. These action potentials were usually observed in phase I and at the beginning of phase II (FIgure 3).

The frequency of sphincter of odd splke potentials was regular and increased gradually from phase $I$ to reach the maximum frequency in phase III, then it decreased rapidiy during phase IV to start a new myoelectric complex (Table 


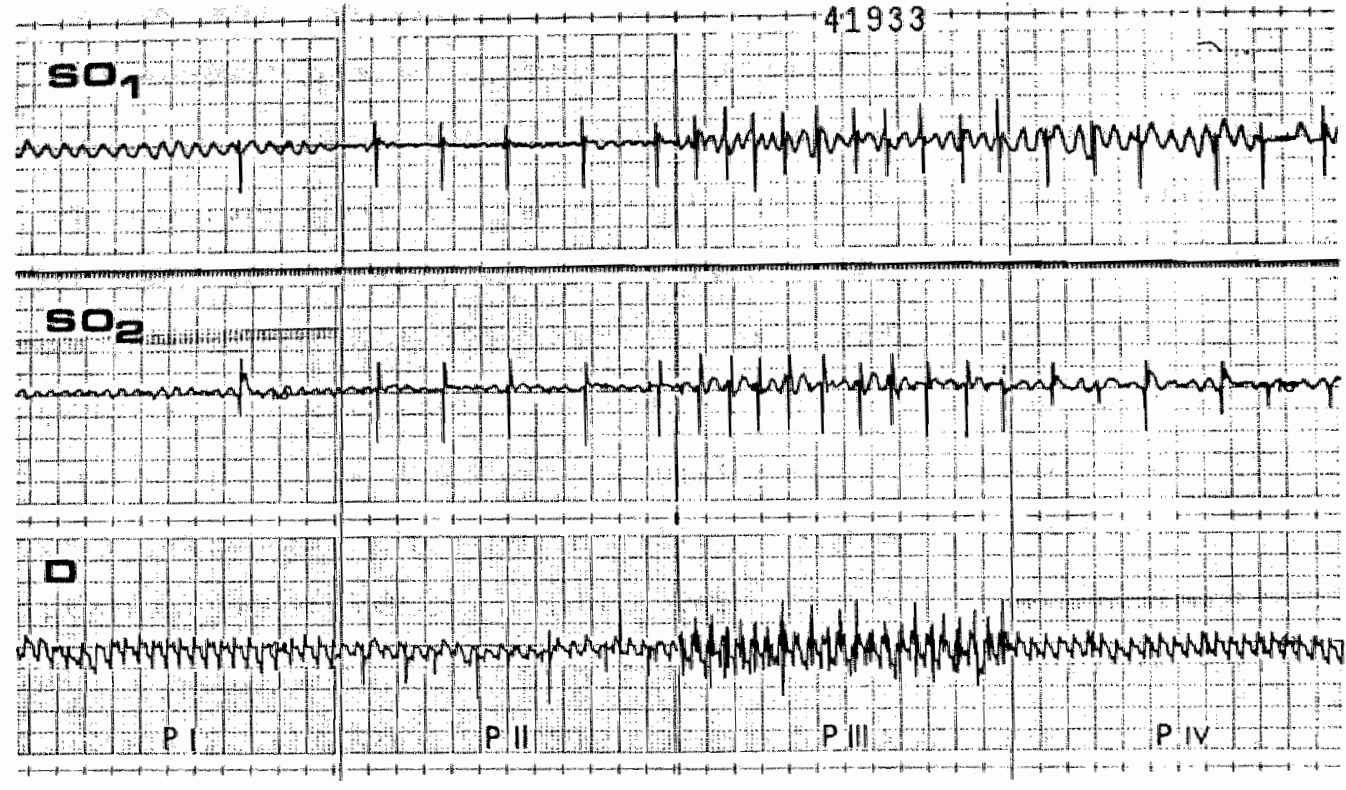

Figure 2. Myoelectric migrating complex phases (P) of the proximal ( $\mathrm{SO}_{1}$ ) and distal ( $\mathrm{SO}_{2}$ ) sphincter of oddi and duodenom (D). 


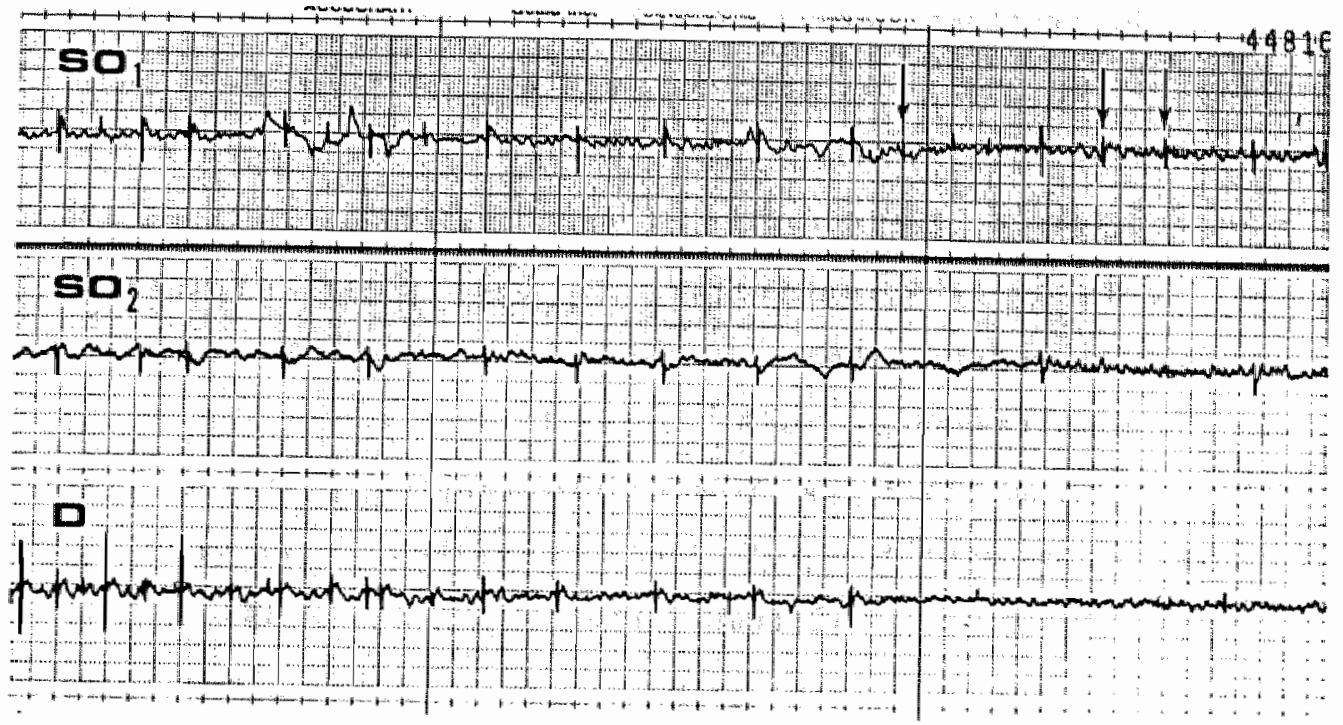

Figure 3. Electromyographic recording at the beginning of phase I shows spike potentials (arrows) originated in the proximal portion of the sphincter of Oddi (so), that do not propagate distally $\left(\mathrm{SO}_{2}\right)$. These spikes have less amplitude. Duodenal tracing (D) can also be appreciated. 
1). The sphincter of oddi splke potentials never disappeared completely, even during phase I.

Table 1 also shows the average frequency of spike potentlals of each phase in the duodenum and the duration of each migrating myoelectric complex phase. Since the number of slow waves and splke potentials were similar in the proximal and distal duodenum electrodes, only the distal electrode tracings were considered for analysis. This also pertains to the proximal and distal sphincter of odd electrodes, and only the distal sphincter of odd1 recordings were considered. The duration of each cycle was the same in the duodenum and sphincter of oddi. All migrating myoelectric complex phases in the sphincter of oddi started almost situltaneously with duodenal phases. The average duration of a migrating myoelectric complex cycle was 92 minutes. The amplitude of duodenal spike potentials was greater during phase III than during the other phases of the inigrating myoelectric complex.

In the recordings of one opossum, Influence of the duodenal myoelectric activity was observed on the sphincter of Oddi tracings. This ellectrical influence mas situltaneous to the duoderal splke potentials and it tas smaller (1ess than $2 \mathrm{mV}$ ) than the sphincter of oddi spikes (Figure 4 ). Myolectric influence of the sphincter of oddi spike potentials on the duodenal tracings was also observed in the recordings of the same animal.

After feeding, the lnterdigestive phases of the 
Table 1

Interdigestive Myoelectrical Activity of Sphincter of Oddi and Duodenum

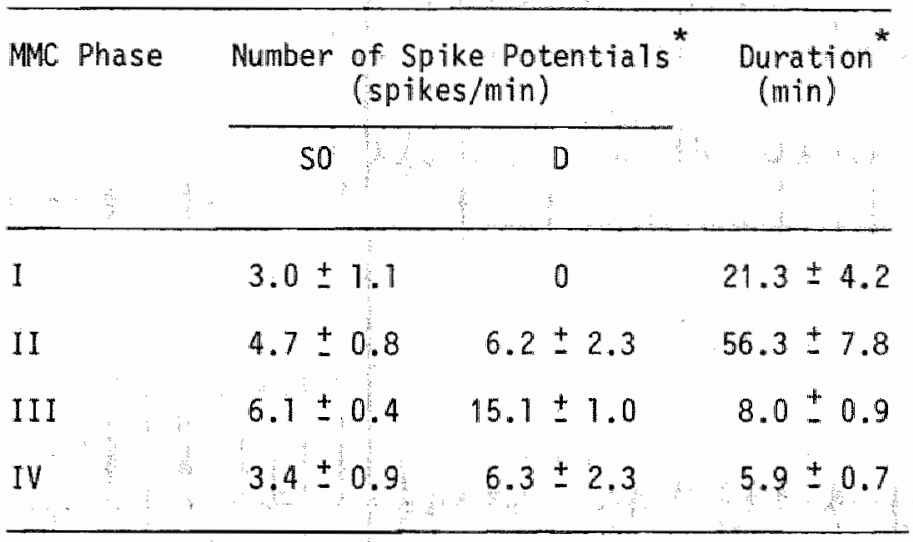

Legend: SO, sphincter of addi; $D$, duodenum; MMC, myoelectric migrating complex.

* Values given as mean \pm 1 so 


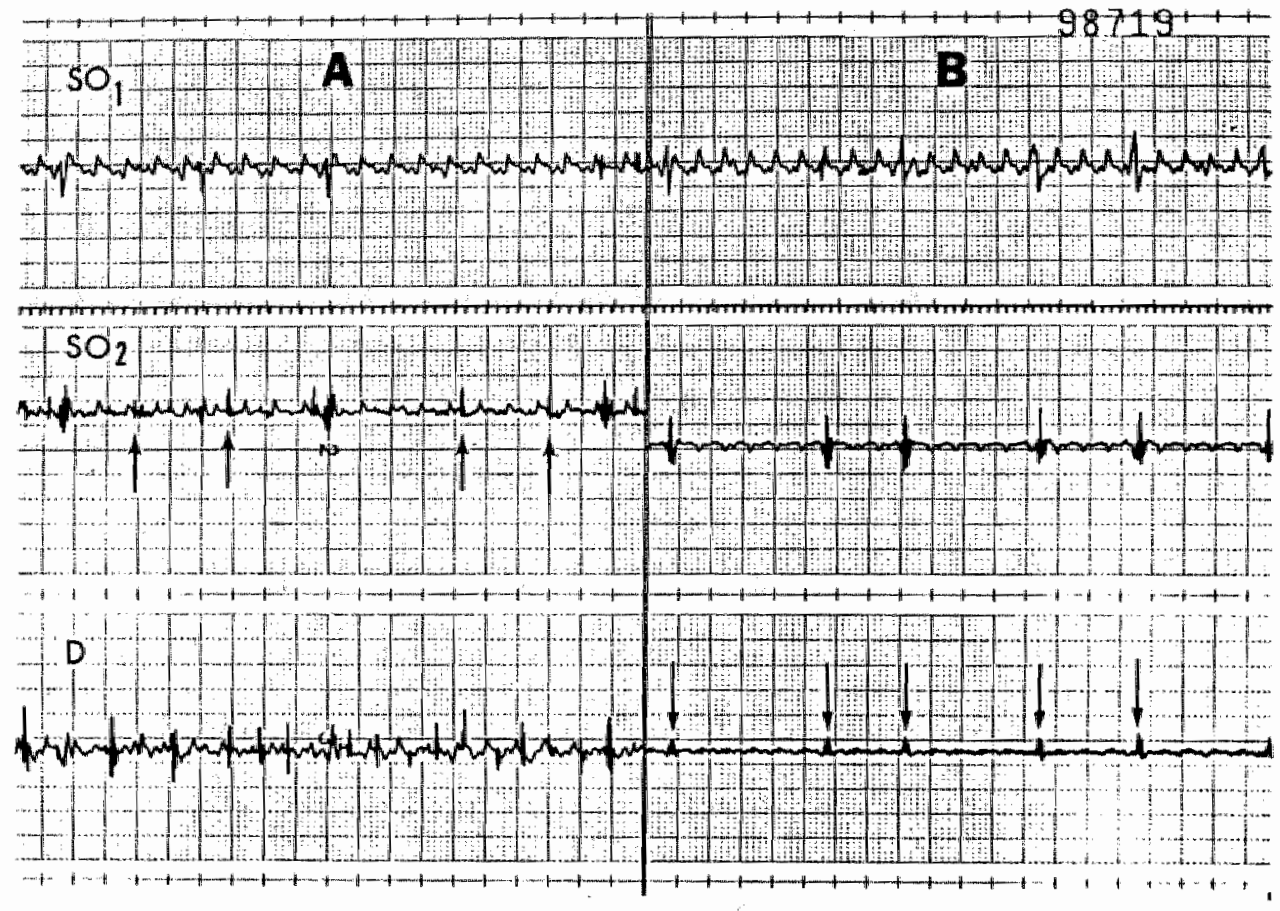

Figure 4. Recording $A$ shows electrical influence (arrows) of the duodenal. (D) spikes on the distal sphincter of odi (so $\left.{ }_{2}\right)$ tracing. These influences are not observed in the proximal part of the sphincter of oddi ( $\left.\mathrm{SO}_{1}\right)$. Recording $B$ depicts electrical influence (arrows) of the so spikes on the $D$ tracing. 
migrating myoelectric complex in the sphincter of oddi and duodenum were abolished and substituted by a feeding activity pattern (Figure 5). The feeding state was

characterized by an average number of splke potentials in the sphincter of oddt and duodenum of $6.6 \pm 0.7$ per minute (mean $\pm 1 S D)$ and $10.7 \pm 1.6$ per minute, respectively. The Erequency of spikes in the sphincter of odd1 was more regular than in the duadenum. There was no change in the frequency of slow waves in the sphincter of odd and duodenum. The amplitude of sphincter of oddi spike potentials was the same in, the feeding and fasting states. After 2 to 3 hours the end of the feeding activity pattern was easily recognized by the reappearance of phase III.

\section{Pressure studies.}

The mean fasting pressure in the pancreatic and billary ducts was 15 and $13 \mathrm{mmHg}$, respectively, and they ranged from 10 to $25 \mathrm{mmg}$ in the pancreatic duct and from 7 to $25 \mathrm{mmg}$ in the biliary duct. The pressure in the pancreatic duct wa greater than the pressure 1 in the billary duct in $75 \%$ of the experiments, equal in $15 \%$, and 10 wer in $10 \%$

Pressure changes in the pancreatic and biliary ducts vere of two types. F1rst, there was a pressure osclilation of 1 to $3 \mathrm{mmHg}$ synchronous with resplratory movements. Th1s pressure variation could be eliminated fom the recordings by turning the high-frequency cutoff filter knob to the wean position. The second type of pressure change was related to 


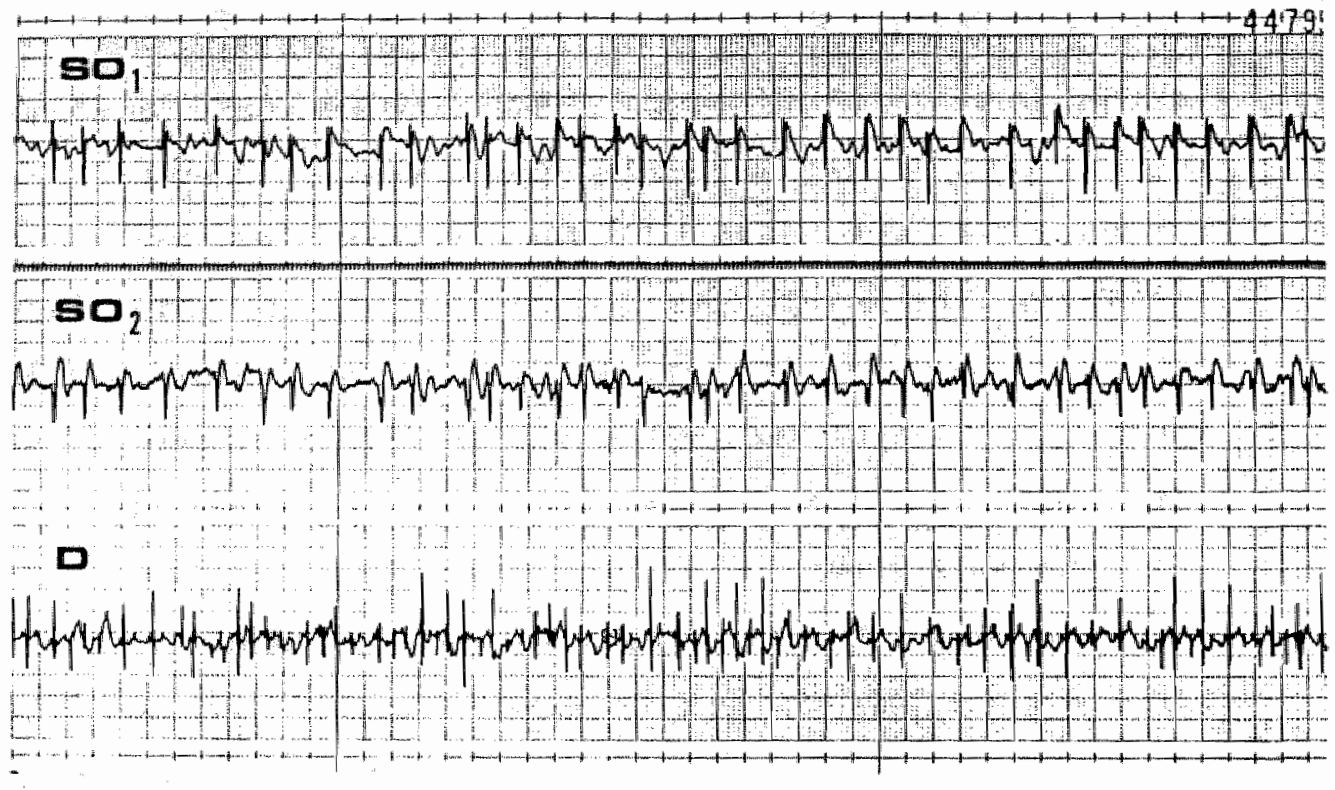

Figure 5. Feeding activity pattern of the proximal (SO)' and distal $\left(\mathrm{SO}_{2}\right)$ sphincter of Oddi and duodenum (D). 
the sphincter of oddi myoelectric activity. A temporary elevation of pancreatic and biliary duct pressures of 1 to 3 mig was observed with each sphincter of oddi spike potential in most experiments (Figure 6). There was no pressure variation among the different migrating myoelectric complex phases.

There was an increase in the number of pressure elevations related to spike-burst potentials during feeding, but base pressure remalned constant.

\subsection{DISCUSSION}

Several studies have been conducted to describe the dynamics and relationshtp of the pancreatic and bildary ducts to the sphincter of oddi. Most methods of recording pancreatic and biliary duct pressures interfere with the flow of bile or pancreatic julce into the duodenum by occlusion of the ducts or interference with the normal sphincter activity $(8,9)$. Recently, manometry during endoscopic cannulation of the papilla of vater has been used extensively to measure the pancreatic and biliary ducts and sphincter of odd1 pressures $(2,9)$. However, cannulation of the sphincter of odd1 can also interfere with 1 to sphincteric activity or cause occlusion of the pancreatic or common duct.

Our model combines recording of sphlncter of add myoelectric activity with measurement of pancreatic and bl1 lary duct pressures under circumstances that minfmally 


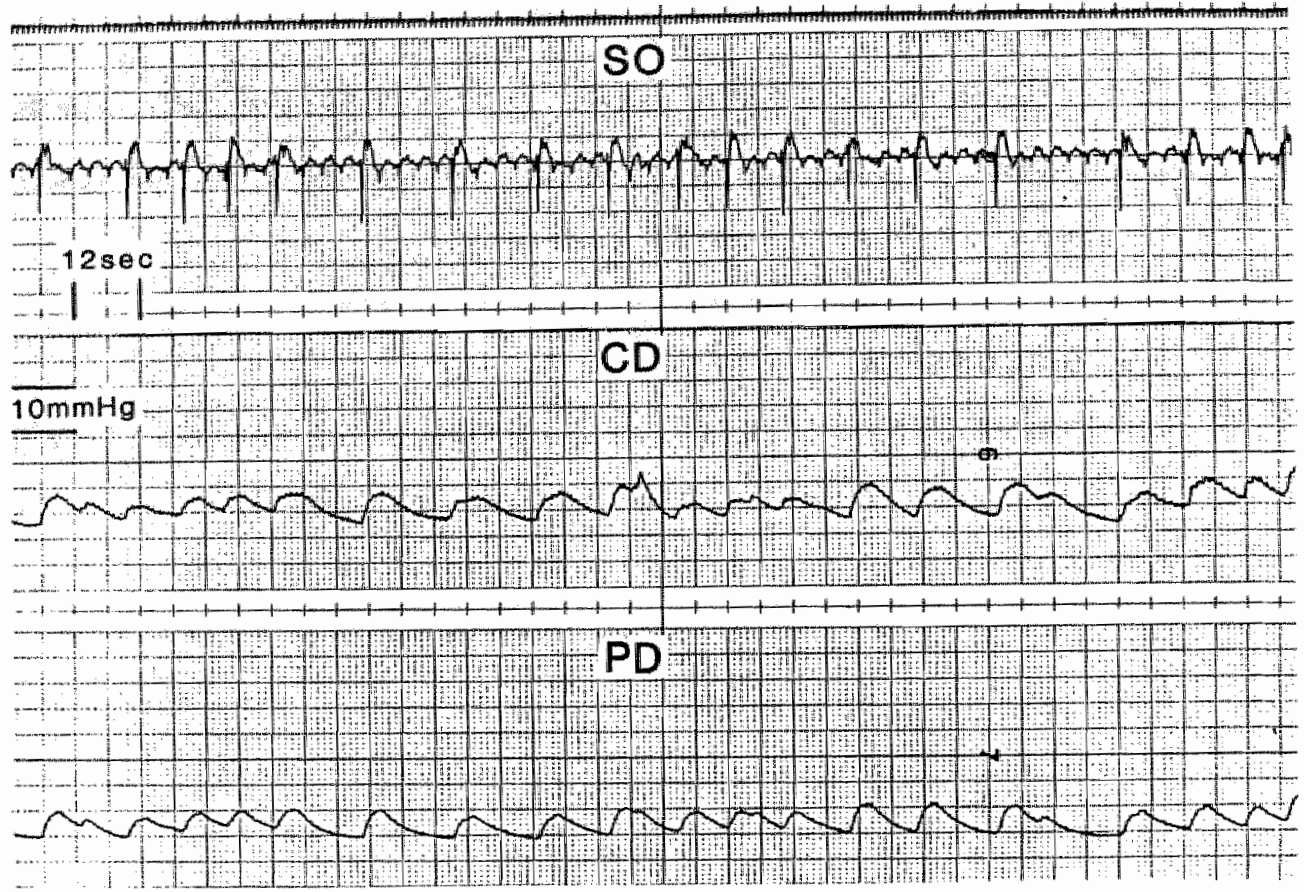

Figure 6. Recordings of the sphincter of oddi (so) myoelectric activity, common duct pressure (CD), and pancreatic duct pressure (PD). Temporary elevation of PD and CD pressures with each so spike potential is seen. oddi (so) 
alsturb the normal pancreatoblliary physiology. The opossum was selected for this study because the sphincter of oddi in this species is mostly extraduodenal and measures 2 to $3 \mathrm{~cm}$ in length and, therefore, is easily accessible. placement of electrodes along the sphincter of oddi may thus be accomplished without dissection of the pancreas and duodenum. In addition, the opossum provides another important advantage. These animals lle quietiy during the day for many hours without the need of drug administration or use of restraints since they are nocturnal feeders.

The sphincter of oddi in the opossum exhibited spontaneaus spike potentials, which propagated from the proximal to the distal portion of the sphincter. Interestingly, the slow-wave frequency was the same 1 in the sphincter of oddi and duodenum, an average of 19 per minute. The number and amplitude of splke potentials in the sphincter of oddt are different from those in the duodenum, but both the sphincter of odd and the duodenum exhibit cyclic changes in the frequency of splike potentials that correlate with the migrating myoelectrlc phases. The frequency of sphincter of $0 d d 1$ and duodenal splke potentials Hncreased from phase $I$ to phase III of the migrating myoelectric complex and then 1 tecreased rapidiy during phase IV to start a new cycle. The average duration of each cycle was 92 minutes. The onset and duration of each phase were stmilar in the sphincter of oddi and duodenum. During phase I occasional or no splke potentials were recorded on 
the duodenum, while spikes were alvas present in the sphineter of oddi.

Althoug the myolectric activity of the sphticter of odd and duodenum $1 \mathrm{~s}$ different, electrodes placed in the ophincter of oddi close to the duodenum may record spike potentials generated in the duodenum and vice versa. This may be responsible for the electrical fifluence of the sphincter of oddi spikes in the duodenum in the recordings af one of our antmals. These electrical influences can be differentlated from true splke potentials because they are smaller than the spikes and are simultaneous to the action potentials that originated them. Electric currents propagate to any adjacent reglon in the small intestine as demonstrated by specht and Bortoff (10).

The interdigestive migrating myoelectric complex cycles were distupted by food. The feeding activity pattern was characterized by an 1 ncrease in the number of spike potentials, both in the sphincter of oddi and duodenum. De Wever et al. determined that the duration of the migrating myoelectric complex disruption ls dependent on the quantity and nature of the food ingested (11). The distuptive effect is longer for fat than for carbohydrate. Protedn abolished the migrating myoelectric complex for only short periods of tiline.

There is great controversy in the literature about the normal pancreatic and biliary pressures $(1,2,8,9)$. The wide range of results is probably related to the numerous models, 
techniques, and animals that have been used. In our study the recordings were performed in conscious opossums without the need for sedation, analgesics, or other drug-induced variables. The instruments used had high sensitivity and the electrodes and catheters probably did not disturb the pancreatobliloduodenal physiology. In prelimtinary studies we observed that infusion of large volumes of fluld Into the pancreatic and biliary ducts disturbed the normal myoelectric activity of the sphincter of oddi in some experiments. Therefore the rate of fluid admintstration was mindmal.

The mean fasting pancreatic and billary pressures were 15 and $13 \mathrm{mmHg}$, respectively. Temporary pressure elevations synchronous with each sphincter of oddi splke potential were observed. The baseline pressure remained constant after feeding and during all migrating myoelectric complex phases. The role of sphincter of oddi splke potentials in the regulation of the pancreatic and biliary pressures is controversial. It has been suggested by combined electromyographic and cineradiographic studies that sphincter of odd splke potentials in opossum are assoclated with peristaltic contractions of the sphincter of Oddi that would have the function of transporting bile from the sphincter of odd into the duodenum $(12,13,14)$. Simultaneously, the bile flow from the terminal common duct into the sphincter of odd1 would be interrupted temporarily with a secondary discrete increase in the billary duct 
presicure. After the sphincter of oddi contraction, the spincter seguent would be refilled by passive inflow of blle fram the comon duct, and the baseline blliary pressure would be reestablished. A similar mechanism may also take place durfig pancreatic secretion. The constant baseline pancreatlc and billary duct pressures during all migrating myoelectric complex phaseg and feeding state suggest that presure $1 \mathrm{~s}$ not the main regulatory mechanism of bile and pancreatic juice flow into the duodenum. The purpose of different spike potentials during the various migrating myoelectrite complex phases is unkmown. We suggest that this splke potential variation may have an lmportant role in regulating the rate of biliopancreatic secretion into the duodenum. Therefore biliary and pancreatic exocrine secretions would be more intense during phases II and III than during phases I and IV. This concurs with the study of Kaene et al. on dogs in which the trypsin and bicarbonate outputs were minfmal during phase $I$ and maximal during phase I I and III, respectively. It is possible that the number of sphincter of oddi splke potentials and the secretion of bile and pancreatic julce into the duodenum may be controlied simultaneously by a comon mechaism, prabably nervous or hormonal.

It is concluded that the sphincter of oddi of the fasting opossum exhibits cyclic changes in the number of spike potentials that correlate with the migrating myoelectric complex in the duodenum. However, the number and 
amplitude of spike potentials are different in the sphincter of oddi and duodenum. Food ingestion disrupts the migating ryoelectric complex and Increases the number of splke potentials in the sphincter of oddt and duodenum. There was no change in the baseline pressure during fasting and feeding states, and a temporary pressure elevation synchronic with each sphincter of odd splke potential was observed.

\subsection{BUMMARY}

Myoelectric activity of the sphincter of oddt and duodenum was correlated wh pancreatic and biliary duct pressures in eight opossums, in both the fasted and fed states. Four bipolar electrode pairs were implanted in the sphincter of oddi and duodenum. A polyethylene $T$ tube was placed in the pancreatic duct. The common duct was cannulated through a small bile duct. This method allowed pressure recording for several we ks and avolded interference with the flow of bile or pancreatic fulce linto the duodenum. The frequency of slow waves was the same $1 \mathrm{n}$ the sphincter of addi and duodenum (19 per minute). The warlation in the frequency of splke potentials in the sphincter of oddi correlated to that of the migrating myolectric complex in the duodenum. The average frequency of slow waves that have superimposed splke potentials in the sphincter of $0 \mathrm{dd} 1$ and duodenum was 3.0 and 0 in phase $1,4.7$ and 6.2 in phase II, 6.1 and 15.5 in phase III, and 3.4 and 
6.3 in phase IV, reapectively. The average duration of a migrating myolectric camplex cycle was 92 minutes. After feeding, the interdigestive phases of the migrating myoelectric complex were abolished and substituted by a feeding pattern that was characterized by an awerage number of sphincter of odd1 and duodenum spikes of 6.6 and 10.7 , respectively. The mean fasting pressure in the pancreatic and billary duct was 15 and $13 \mathrm{~mm} \mathrm{Hg}$, respectively. Pressure changes were of two types: synchronous with respiratory movements and with each sphincter of oddi spike potential. There was no warlation in the baseline pressure during the migrating myoelectric complex phases and the fed state. It is concludied that the sphincter of oddi of the fasting opossum exhibits cycilc changes in the number of spike potentials that correlate with the migrating myoelectric complex in the duodenum. However, the number and amplitude of spike potentials are different in the sphincter of oddi and duodenum. There is no change in the baseline pressure during fasting and feeding states, and a temporary pressure elevation synchronic with each sphincter of oddi splke potentelal was observed.

\subsection{REFERENCES}

1. Elliott DW, Williams RD, Zollinger RM. Alterations $1 \mathrm{n}$ the pancreatic resistance, to bile in the pathogenesis of acute pancreatitis. Ann Surg 
$146: 669-682,1957$.

2. Geenen JE, Hogan WJ, Dodds WJ, steward ET, Arndorfer RC. Intraluminal pressure recording from the hum sphincter of oddi. Gastroenterology $78: 317-324,1980$.

3. Nebe1 OT. Manometric evaluation of the paptila of Vater. Gastrointest Endosc $21: 126-128,1975$.

4. Becker JM, Moody FG, Zinsmeitser AR. Effect of gastrolntestinal hormones on the biliary sphincter of the opossum. Gastroenterology $82: 1300-1307,1982$,

5. Code CF, Marlett JA. The interdigestive myoelectric complex of the stomach and small bowel of dogs. J Physio1 (London) 246:289-309, 1975 .

6. Marlett JA, Code CF. The interdigestlive gastrointegtinal electric complex. Fed Proc $30: 609,1971$.

7. Carlson GM, Baldider SB, Code E. Mechanism of propagation of intestinal interdigestive myoelectric complex. Am J Physiol 222:1027-1030, 1972 .

8. Menguy RB, Hallenbeck GA, Bollman JL, Grindlay JH. Intraductal pressures and sphicteric resistace in canine pancreatic and billary ducts after variou st1mu11. Surg Gynecol obstet 106:306-320, 1958.

9. Parry EW, Hallenbeck GA, Grindiay JH. Pressures in the pancreatic and common ducts. Arch Surg 70:757-765, 1955 .

10. Specht PC, Bortoff A. Propagation and electrical entiertalnment of intestinal slow waves. Am J DIg DIs $17: 311-316,1972$

11. De Wever I, Eeckhout $C$, Vantrappen $G$, Hellemans J. 
Discuptive effect of test meals on interdigestue motor complex In dogs. Am J Physiol 235: E661-E665, 1978.

12. Honda R, Toou11 J, Dodds WJ, Sarna $S$, Hogan WJ, Itoh Z. Relationship of sphineter of oddi splke bursts to gastrolntestinal myoellectic activity in conscious opossum I C1 In Invest $69: 770-778,1982$.

13. Toou11 J, Honda $R$, Dodds. WJ, Hogan WJ, Orlowski JM, Sarnes, Arndorfer RC. Manometric and electromyographic fertures of the apossum sphincter af oddi. Gastroenterology $78: 1279,1980$.

14. Tooul1 J, Honda R, Dodds WJ, Hogan WJ, Sarna S, Eg1de MS, Arndorfer RC. Manometric, electric and flow properties of the opossum sphincter of oddi. Dig Dis Scl $25: 719,1980$.

15. Keane FB, DIMagno EP, Doz1os. RR, Go VLW. Canine pancreatic exocrine secretion and levels of pancreatic polypeptide related to fasting duodenal motility. In Christensen $J$, editor. Gastraintestinal Motility. New York, Raven Press, 1980, pp.319-321. 


\section{THE EFFECT OF FEEDING ON MYOELECTRIC ACTIVITY OF THE SPHINCTER OF ODDI AND GASTROINTESTINAL TRACT IN THE OPOSSUM}

\subsection{INTRODUCTION}

Characteristic patterns of myoelectric activity occur in the gastrointestinal tract during fasting and after feeding in several species $(1,2)$. The myoelectric migrating complex (MMC) is present during the fasting state and sweeps the gastrointestinal tract cyclically from the stomach to the terminal ileum. This pattern was first described by Szurszewski in 1969 and comprises four phases (3). During phase I, occasional or no spike potentials are observed. In phase II, spike potentials are superimposed on the slow waves in random fashion; phase III consists of spike potentials of high amplitude on each slow wave. During phase IV, the frequency and amplitude of spike potentials decrease rapidy to begin a new MMC. Feeding interrupts the MMC and results in a noncyclical pattern of intermittent spike potentials that persists for the duration of the postprandial period.

Recently, electromyography has been used to study the motility of the sphincter of oddi $(4,5)$. Honda et al. and our group have demonstrated that the sphincter of Oddi of the fasted opossum exhibited cyclic changes in the frequency of bursts of spike potentials that correlated with the MMC 
phases $(6,7)$. Feeding abolished the MC phases in the sphincter of oddi. The fed pattern of the small bowel has been reported in several studies $(8,9,10)$. However, the effect of different foods on the myolectric activity of the antrum and sphincter of oddi has not been evaluated. $A$ relationship between flow of biliary and pancreatic secretions into the duodenum and the MMC phases has also been reported (11). Our objective in the present study is to determine the effect of different foods on the myoelectric activity of the sphincter of oddi and correlate it with the fed patterr of the gastrointestinal tract in the oposium. Simultaneous gallbladder pressure recordings were also obtained.

\subsection{MATERIAL AND METHODS}

The opossum was selected for this study because its sphincter of oddi is mainly extraduodenal and measures 2 to $3 \mathrm{~cm}$ in length and, therefore, dissection of the pancreas and duodenum is not necessary to implant the electrodes. In addition, in the opossum, as in the human, the main pancreatic duct joins the common duct at the proximal portion of the sphincter of oddi.

Laparotomy was performed in five opossums of either sex weighing 2.5 to $3.5 \mathrm{~kg}$. The animals were anesthetized with $25 \mathrm{mg}$ of sodium pentobarbital per $\mathrm{kg}$ administered intraperitonea11y.

A total of 14 bipolar electrodes were implanted as 
pairs into the sphincter of oddi, distal gastric antrum, duodenum, proximal jejunum, mid-jejunum, terminal jejunum, and terminal ileum. The electrodes consisted of stranded silver-plated copper wire of 36 AWG (American Wire Gauge) size with teflon insulation. The wire was placed in the muscular layer of the gastrointestinal tract through a 25 gauge hypodermic needle and the end was tied off. The free end was trimued.

A large silastic tube ( $1 / 16$ inch $I . D$. and $1 / 8$ inch O.D.) was placed into the stomach, $2 \mathrm{~cm}$ distal to the esphagogastric junction. A cholecystostomy was performed with PE-50 polyethylene tubing in the fundus of the gallbladder in four animals. The tubes and the wires were passed through a subcutaneous tunnel to the back of the animal.

An eight-channel Gould 2800 s instrument (Gould Inc., Recording Systems Division, Cleveland, Ohio) was employed to record the electromyographic activities and the gailbladder pressure. Experiments were begun seven to ten days after the operation and were performed on conscious animals fasted for 12 hours.

Pressure was recorded by connecting the gailbladder catheter to the recording instrument through a Gould P23 pressure transducer (Goula statham Instruments, Inc., Hato Rey, Puerto Rico). An Arndorfer hydraulic capillary infusion system (Arndorfer Medical specialties, Inc., Greendale, Wisconsin) was employed to infuse water into the catheter at 
a low constant rate of $0.04 \mathrm{ml} / \mathrm{min}$. In order to eliminate the pressure secondary to the tubing resistance to the water flow, another catheter with the same diameter as that placed in the gallbladder was perfused with water at the same rate. The pressure recorded from the external catheter was considered to be zero.

Four types of food were studied: $90 \%$ protein (Milk and Egg protein, Fillmore Foods, Inc., Suisun, California), pure fat (Corn oil, Sigma Chemical Co., St. Louis, Missouri), pure carbohydrates $(C \& C$ Sugar, Califormia and Hawalian Sugar Co., San Francisco, California), and mixed food that contained the same amount of calories in fat, protein, and carbohydrates.

Because caloric content was the only common property of the meals, the quantity of food used was expressed in calories as suggested by De wever et al. (6). Each meal, at $20 \mathrm{Cal} / \mathrm{kg}$, was given through the gastrostomy tube to make certain that the food was completely ingested. The food was mixed with water to obtain meals with a constant volume of $50 \mathrm{ml}$.

Ten studies were obtained for each type of food. Each study included recordings of one MMC preceding instillation of food, the fed pattern, and one MMC floowing the meal. The meal was given during phase I of the MMC.

The duration of the fed pattern was determined by measuring the interval between feeding and the reappearance of the first phase III in the duodenum that migrated 
distally to the ileum, and it was followed by phase I. The frequency of bursts of spike potentials in the sphincter of oddi, antrum, duodenum, and mid-jejunum was determined by dividing the recordings into two-minute intervals and averaging the number of slow waves with spikes in each interval during the entire fasted and fed states. The MMC was divided into four phases as described by code and Marlett (12). The data were analyzed statistically by means of analysis of variance. Correlation between frequency of spike potentials in the sphincter of oddi and small bowel and the duration of the fed pattern was determined by linear correlation analysis.

\subsection{RESULTS}

\section{Fasting Myoelectric Activity}

The frequency of slow waves (presetter potential) was the same in the sphincter of oddi and duodenum, and decreased from $19 / \mathrm{min}$ in the auodenum to $16 / \mathrm{min}$ in the ileum. The presetter potential frequency in the antrum was the lowest, $3.5 / \mathrm{min}$. The frequency of slow waves with spike potentials in the sphincter of oddi and gastrointestinal tract for each MMC phase is shown in Table 1. Burstg of spike potentials never disappeared completely in the sphincter of oddi, even though no spike potentials were observed in the stomach and small bowel during phase I. Phase III in the small bowel was characterized by spike potentials on each slow wave. However, spike potentials were 
observed in onlly $78 \%$ and $23 \%$ of the slow waves in the antrum and sphincter of dad, respectively, during phase III (Figure 1). The average duration of the MMC was 81 min with phase II being the longest (Table 1 ).

\section{Fed Myoelecytrie Activity}

Feeding caused appearance of spike activity in the duodenum and sphincter of oddi in five minutes and in the jejunum in ten minutes. All meals caused an increase of slow waves with spikes in the duodenum ( 9.5 spike bursts/min) and sphincter of addi ( 7 spike bursts/min) during the first two minutes as compared to the frequency of bursts of spikes observed during the 15 minute interval preceding the feeding. This burst of spike potentilals was followed by a pattern of irregular spike activity. This fed pattern was the longest for fat and the shortest for carbohydrates $(\mathrm{p}<0.01)(\mathrm{Table} 2)$.

The average number of slow waves with superimposed spike potentials following feeding of each type of food is also shown in Table 2. Feeding of fat and mixed food resulted in the greatest incidence of spike activity in the duodenum and jejunum, followed by protein. The lowest incidence of slow waves with spikes in the duodenum and jejunum followed feeding of carbohydrates (p<0.01). There were no differences between fat and mixed food except for spike activity in the jejunum, which was higher for fat (p<0.01). There was a correlation between the frequency of 


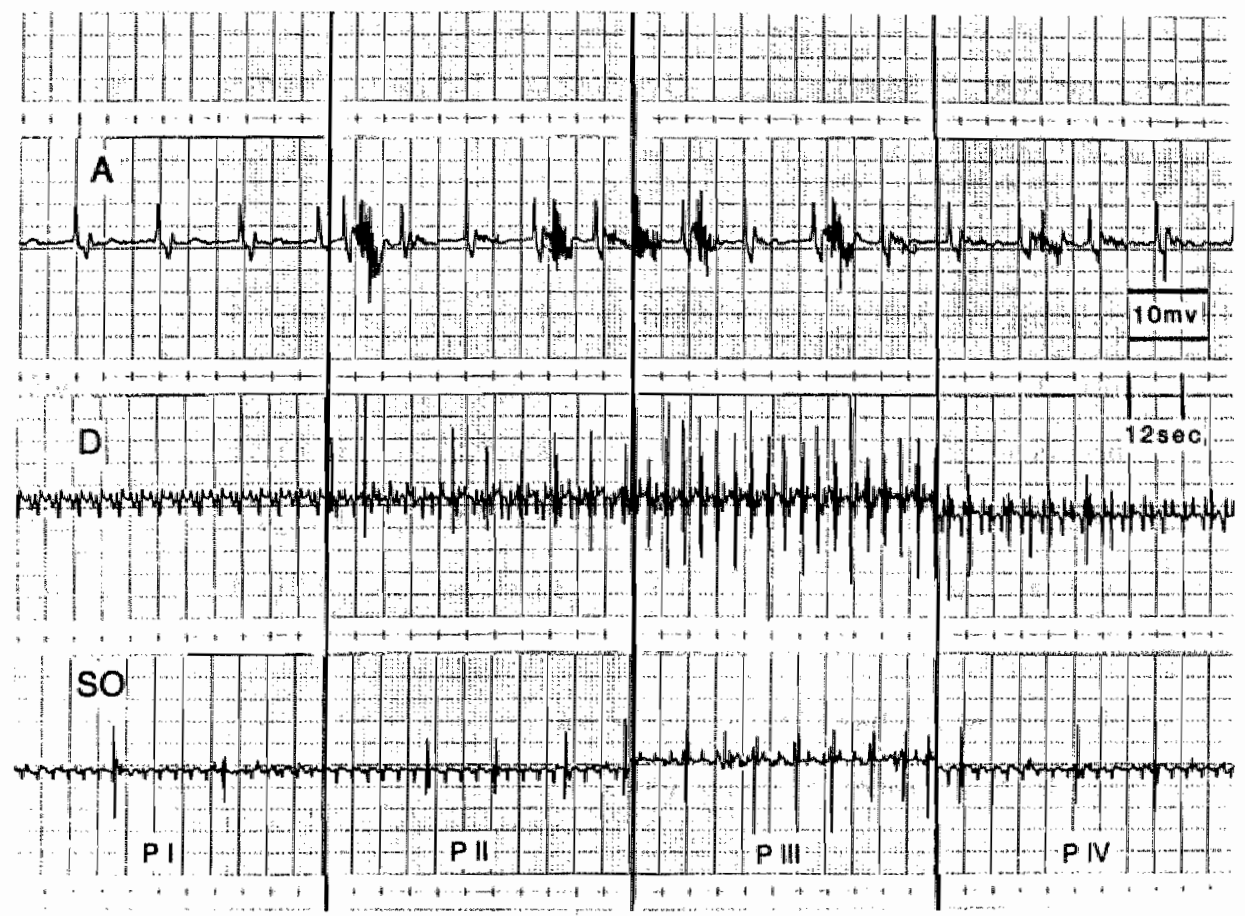

Figure 1. Myoelectric migrating complex phases (P) of the gastric antrum (A), duodenum (D), and sphincter of oddi (SO) in the fasted opossum. The phases observed in the jejunum and ileum were similar to those recorded from the duodenum except for the frequency of the slow waves, which were slightly lower in the jejunum and ileum. 
TABLE 1

Myoelectric Activity of the Sphincter of oddi and Gastrointestinal Tract During Fasting

Spike Activity Freguency

Myoelectric Migrating Complex Phases

(spike borsts/min) $(\mathrm{n}=40)$

I

II

III

IV

Sphincter of Oddi

$1.1+0.4$

$3.4+0.7$

$4.3+0.6$

$3.2+0.7$

Antrum

$2.3+0.3$

$2.7+0.3$

$2.1+0.4$

Duodenum

$3.5+0.8$

$17.8+0.6$

$4.9+1.5$

Jejunum

0

$6.1+0.9$

$17.1+0.7$

$5.0+1.7$

*Duration (min)

$27.7 \pm 3.9$

$39.3+5.9$

$8.0+0.4$

$5.8+0.7$

* Duration of each phase in the duodenum

$n$ refers to the number of experiments 
TAEL 2

Myoelectric Activity of the Sphincter of Odai, Duodenum and Jejunum After Feeding

Spike
Activity Frequency
$\begin{aligned} & \text { (spike bursts } / \text { min) } \\ & (n=10)\end{aligned}$

$\begin{array}{lcccc}\text { Sphincter of oddi } & 4.3 \pm 0.8 & 3.7 \pm 1.1^{*} & 2.8 \pm 0.6 & 4.2 \pm 1.0 \\ \text { Antrum } & <0.5 & <0.5 & <0.5 & <0.5 \\ \text { Duodenvm } & 6.9 \pm 0.9 & 6.3 \pm 1.5^{* *} & 3.1 \pm 0.8 & 7.3 \pm 1.7 \\ \text { Jejunum } & 10.6 \pm 1.1^{* \star} & 7.7 \pm 1.2^{* *} & 5.6 \pm 0.7 & 8.6 \pm 1.4 \\ \text { Duration (min) } & 218 \pm 47^{* *} & 165 \pm 26^{* *} & 131 \pm 26 & 197 \pm 61\end{array}$

"Indicates that this value is significantly greater than the corresponding value in the next collumn to the right at the 5 percent level, $\mathrm{p}<0.05$.

** Indicates that this value is significantly greater than the carresponding value in the next column to the right at the 1 percent level, $\mathrm{p}<0.01$.

$\mathrm{n}$ refers to the number of expeniments. 
bursts of spike potentials in the small bowel and sphincter of Oddi and the duration of the fed pattern (correlation coefficient $=0.605 ; \mathrm{p}<0.01)$.

Only spike potentials of low amplitude were observed in the antrum following all types of meals (Figure 2). Although these spike potentials occurred during the entire fed state, they were more frequent immediately after feeding and in the 10 minute period preceding the reappearance of phase III.

The lowest incidence of spike potentials in the sphincter of Oddi was observed after feeding carbohydrate $(p<0.05)$. There was no significant difference in frequency of spike potentials in the sphincter of oddi between fat, protein, and mixed food. There was a correlation between the frequency of bursts of spike potentials in the sphincter of Oddi and duodenum (correlation coeficient $=0.538 . p<0.01$ ) and sphincter of Oddi and jejunum (correlation coeficient = $0.339 ; \mathrm{p}<0.05)$.

\section{Gallbladder Pressure}

There was no significant change in gallbladder pressure during. fasting and following feeding of different aliments. The mean gallbladder pressure during fasting was $8.7 \pm 1.5 \mathrm{mmHg}$ and ranged from 7 to $12 \mathrm{mmHg}$. The mean pressures after feeding were $10.3 \pm 2.1$ for fat; $9.7 \pm 1.9$ for carbohydrates, and $9.5 \pm 1.6$ for mixed food. 


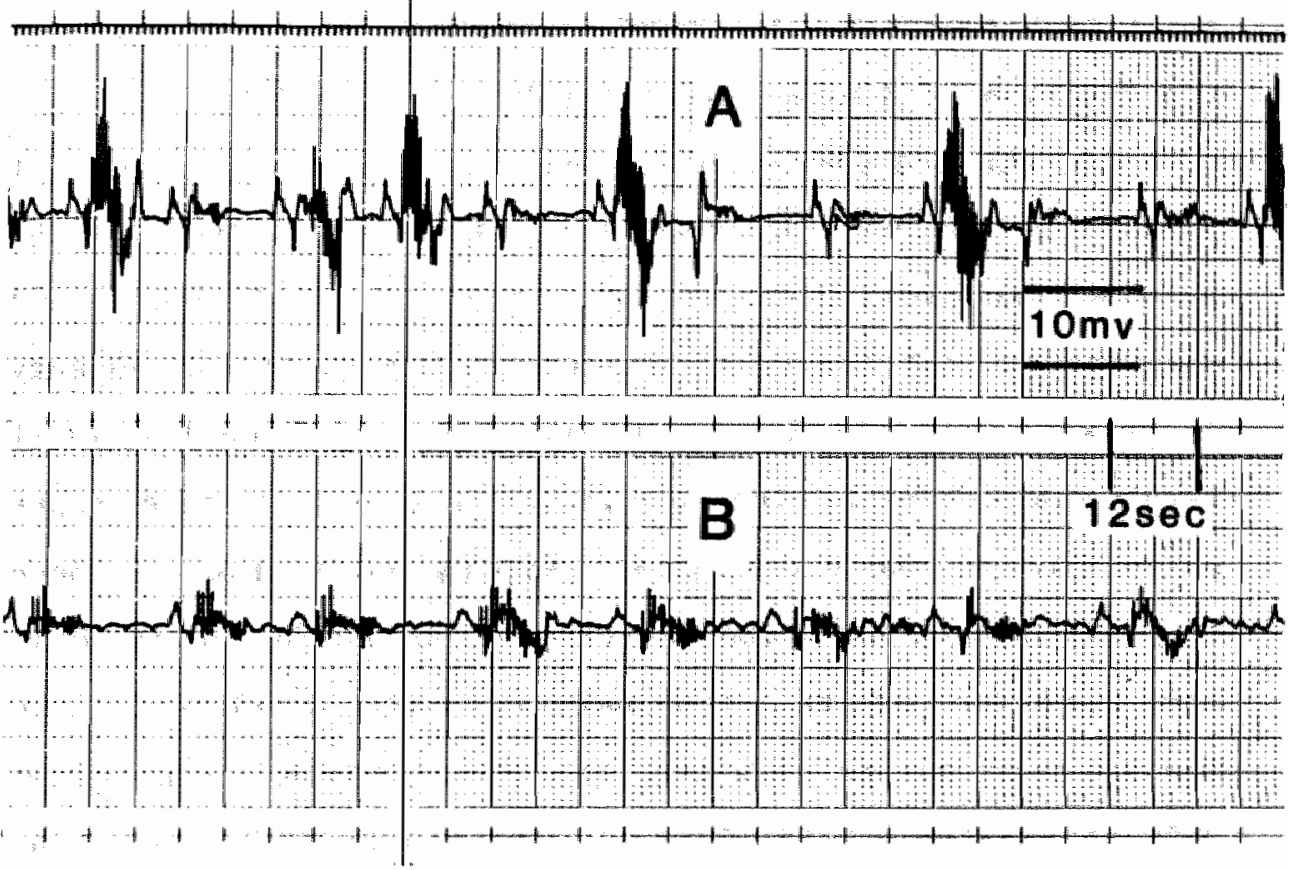

Figure 2. Electromyographic recordings of the gastric antrum obtained from the same animal in one experiment. Recording $A$ shows slow waves with spike potentials of large amplitude observed during phase II of the myoelectric complex. Recording B depicts slow waves with spikes of low amplitude seen during the fed pattern. 


\subsection{DISCUSSION}

The myoelectric activity of the small bowel after feeding has been studied previously in other species (13,14, 15). Ruckebusch et aI. determined in pigs that the duration of distuption of the MMC after feeding depended on the volume of the meal. (16). De Wever et al. observed a 1 inear relation between the amount of calories of the test meal and the duration of disruption of the MMC in ags (10).

In the present study, we have evaluated the effect of isocaloric amounts of pure and mixed nutrients on the myoelectric activity of the sphincter of oddi and gastrointestinal tract. A correlation between the frequency of spike potentials in the sphincter of oddi and the small bowel was observed. The nutrients that caused more spike potentials in the duodenum and jejunum were also the ones that increased more spike activity in the sphincter of adal. The duration of the fed pattern correlated with the frequency of bursts of spike potentials in the sphincter of oddi and gastrointestinal tract. Fat and protein caused the greatest frequency of spike activity in the sphincter of Oddi and mall bowel, and the longest fed pattern. The spike activity of the sphincter of odal and small bowel after feeding carbohydrate was the lowest.

The low frequency of spike activity in the antrum observed after feeding was probably related to the consistency of the food employed. In contrast to its major role in gastric emptying of solids, the antrum has a less 
essential role in the propulsion of liquids. Although antral contractions most likely aid propulsion of liquid from the stomach regardless of the presence or absence of such contractions $(17)$.

Gastric emptying of carbohydrates is generally faster than proteins, which empty faster than fats (18). However, when isocaloric amounts of nutrients are employed, fat, protein, and carbohydrates empty at similar rates (I9). Therefore, gastric emptying possibly did not play a role in the duration of the fed pattern or in the intensity of the spike activity of the small intestine in the present experiment.

Recently, gallbladder pressure has been correlated with MMC phases in the duodenum. Itoh and Takahashi observed that gallbladder pressure in the dog increases when duodenal phase II of the MMC starts and decreases toward phase II (20). Traynor et al. reported a brief elevation of gallbladder pressure in the dog for two minutes at the beginning of phase I (21). The pressure during phase III was constant and similar to phase I of the MMC. We have not observed pressure changes during the MMC phases and the increase in gallbladder pressure following feeding was not statistically significant. These differences may be related to the species employed. Dubois and Hunt reported differences in gallbladaer contraction between different species (22). The gallbladder of the opossum usualy evacuated less than one-third of its contents after a fat 
meal. while the gallbladder of the cat emptied all its contents under the same conditions. They suggest that this difference may be related to the larger volume and thinner muscular layer of the gallbladder of the opossum as compared to the gallbladder of the cat. However, the transit time of bile in the biliary ducts was the same in the two species. Therefore, only smaller changes in gallbladder pressure may be necessary for evacuation of the same volume of bile in the opossum. These small increases in pressure may be difficult to detect due to the wide range of resting gallbladder pressure.

We conclude from this study that fat and mixed food caused the highest spike activity in the duodenum and jejunum, followed by protein. There was no difference in frequency of sphincter of oddl spike potentials between fat, mixed food, and protein. Carbohydrates caused the lowest incidence of spike activity in the sphincter of oddi and small bowel.

\subsection{SUMMARY}

The effect of different foods on the myoelectric activity of the sphincter of oddi and gastrointestinal tract was evaluated in the opossum. Gallbladder pressure was also recorded. Feeding fat and mixed food resulted in the greatest incidence of spike activity in the duodenum and jejunum, followed by protein. The lowest incidence of slow waves with spikes in the duadenum and jejunum followed 
feeding of carbohydrates $(\mathrm{p}<0.01)$. Likewise, the lowest spike activity in the sphincter of odd was observed after carbohydrate (p<0.05). Threre was no significant difference in the incidence of spike potentials in the sphincter of oddi when fat, protein, or mixed food was fed. No significant change in gallbladder pressure during fasting and following feeding of different aliments was observed. We concluded that there is a correlation between the frequency of spike potentials in the sphincter of oddi and in the small bowel following feeding. The duration of the fed pattern for each type of food correlated with the number of spikes in the sphincter of oddi and gastrointestinal tract.

\subsection{REFERENCES}

1. Rees WDW, Malagelada J-R, Miller LJ, Go VLW. Human interdigestive and postprandial gastrointestinal motor and gastrointestinal hormone patterns. Dig Dis Sci $27: 321-329,1982$.

2. Summers RW, HeIm J, Christensen J. Intestinal propulsion in the dog. Gastroenterology 70:753-758, 1976.

3. Szurzewski JH. A migrating electric complex of the canine ma11 intestine: Am J Physiol 217:1757-1763. 1969.

4. Becker JM, Moody FG, Zinsmeister AR. Effect of gastrointestinal hormones on the biliary sphincter of the opossum. Gastroenterology $82: 1300-1307,1982$. 
5. Toouli J, Dodds W, Honda R, Sarna 5 , Hogan WJ. Komarowski RA, Linehan JH, Arndorfer RC. Motor function of the opossum sphincter of oddi. J Clin Invest $71: 208-220,1983$.

6. Honda R, Tooul1 J, Dodds WJ, Sarna S, Hogan WJ, Itoh Z. Relationship of sphincter of oddi spike bursts to gastrointestinal myoelectric activity in conscious opossums. I Clin Invest $69: 770-778,1982$.

7. Coelho JCU, Moody FG, Senninger N. A new method for correlating pancreatic and biliary duct pressures and sphincter of oddi electromyography. Surgery 97:342-349, 1985.

8. Weisbrodt NW, Copeland EM, Thor PJ, Dudrick SJ. The myoelectric activity of the small intestine of the dog during total parenteral nutrition. Proc soc Exp Biol Med $153: 121-124,1976$.

9. Sarr MG, Kelly KA, Phillips sF. Canine jejunal absorption and transit during interdigestive and digestive motor states. Am J Physiol 239:G167-G172, 1980 .

10. De Wever I, Eeckhout C, Vantrappen G, Hellemans J. Disruptive effect of test meals on interdigestive motor complex in dogs. Am J Physiol 235:E661-E665, 1978.

11. Keane FB, DiMagno EP, Dozois RR, Go VL. Relationships among canine interdigestive exocrine pancreatic and biliary flow, duodenal motor activity, plasma pancreatic polypeptide, and motilin. Gastroenterology 
$78: 310-316 ; 1980$

12. Code CF, Marlett JA. The interdigestive myoelectric complex of the stomach and small bowel of dogs. I Physiol 246:289-309, 1975 .

13. Sarr MG, KellY KA. Patterns of movement of liquids and solids through canine jejunum. Am J Physiol $239: G 497-G 503,1980$.

14. Thompson G, Archer I, Green WJ, Wingate DL. Fasting motor activity occurs during a day of normal meals in healthy subjects. Gut $22: 489-492,1981$.

15. Eeckhout C, Vantrappen G, Peeters TI, Janssens J, De Wever I. Different meals produce different digestive motility patterns. Dig Dis Sci 29:219-224, 1984.

16. Ruckebusch $Y$, Bueno L. The effect of feeding on the motility of the stomach and small instestine in the pig. Brit J Nutr 35:397-405, 1976.

17. Stemper TJ, Cooke AR. Gastric emptying and its relationship to antral contractile activity. Gastroenterology $69: 649-653,1975$.

18. Kelly KA. Motility of the stomach and gastroduodenal junction. In Johnson LR, editor. Physiology of the Gastrointestinal Tract. New York, Raven Press, 1981, $\mathrm{pp} \cdot 393-410$

19. Hunt $\mathbb{J N}$, stubbs DF. The volume and energy content of meals as determinants of gastric emptying* I Phisiol $245: 209-225,1975$.

20. Itoh $\mathrm{Z}$, Takahashi T, Periodic contractions of the 
canine gallbladder during the interdigestive state. Am J Physiol 240:G183-G189, 1981 .

21. Traynor OJ, Dozois RR, DiMagno EP: Canine interdigestive and postprandial gallbladder motility and emptying. Am J Physiol 246:G426-G432, 1984 .

22. Dubols FS, Hunt EA. A comparative study of the emptying of the gallbladder in the opossum and the cat, together with notes on the anatomy of the biliary tract of the opossum. Anat Rec 54:289-306, 1932 . 
CHAPTER 4

\section{EFFECT OF GASTROINTESTINAL HORMONES ON THE} SPHINCTER OF ODDI AND DUODENUM MYOELECTRIC ACTIVITY AND ON PANCREATIC AND BILIARY PRESSURES IN THE OPOSSUM

\subsection{INTRODUCTION}

Although disturbances of the sphincter of oddt heve been Implicated in the pathogenesis of biliary and pancreatic diseases, 11ttle $1 \mathrm{~s}$ known about 1 ts normal sphincteric physiology. Manometric, flowetric, claeradiographic, and endoscoplc techniques have been employed to evaluate the dynamics of the sphincter of odd $(1-4)$. Recentiy, electromyography has been used to atudy the motility of the gastrolntestinal tract and 1 ts sphincters (5-8). Several animals, 1 ncluding man, opossum, and dog, exhibit a characteristic gut motility during the fasting state that has been termed the migrating myoelectric complex (MMC) which periodically propagates down the digestive tract from the stomach to the terminal ileum $(5,6)$. Following 
feeding, the MMC eycle is temporarily substituted by a moelectric fed pattern. Honda et al. and our group have demonstrated that the sphincter of oddi of a fasting opossum exhlbits cyclic changes in the frequency of splke potentials that correlate with the MMC in the duodenum $(5,6)$.

Correlation between myographic activity of the sphincter of odd and pancreatic and biliary duct pressures has not yet been evaluated. We have developed a chronic model that allows situlaneous recording of the sphincter of odd electromyography and measurement of pancreatic and billary pressures. Our objective 1 n the present study is to evaluate the effect of gastrointestinal hormones and acetylcholine on the sphincter of oddi and duodenum myolectric activity and on pancreatic duct and common duct presiures in the awake, nonmedicated opossum.

\subsection{MATERIAL AND METHODS}

Experiments were performed in elght adult opossums of efither sex we $1 \mathrm{ghing} 3$ to $5 \mathrm{~kg}$. The animals were anesthetized Wth $25 \mathrm{~kg}$ of sodium pentobarbital per $\mathrm{kg}$ administered Intraper tonea $11 y$.

At laparotomy, performed through an upper midine inciston, the main pancreatic duct at the head of the pancreas was catheterized with a $P E-50$ palyethylene $T$-tube 
(Figure 1). The bile duct, which connects the right lateral lobule of the liver to the common duct, was cannulated with a PE-50 polyethylene tube.

Four pairs of bipolar extracellular electrodes were lmplanted 1nthesphincter of odd1 and duodenum, two 1 neach site. In the sphincter of oddi, which measures 2 to 3 cm in length ta the opossum, the electrode palrs were placed 1 cm and 2 cm proximal to the sphincter of odd1-duodenal junction. The third and fourthpals of electrodes were flxed in the duodenum $2 \mathrm{~cm}$ proximal and $2 \mathrm{~cm}$ d $1 \mathrm{sta} 1$ to the splncter of oddi-duodenal junction. The electrodes cons1sted of stranded silver-plated copper wire with teflon Insulation of 36 AHG size.

The billary and pancreatlc catheters and the wires were previously passed through a subcutaneous tunnel from the back to the right upper quadrant of the abdomen. The w1res were soldered to a female connectorprior to the operation. After abdominal wall closing, a s1labtc tube was inserted into the internal jugular vein. The tube was passed to the anlmal's back where 1 t exited. The socket and the tubes were stitched to the skin.

Electromyographic activities and biliary and pancreatic duct pressures were simulaneously recorded on an eight-channel Gould 2800 s instrument (Gould Inc., Recording Systems Division, Cleveland, ohio). Experiments were begun seven to ten days after the operation and were performed on conscious fasted animals. Recording sessions of five to 


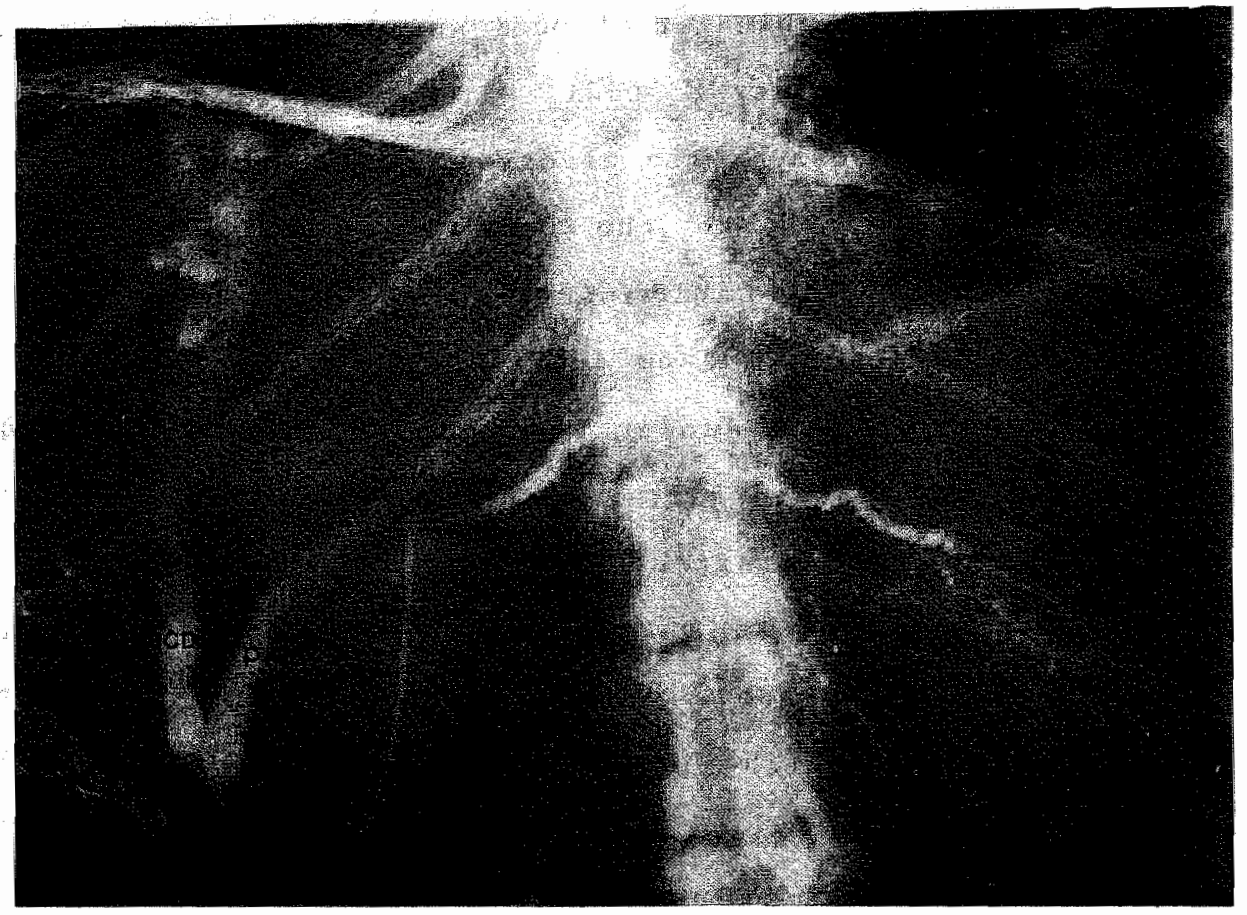

Eigure 1. Cholanglopancreatogram showing the common duct (CD) and a T-tube placed in the main pancreatic duct ( $P$ ). 
eight hours were obtalned in each anlmal for pertod of one to four months with an average of elght recording sessions pér opossum.

The following substances and doses were studied: 0.02 , 0.1 and $0.5 \mu \mathrm{g} / \mathrm{kg} / \mathrm{h}$ of cholecystokinin-octapeptide (E.R. Squibb \& Sans, Inc., Princeton, New Jersey); 1,2 and $4 \mu g /$ $\mathrm{kg} / \mathrm{h}$ of pentagastrin (Ayerst Laboratortes, New York, New York); 1,2 and $10 \mu \mathrm{g} / \mathrm{kg} / \mathrm{h}$ of glucagon (E11 LIIIy, Indianopolis, Indlanna); 1,2 and $10 \mu \mathrm{g} / \mathrm{kg} / \mathrm{h}$ of secretin (Squibb \& Sons, New York, New York); and 50,100 and 200 $\mu \mathrm{g} / \mathrm{kg} / \mathrm{h}$ of acetylcholine (Merck Co. Inc., Rahway, New Jersey). six observations were obtalned for each substance and dose. The substances were infused intravenously at a rate of $0.1 \mathrm{~m} / \mathrm{min}$ employing a Harvard pump. The infusion started at the beglnning of phase I of the MMC and lasted for one MMC or, In the case of MMC Interruption, for ane to two hours. Acetylcholine was usually administered for only 15 in 1 nutes due to intense collateral effects observed in the animals, namely dyspnea, sialorthea, and agitation. one normal MMc was recorded as control preceding the tnfusions. Each substance was adminlistered two or three times 1 i each animal with an interval of at least three day betwen the infusions.

For each recording sesion, a male socket connected through lisolation preamplifiers to the recording oystem plugged into the antmal back socket. Electromyographic recordings were performed ust $\mathrm{ng}$ a paper speed of $1 \mathrm{~mm} / \mathrm{s}$, $10 \mathrm{w}$ 
frequency: cut-off filer of $1 \mathrm{~Hz}$, high frequency cut-off Ellter of $10 \mathrm{~Hz}$, and overall sensitivity of $100 \mathrm{mV}$.

Pressures were reglistered by connecting the pancreatic and blitary catheters to the recording instrument through Gould P23 pressure transducers (Gould statham Instruments, Inc., Hato Rey, Puerto Rico). The catheters were infused wth water at a constant rate of $0.04 \mathrm{ml} / \mathrm{m} 1 \mathrm{n}$ employing an Arndorfer hydraulic caplilary infusion syatem (Arndorfer Medtcal specialties, Inc., Greendale, Wisconsin). The Arndorfer 1nfusion system measures pressure resistance to a constant fluld infusion rate delivered through stainless steel capiliaries. In order to eliminate the pressure secondary.to water flow into the tubes, catheters equal to those placed In the pancreatic and blitary ducts were perfused with water at flow rate of $0.04 \mathrm{ml} / \mathrm{min}$. The tip of each external catheter was placed at the same height as the internal catheter while the opossum wayn on lts abdomen. The pressure recorded from the external catheters wa constidered to be zero level.

Although reduction of the flow rate decreases the sensitivity of the presoure recording systen, we have selected smller lnfusion rate $(0.04: \mathrm{ml} / \mathrm{m})$ than the recommended $(0.25 \mathrm{~m} \mathbb{H} / \mathrm{mIn})$ by the mufacter of the Arndorfer infusion system to study biliary pressure. We have observed in preliminary experiments that flutd lifusion at 0.25 milmin into the small pancreatic and billary ducts of the opossum increased the motility of the sphincter of oddi and 
artiflcially elevated the billary and pancreatcoresures. The sensitivity of the pressure recording system was tested by elevating the tip of the external catheters $10 \mathrm{~cm}$, This caused an 1 ncrease in pressure of $7.5 \mathrm{~mm}$. The time constant at flow rate of $0.04 \mathrm{ml} / \mathrm{min}$ was 1.68 sec and at $0.25 \mathrm{ml} / \mathrm{min}$ was $1.2 \mathrm{sec}$. The time constant was deflned as the time in seconds for the pressure to rise to approximately two-thirds of $10 \mathrm{mmHg}$.

MMC activity in the duodenum was divided into four phases according to the method described by code and Marlett (9). Since changes in the sphincter of oddi frequency of spike potentials correlate with the MMC cycle in the duodenum, the myoelectric activity of the sphincter of odd1 was also divided Into four phases. Inspection of the recordings revealed that the number of slow waves and splke potentials was similar in the proximal and distal duodenum electrodes and in the proximal and distal sphincter of odd electrodes; therefore, only recordings of the distal duodenum and sphincter of oddi electrodes were considered for analysis. The recordings were divided into two-minute Intervals and the average frequency of siow waveg with superloposed spike potentials for each phase of the MMC as determined. In 1 instances of MMC unterruption, the average frequency of spike potentials was calculated from $15 \mathrm{~min}$ to 60 min after the onset of hormone infuston. The data were analyzed statistically by means of the student two-talled test. Determination of dose dependency was made by linear 
regression analysis. The average frequency of spike potentlals for each experiment was plotted against the logarlthmic hormone concentration. In the text, averaged values are given as meari $\pm \mathrm{IDD}$.

\subsection{RESULTS}

\section{Control Fasting Myoelectric Patern}

Although the Erequency of spike potentials was different in the sphincter of oddi and duodenum, both Erequencles increased gradualiy from phase I to reach the maximum frequency in phase III, then they decreased rapidy during phase IV to start a new MMC. The varlation 1 n the frequency of spike potentials in the sphincter of oddi correlated with the MMC phases in the proximal duodenum and, therefore, myoelectric activity of the sphincter of odd was a 180 divided in phases I, II, III and IV (Figure 2). AII phases in the sphincter of oddi started almost stmultaneously with the MMC phases in the proximal duodenum. The average frequency of spike potentials in the sphincter of 0 dd and duodenum for each MMC phase and the duration of each phase in the duodenum are shown in Table 1. The frequency of slow waves the same in the sphincter of oddi and duodenum, and averaged $18 / \min$. 

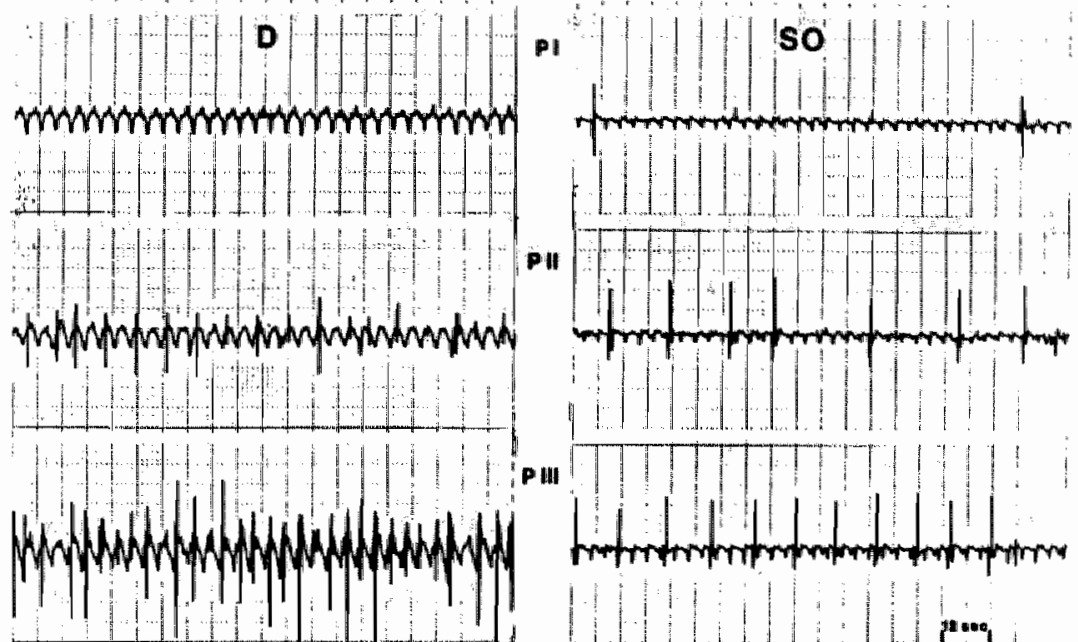

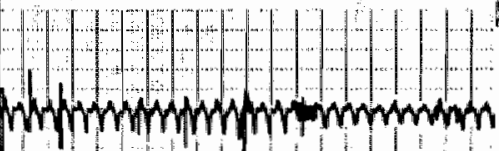

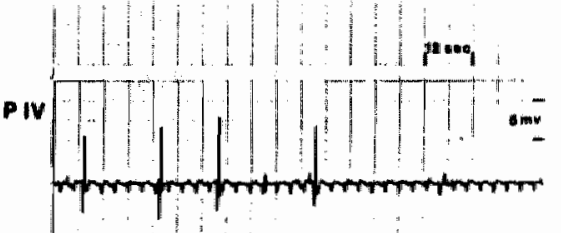

Figure 2. Myoelectric migrating complex phases (P) of the duodenum (D) and sphincter of Oddi (SO). 
$-80-$

TABLE 1

Normal Myoelectric Migrating Complex (MMC)

Of the Sphincter of Oddi (SO) and Duodenum (D)

MMC Phase Frequency of Spike Potentials
So (spikes/min)

$2.9 \pm 1.0$

0

$28.0 \pm 5.1$

II

$4.7 \pm 1.1 \quad 6.4 \pm 2.0$

$48.8 \pm 6.9$

III

$5.9 \pm 0.4$

$15.3 \pm 1.0$

$8.0 \pm 0.9$

IV

$3.2 \pm 0.6$

$5.7 \pm 1.8$

$5.5 \pm 0.8$ 
Effect of Cholecystokinin and Pentagastin on Myoelectric Activity

Within elght winutes after the beginning of cholecystokinin or pentagastrin infusion, sphincter of odd and duodenum spike potential frequency started to increase in all experiments. Interruption of the MMC was observed in $12(67 \%)$ experiments ith cholecystokinin and 16 (89\%) Ith pentagastrin. The new moelectric activity pattern resembled that of a fed state with average spike potential frequencles that varied from $6.4 \pm 0.7$ to $7.7 \pm 1.1$ in the sphincter of odd 1 and from $5.5 \pm 0.9$ to $7.9 \pm 0.8$ in the duodenum (Table 2). These values were all signiflcantly higher than the control values of $2.9 \pm 1.0$ in the sphincter of odd 1 and 4.1 \pm 1.2 in the duodenum, obtalned by averaging the frequency of splke potentials during phases $I$ and II of the normal MMCs $(p<0.01)$. The change in sptke activity was dose-dependent both in the sphincter of oddi and duodenum $(p<0.01)$. Although there was an increase in the number of sphincter of odd and duodenum splke potentials during phase II, no MMC interruption was observed in six instances ( $3 \%$ ) of cholecystokinin infusion (4 experiments - $0.02 \mu \mathrm{g} / \mathrm{kg} / \mathrm{h}$ and 2 experiments - $0.1 \mu \mathrm{g} / \mathrm{kg} / \mathrm{h})$ and in two $1 \mathrm{nstances}$ of pentagastrin adminlstration ( $1 \mu_{g} / \mathrm{kg} / \mathrm{h}$ ach).

Effect of Glucagon and Secretin on Myoelectric Activity

Glucagon and secretin inhibited the onset of MMC for at least one hour in four $(22 \%)$ and ten (56\%) experiments 


\section{TABLE 2}

Myoelectric Activity of the Sphincter of Oddi and Duodenum Following Cholecystokinin and Pentagastin Infugion

\section{Frequency of Spike Potentials} (spikes/min)

cholecystokinin $^{*}$
$0.02 \mu \mathrm{g} / \mathrm{kg} / \mathrm{h}$
$6.4 \pm 0.7$
$6.1 \pm 0.9$
$0.1 \mu \mathrm{g} / \mathrm{kg} / \mathrm{h}$
$7.4 \pm 0.8$
$7.2 \pm 1.0$
$0.5 \mu \mathrm{g} / \mathrm{kg} / \mathrm{h}$
$7.7 \pm 1.1$
$7.9 \pm 0.8$

pentagastrin *
$1 \mathrm{\mu g} / \mathrm{kg} / \mathrm{h}$
$6.3 \pm 0.6$
$5.5 \pm 0.9$
$2 \mu \mathrm{g} / \mathrm{kg} / \mathrm{h}$
$7.0 \pm 1.0$
$7.0 \pm 0.6$
$4 \mu \mathrm{g} / \mathrm{kg} / \mathrm{h}$
$7.7 \pm 0.9$
$7.8 \pm 0.6$

\footnotetext{
* The correlation coefficlent for cholecystokinin in the sphincter of Oddi and duodenum was 0.789 and 0.790 respectively $(p<0.01)$. The coeffictents for pentagastrin were 0.653 and 0.822 respectively ( $p<0.01$ ).
} 
respectively, in which occacional or no splke potentials were observed in the sphincter of oddl and duodenum during the entire infusion period. In these instances, glucagon was infused at $10 \mu g / \mathrm{kg} / \mathrm{h}$ in a 11 four experiments and secretin at $10 \mu \mathrm{g} / \mathrm{kg} / \mathrm{h}$ in six experiments, at $2 \mu \mathrm{g} / \mathrm{kg} / \mathrm{h}$ in $\mathrm{three}$ experiments, and at $1 \mu \mathrm{g} / \mathrm{kg} / \mathrm{h}$ in one experiment. This sphincter of oddi electromyographic pattern differs from the normal MMC in which spike potentials were always observed in the sphincter of oddi. In the remalning instances, infusion of glucagon and secretin reduced the total percentage of slow waves with superimposed spike potentials in the sphincter of oddi and duodenum. The average number of splke potentials in the sphincter of addi and duodenum for each MMC phase after administration of glucagon and secretin is shown in Table 3 . For this analysis, the responses to the three doses of glucagon and secretin were averaged. When compared to the MMC preceding glucagon and secretin Infuston, this redurtion of splke potentialo was statisticaliy significant during phases $I$ and It in the sphincter of odd1 and during phases II and IV in the duodenum $(p<0.01)$.

\section{Effect of Acetylcholine on Myoelectric Activity}

Acetylcholine increased the number of eplke potentialo In the sphincter of add and in the duodenum. For this analysis, the average frequency of siow waves with superimposed splke potentials was determined from 2 min to 
TABLE 3

Myoelectric Migrating Complex (MMC) Of Sphincter of OddI (SO) and Duodenum (D) Following Glucagon and Secretin Infusion ${ }^{\dagger}$

Frequency of Spike Potentials (spikes/min)

MMC Phase Glucagon Secretin Control

\begin{tabular}{lcccccc} 
& \multicolumn{1}{c}{ SO } & D & SO & D & SO & D \\
\cline { 3 - 5 } & & & & & & \\
I & $1.6 \pm 0.8^{*}$ & 0 & $1.6 \pm 0.4^{*}$ & 0 & $2.9 \pm 1.0$ & 0 \\
II & $3.2 \pm 0.8^{*}$ & $4.8 \pm 1.4^{*}$ & $2.8 \pm 0.5^{*}$ & $2.1 \pm 0.8$ & $4.8 \pm 0.7$ & $6.3 \pm 1.2$ \\
III & $5.6 \pm 0.4$ & $14.8 \pm 0.8$ & $5.4 \pm 0.5$ & $14.8 \pm 0.6$ & $5.6 \pm 0.8$ & $15.2 \pm 0.4$ \\
IV & $2.9 \pm 0.4$ & $4.1 \pm 0.6^{*}$ & $3.0 \pm 0.4$ & $4.5 \pm 0.8$ & $2.8 \pm 0.8$ & $5.8 \pm 0.8$
\end{tabular}

tour experiments of giucagon infusion and ten experiments of secretin infusion in which the MMC was inhibited were not included in this analysis. In these instances, the frequency of spike potentials in the sphincter of Oddi and duodenum was 0 .

*Indicates that this value is significantly smaller than the corresponding control value at the 1 percent level, $p<0.01$. 
15 min after the onset of acetylcholine infusion. The largest increase in spike potential frequency was observed with infusion of $200 \mu \mathrm{g} / \mathrm{kg} / \mathrm{h}$; at this dose, almost each slow wave was superimposed with splke potentials in the sphincter of odd $117 \pm 0.1)$ and duodenum $(18 \pm 0.1)$. Average splke potential frequencles following infuston of 50 and 100 $\mu \mathrm{g} / \mathrm{kg} / \mathrm{h}$ of acetylcholine were $11 \pm 0.2$ and $14 \pm 0.1$ spikes/min in the sphincter of oddi and $13 \pm 0.2$ and $16 \pm$ 0.1 spikes/min in the duodenum respectively. The Increase in frequency of spike potentials in the sphincter of odd and duodenum was dose-dependent and the correlation coeffictents were 0.882 and 0.869 respectively.

\section{Biliary and Pancreatic Pressure studies}

The mean control pressures in the comon and pancreatic ducts were $14 \pm 2.5$ and $15 \pm 2.6$ mmg respectively and they ranged from 7 to $17 \mathrm{~mm} H \mathrm{H}$ in the common duct and from 8 to $19 \mathrm{~mm} H \mathrm{in}$ the pancreatic duct. Temporary elevations of the billary and pancreatic pressures of $1-3$ mig were seen slmultaneously with each splke potential in the sphincter of odd1 and with the respiratory movements. There was no baseline pressure variation among the different MMC phases.

Although there was varlation in the frequency of pressure elevations related to sphincter of oddi sike potentials, the baseline pressures remalned constant durtug infusion of the hormones (Figure 3). The mean bilidry and 

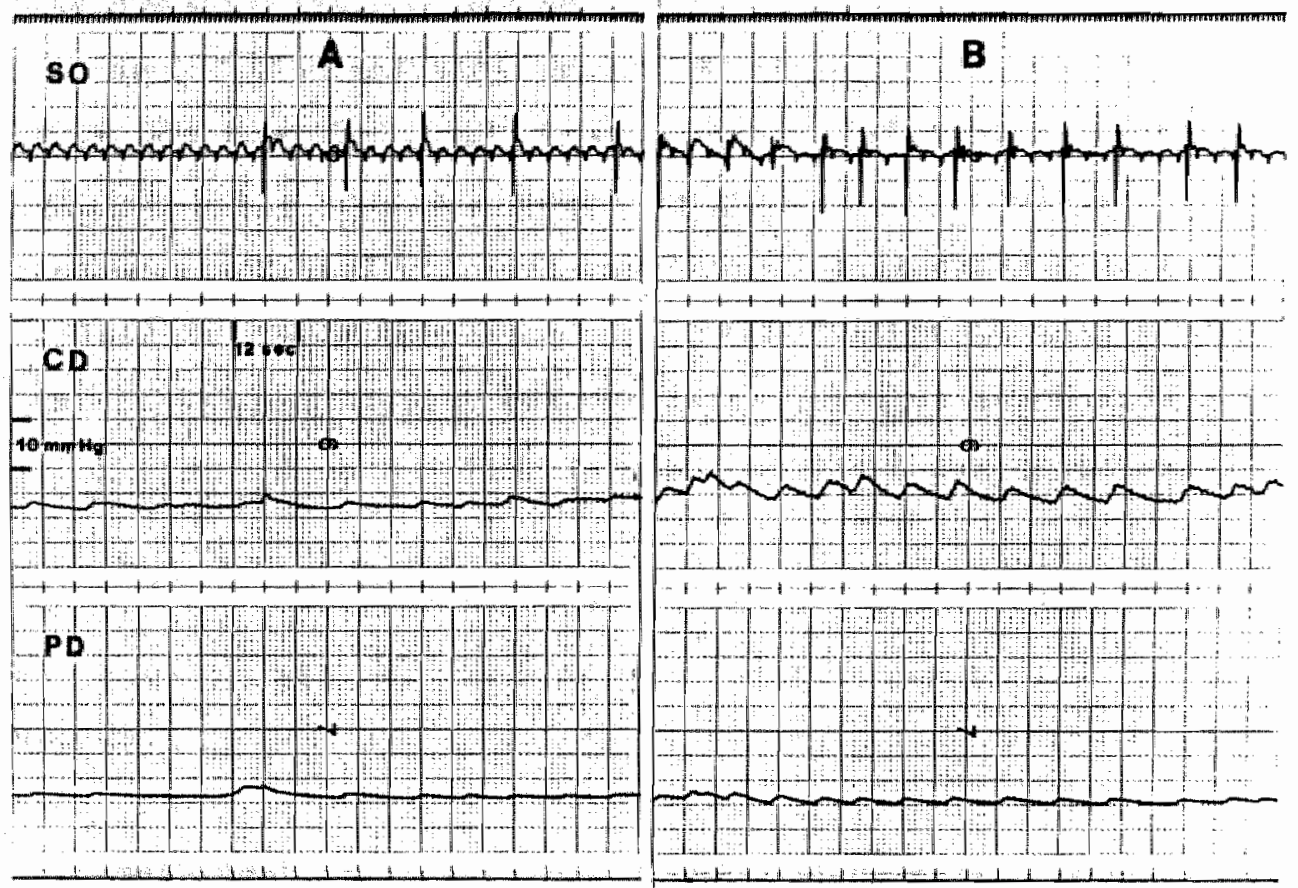

Figure 3. Recordings of the sphincter of oddi (SO) myoelectric activity, common duct pressure (CD), and pancreatic duct pressure (PD) before (A) and $15 \mathrm{~min}$ after the beginning of pentagastrin infusion at $2 \mu \mathrm{g} / \mathrm{kg} / \mathrm{h}$ (B). Pentagastrin increased the spike potential frequency in the sphincter of oddi and the frequency of biliary and pancreatic pressure oscillations related to sphincter of Oddi spike potentials, but the base-line pressures remained constant. 
pancreatic pressures were respectively $13.7 \pm 2.1$ and $14.2 \pm$ 1.7 for cholecystokinin; $13.4 \pm 1.4$ and $14.3 \pm 2.7$ for pentagastrin; $13.2 \pm 1.9$ and $14.7 \pm 1.6$ for glucagon and $14.0 \pm 2.3$ and $15.3 \pm 2.2$ for secretin. Acetylcholine infusion increased the mean blliary and pancreatic pressures to $29.0 \pm 4.6$ and $31.0 \pm 5.6$ respectively $(p<0.01)$ (F1gure 4).

\subsection{DISCUSSION}

Recent advances in electromyographic techniques allowed a more direct evaluation of the sphincter of oddi. function. It has been demonstrated that the sphincter of oddi in the opossum exhibits spontaneous spike potentials which propagate from the proxinal to the distal portion of the sphincter (5). Although the number and intensity of spike potentials in the sphincter of odd are different from those in the duodenum, both the sphincter of odd and duodenum exhiblt cyclic changes in the frequency of spike potential that correlate with the phase of the MMC. Both frequencles increase gradually from phase I to phase III then they decrease rapidly durling phase IV to start a new $M M C$.

Several studies, Including this one, have demonstrated that cholecystokinin and pentagastin lncrease the spike burst frequency of the sphincter of odd1 and duodenum and, 


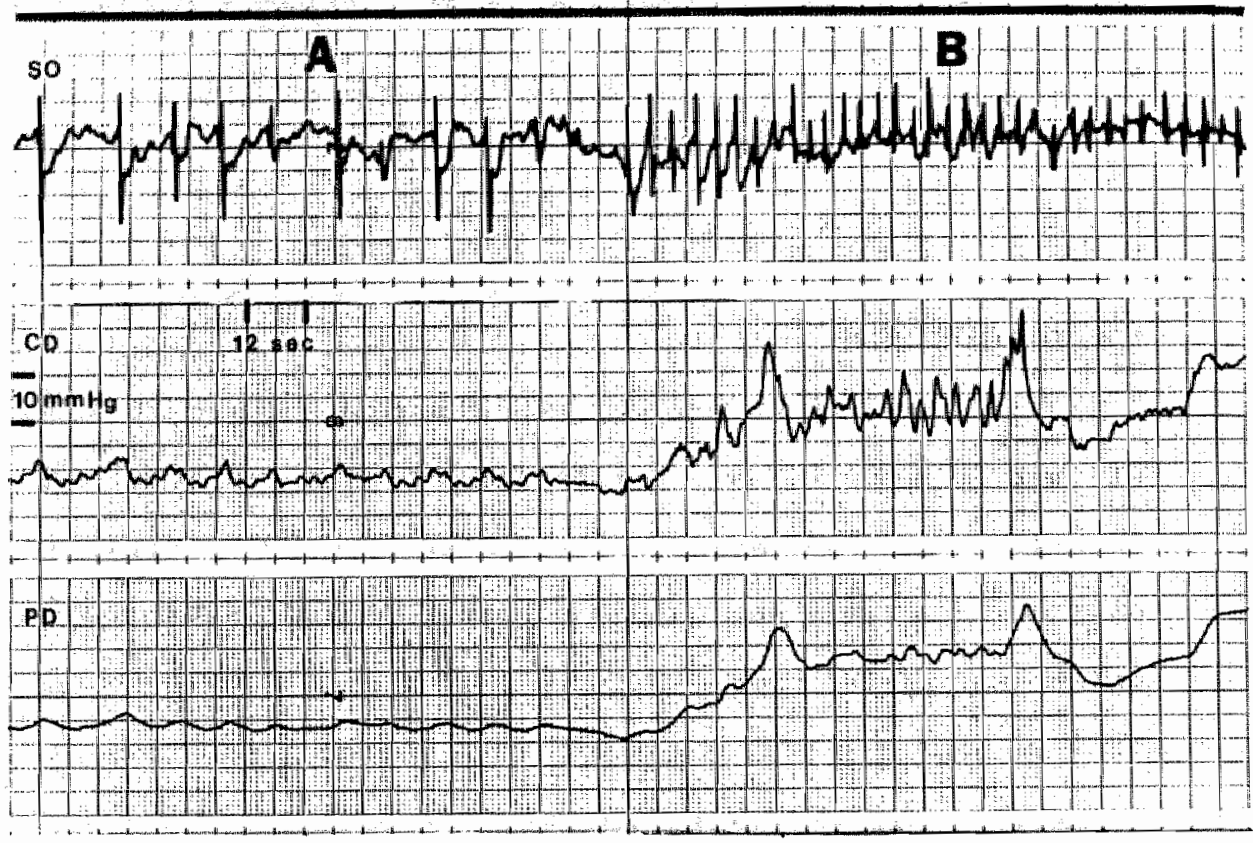

Figure 4. Recordings showing the effect of acetylcholine infusion (arrow) at $200 \mu \mathrm{g} / \mathrm{kg} / \mathrm{h}$ on the sphincter of Oddi (so) myoelectric activity, common duct pressure (CD) and pancreatic duct pressure (PD). Temporary elevation of $C D$ and $P D$ pressures with each so spike potential is seen before acetylcholine administration. Intense so spike activity and continuous elevation of $C D$ and $P D$ during acetylcholine infusion is also shown. 
In most instances, these hormones distupt the MMC $(10,11)$. The new myolectric pattern resembles thet of the fed state. Few studies have evaluated the effect of glueggon on the myoelectric activity of the gastrolntestinal tract. Honda et al. have described recently that glucagon infusion decreased the spike burst frequency of the sphincter of oddi and may abolish the appearance of MMC activity of the gastrointestinal tract of the opossum (10). Geenen et al. observed a reduction in sphincter of oddi pressure activity on intraluminal pressure recording of human sphincter of odd (12). Our study also demonstrated that gluoagon infusion depressed slignificantly the frequency of sphincter of $0 \mathrm{dd} 1$ and duodenum splke potentils.

The effect of secretin on the myoelectric activity of the sphincter of odd1 is controversial. Becker et al. observed no significant effect on sphincter of oddi motor activity of the opossum (7). Geenen et a1. described that secretin caused a mixed response of excltation followed by Inhibition of the sphincter of oddl motor activity of the human (12). We have observed that secretin consistentiy decreased the sphincter of oddi and duodenum oplke burst frequencies and that in most instances it delayed the onset of the MMC. Our findings concur with the itudies of Mukhopadhyay et a1. (13) and Wingate et a1. (14) on the effect of secretin on the myoelectric activity of the small Intestine of the dog. Mukhopadhyay et al. demonstrated that secretin blocked the lnitlation of the moelectric complex 
In the small bowel and Wingate et a1. showed that the splke activity of the duodenum and jefunum was decreased during Infuston af secretin.

The doses of the substances administered in this study were the same employed in other works to evaluate the motility of the gut $(7,10-14)$. The physlologic doses of hormones have been dificult to determine since the hormonal levels vary widely wh the animal species, the method used, and with the prandial state of the animal.

In order to measure the pancreatic and biliary duct pressures, we have developed a model which minimally disturbs the pancreatobliloduodenal physlology. This model allowed pressure recordings. for several weeks in conscious animals whout the need of anesthesia or drugs.

Toouli et a1., using combined electromyographic and cHneradiographic techniques in the opossum, have observed two mechanisms of fluid transport from the common bile duct into the duodenum $(15,16)$. First, splke potentials in the ophlncter of odd were associated with peristaltic contractions of the sphtncter and milking of contrast fluld Into the duodenum. This concurs th our abservation that spike activity of the sphincter of oddi increases during fluid infusion into the common bile duct. In addition, this inght also explain the paradoxical effect of cholecystokinin on the sphincter of odd of opossum. Infuston of cholecystokinin stimulates the sphincter of oddi spike potential, possibly allowing the transport of excess bile 
originating from the gallbladder into the duodenum. A second wechanism was observed during administration of histamine and amyl nitrate, substances known to cause inhibltion of sphincter of addi spike activity (17). These drugs abolished sphincter of oddi contractions and caused the entire sphincter of oddi to remain open while contrast medium flowed passively into the duodenum. Secretin causes a sphincter of oddi myoelectric activity pattern similar to that of histamine and, therefore, secretin possibly may also Increase the flow of fluid into the duodenum by relaxing the entire sphincter segment.

Toouli et al. have demonstrated in the opossum that the bile flow from the terminal common duct into the sphincter of odd1 would be interrupted temporarily at the moment the peristaltic contraction reaches the proximal portion of the sphincter of oddi (17). This would cause a temporary increase in the common duct pressure with each sphincter of oddi splke potential, which we have recorded in our study. Following the sphincter of oddi contraction, the sphincter segment would be refilled by a passive inflow of bile from the common duct and the baseline blliary pressure would be re-established. Intense sphincter of odd splke activity, as observed during acetylchollne 1 nfusion, would hamper bile reflling of the sphincter of oddi and therefore would elevate the bile duct pressure. This would be analogous to cardiac fibrillation. A similar mechantsm may also take place during pancreatic secretion. 
Varlation of the number of pancreatic and biliary duct presure osciliations related to change in spike potential frequency a observed during hormone infusions but the baseline pressure remained constant. On the contrary, Becker et al. observed that the common duct pressure increased during administration of cholecystokinin in the opossum (7). The conficting results may be related to the higher infusion rate of flude into the common bile duct employed by Becker et al. Our findings suggest that the pancreatic and bfliary duct pressures are malntalined at a constant level by lncreasing or decreasing the flow of bile or pancreatic Julce into the duodenum through changes in the frequency of sphincter of oddi splke potential. It is possible that the substances that increase the secretion of bile and pancreatic fulce in the opossum would also sinultaneously change the frequency of sphincter of oddi spike potentials and therefore maintain constant duct pressures.

We conclude that cholecystokinin and pentagastrin stimulates the spike potential frequency of the sphincter of odd 1 and may change the myoelectric activity to a fed-like pattern. Glucagon and secretin decrease the burst splke activity and may inhibit the onset of the MMC. These hormones may have an important role in regulating the excretion of bile and pancreatic julce into the duodenum. 


\subsection{SUMMARY}

Myoelectric activity of the sphincter of oddi and duodenum was correlated with common duct and pancreatic duct pressures in consious opossums after infusion of the followidg substances: cholecystokinin, pentagaterin, glucagon, secretin, and acetylcholine. Cholecystokinin and pentagastrin tncreased and glucagon and secretin decreased the frequency of splke potentials in the sphincter of odd and duodenum. Acetylcholine was assoclated with the largest increase in spike potentials in both the sphincter of oddi and duodenum. Although there was varlation in the number of pressure elevations related to sphincter of oddi spike potentials, the baseline pressure remalned constant during admintstration of the hormones. Acetylcholine infusion increased the billary and pancreatic pressures to 29 and 31 mmg respectively $(p<0.01)$. We conclude that gastrointestinal hormones may have an important role in regulating the excretion of bile and pancreatic juice into the duodenum.

\subsection{REFERENCES}

1. Menguy RB, Hallenbeck GA, Bollman JL, Grindlay JH. Intraductal pressures and sphicteric restatace 10 canine pancreatic and biliary ducts after varlous stinu11. Surg Gynecol obstet 106:306-320, 1958 . 
2. Mebel or. Manometric evaluation of the paplila of Vater. Gatrolntest Endose 21:126-128, 1975.

3. Parry EW, Hallenbeck GA, Grindiay JH. Pressures $t$, the paricreatic and common ducts. Arch Surg 70:757-765, 1955.

4. Sarles JC, Midejean A, Devaux MA. Electromyography of the sphincter of odd1. Am J Gastroenterol 63:221-231, 1975.

5. Honda $R$, Tooul1 J, Modds WJ, Sarna $S$, Hogan WJ, Itoh z. Relationship of sphincter of oddi spike bursts to gastrointestinal myoelectric activity in conscious opossums. I C11n Invest 69:770-778, 1982.

6. Coelho JCU, Moody FG, Senninger N. A new method for correlating pancreatic and billary duct pressures and sphincter of oddi electromyography. Surgery $97: 342-349,1985$.

7. Becker JM, Moody FG, Zinsmeister AR. Effect of gastrotntestinal hormones on the biliary sphincter of the opossum. Gastroenterology $82: 1300-1307,1982$.

8. Quigley EMM, Philips sF, Dent J, Taylor BM. Myoelectric activity and intraluminal pressure of the cantine lleocolontc sphincter. Gastroenterology $85: 1054-1062,1983$

9. Code CF, Marlett JA. The Interdigestive myoelectric complex of the stomach and small bowel of dogs. J Physiol (London) $246: 289-309,1975$.

10. Honda $\mathbb{R}$, Toouli J, Dodds WJ, Geenen JE, Hogan WJ, Itoh 
2. Effect of enteric hormones on sphincter of odd1 and gastrointestinal myoelectric activity in fasted

conscious opossums. Gastroenterology $84: 1-9,1983$.

11. Weisbrodt NW, Copeland EM, Kearley RW, Moore EP, Johnson LR. Effects of pentagastrin on electrical activity of small intestine of the dog. Am J Phisiol $227: 425-429,1974$.

12. Geenen JE, Hogan WJ, Dodds WJ, Stewart ET, Arndorfer RC. Intraluminal pressure recording from the human sphincter of odd1. Gastroenterology $78: 317-324,1980$.

13. Mukhopadhyay AK, Johnson LR, Copeland EM, We1sbrodt NW. Effect of secretin on electrical activity of small intestine. Am J Phistol 229:484-488, 1975 .

14. Wingate DL, Pearce EA, Hutton M, Dand A, Thompson HE, Wunsch E. Quantitative comparison of the effects of cholecystokinin, secretin and petagastrin on gastrointestinal myoelectric activity in the conscious fasted dog. Gut 19:593-601, 1978.

15. Toouli J, Honda R, Dodds WJ, Hogan WJ, Orlowski JM, Sarna $S$, Arndorfer RC. Manometic and electromyographic features of the oposeum sphincter of odd1. Gastroenterology $78: 1279,1980$.

16. Tooul1 J, Honda R, Dodds WJ, Hogan WJ, Sarna S, Eglde MS, Arndorfer RC. Manometrlc, electric and flow properties of the opossum sphincter of oddi. Dig D1s Sc1 $25: 719,1980$.

17. Tooul1 $J$, Dodds $W$, Honda $R$, Sarna $S$, Hogan WJ, 
Komarowstei RA, Linehan JH, Arndorfer RC. Motor function of the opossum sphincter of odd1. J Clin Invest $71: 208-220,1983$. 


\section{GASTROINTESTINAL MYOELECTRIC ACTIVITY FOLLOWING ABDOMINAL OPERATIONS IN THE OPOSSUM}

\subsection{INTRODUCTION}

The period of fasting after abdominal operations is subject to wide variation, mainly owling to the controversy cancerning the duration of postoperative 11 eus. Some authors have reported that lleus inevitably follows the most trivial intra-abdominal procedures or even a simple pinching of the skin over the abdominal wall $(1,2)$. However, others have described normal intestinal motility after most abdominal operations, Including cholecystectomy and transection and anastomosis of the small bowel (3,5). These conflicting results may be related to different animals and techniques employed, such as clinical evaluation, balloon kymography, radiographic techniques, and lotraluminal pressure measurementes $(6,7)$.

Recent developments of electromyography have allowed a more preclse evaluation of gastointestinal tract motillty. In 1969, Szurszewski described the occurrence of a spectfic pattern of myoelectric activity in the gastrolitestinal tract of the fasted dog (8). Others have confirmed this recurring activity, referred to as myoelectric igrating complex (MMC), in the fasting state of humans, dogs, opossums, and other animals (9-11). A few sudies have been 
reported on the effect of abdominal operations on the MMC $(5,12,13)$. However, the moeletric pattern of the stomach, small bowel, and the sphincter of oddi after feeding has not been studed during the immediate postoperative period. Gatrointegtinal and sphncter of oddi motility disturbances durling both the fasting and the fed states may occur after abdominal operations. Our objective in the present study is to evaluate the effect of abdominal operations on the sphincter of oddi and gastrointestinal myolectric activity both in the fasting and fed tates.

\subsection{MATERIAL AND METHODS}

The myoelectric activity of the stomach, small bowel, and sphincter of odd of the opossum was studied postoperatively to determine the time of appearance of MMC following abdominal operations. The myoelectric pattern after feeding was also analyzed immediately after the aperarance of the $M M C$.

Six opossum of elther sex we1ghing 2.5 to $4.0 \mathrm{~kg}$, were anesthetized with $25 \mathrm{mg}$ of sodium pentobarbital per $\mathrm{kg}$ administered Intraperitoneal1y. Upper midine laparotomy was performed and 7 pairs of blpolar electrodes were implanted 1m the sphincter of oddi, gastric antrum, duodenum, proximal jejunum, midjejunum, termimal jejunum, and terminal lieum. In the antrum, the electrode pair was placed 3 cm proximal to the pylorus, and in the duodenum, the electrodes were fixed 3 cm distal to the sphincter of oddi-duodenal 
function. The electrodes consisted af stranded sllver-plated copper wire with teflon insulation of 36 American Wire Gauge size. The wires were soldered to a female connectar.

A gastrostomy was performed with silastic tubing $(\mathbb{1} / 16$ inch 1 nner diameter and $1 / 8$ inch outside diameter) in the anterior gastric wall, $2 \mathrm{~cm}$ distal to the esophagogastric junction. The gastrostomy tube and the electrode wires were passed through a subcutaneous tunnel to the back of the animal. The abdominal wall was closed and the socket and the gastrostomy tube were fixed to the skin.

Contral recordings were begun $7-10$ days after Implantation of the electrodes. The animals were fasted 15 hours before the studies. Three recording sessions of 4 to 6 hours were performed in each animal.

After the control recordings had been obtained, the abdomen was reopened through the previous incision. The small bowel was exteriorized and handled continuausly for 5 min, I hour, or 3 hours. The selection of the procedure time was randomized. The intestines were then returned to the abdomen and the Incision closed. Electromyographic recordings were performed in the fasted anlmals imediately after the operation and on each subsequent day until normal MC"s were detected for 2 consecutive days.

After complete recovery from the surgery, the same procedure was repeated on 2 additional accasions with different laparotomy times. Thus, each animal was subjected to 3 different procedures, a 5-min, a 1-hour, and a 3-hour 
operation. The interval between the operations was 10-18 days.

Finally, 4 of the 6 opossums were subjected to terminal ileum transection with immediate end-to-end anastomosis. The sma11 intestine was manipulated until 1 hour of operation was completed.

In order to study the electromyographic pattern after feeding, food at $20 \mathrm{Cal} / \mathrm{kg}$ consisting of equal parts of fat. protein, and carbohydrates was instilled into the stomach during phase I of the MMC. Ten control recording sessions were obtained $7-10$ days after implantation of electrodes; and 10 other recordings were performed on the same day that the MMC was first seen after the abdominal operations. studies included recordings of the fed pattern and at least one MMC preceding and following it. In 4 experiments, food was infuged before the appearance of the MMC.

Pive additional opossums were subjected to section of the duodenum $1 \mathrm{~cm}$ distal to the pylorus, closure of the duodenal stump, and gastrojejunal anastomosis. Electrodes were implanted as previously described. The time for this procedure was 1 hour. Again, the same type of recording was obtained from each of the 5 animals.

Electromyographic activities were recorded on an 8-channel Gould 2800 s instrument (Gould Inc., Recording Systems Division, Cleveland, ohiol. For each recording session, a male socket connected through isolation preamplifiers to the recording system was plugged into the 
animal socket. Recordings were made using a paper speed of 1 $\mathrm{mm} / \mathrm{s}$, low frequency cut-off filter of 1 hertz (Hz), high frequency cut-off filter of $10 \mathrm{~Hz}$, and overall sensitivity of 25 or 50 millivolts (mV).

The recordings were analyzed to determine the postoperative time of the appearance of the MMC, the duration of the MMC, and the activity pattern after feeding. The MMC was divided into 4 phases as described by code and Marlett (14). The myoelectric activity of the sphincter of oddi was also divided into 4 phases and correlated with the MMC phases in the duodenum.

\subsection{RESULTS}

\section{Fasting Pattern}

S10w waves we re easily identified in all sites studied in most of the recordings and their frequencles were constant before and after the MMC appearance. The average frequency of slow waves in the antrum was $3.5 / \mathrm{m} / \mathrm{n}, 19 / \mathrm{min}$ in the duodenum, and $17 / \mathrm{min}$ in the terminal 11 eut. The frequency of slow waves in the sphincter of oddi was the same as in the duodenum.

The MMC was considered present only when the 4 phases were identified (Ftgure 1); it migrated distally and its duration was within the range observed in the control recordings, i.e., 66-120 min with an average of $89 \pm 16 \mathrm{~min}$ (mean $\pm \mathbb{I S D})$. In all 5 animals with gastrojejunostomy, phase II I Igrated from the duodenum to the efferent loop of the 


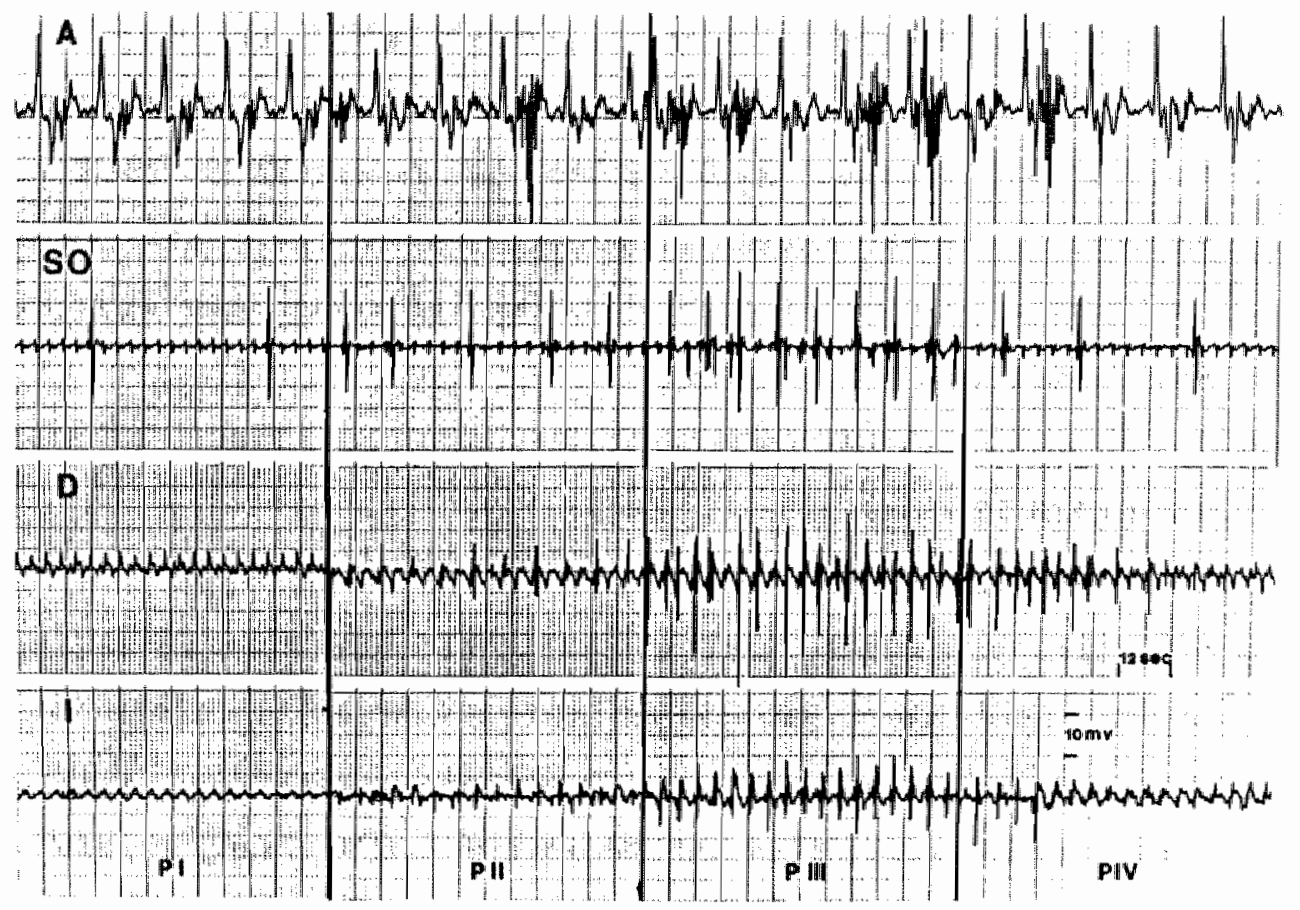

Figure 1. Migrating myoelectric complex phases (P) of the gastric antrum (A), sphincter of oddi (SO), duodenum (D), and terminal ileum (I). 
gastrojejunostomy and down to the lleum. The frequency of sphincter of oddi spike patentials correlated with the MMC phases in the duodenum in all animals after the appearance of the $M M C$.

Time of appearance of the MMC after the abdominal operations varied from immediately after the surgery to the Ifth postoperative day and depended on the type and duration of the surgical procedure (Table l). It was longer after the 3-hour laparotomy than after the 5-min laparotomy, and longer after gastroenterostomy than enteroenterostomy or laparotomy with l-hour intestine handling.

During the time interval between the operation and the MMC appearance, 2 patterns of electromyographic recordings were observed. The most common pattern (75\% of the instances) was the presence of multiple bursts of spike potentials on each slow wave of the duodenum, jejunum, and lleum (Figure 2). The amplitude of these spikes $(8-20 \mathrm{mV})$ was discretely smaller than those observed later during phase III of the MMC (15-30 mV). These bursts lasted from 20 min up to 2 hours and we alternate with quiegcent periods. Unlike phase II, these perlods of intense activity did not migrate distaliy.

The second pattern ( $25 \%$ of the instances) was characterlied by prolonged periods of quiescence with occastonal spikes of low amplitude $(5-10 \mathrm{mV})$ in the duodenum, jejunum, and ileum (Figure 2). Rare splke potentlals were observed in the antrum in both patterns. 


\section{Table 1}

Time of Appearance of MMC after Abdominal Dperations

\begin{tabular}{lccccc}
\hline Type of Operation & $\begin{array}{c}\text { Same } \\
\text { day }\end{array}$ & $\begin{array}{c}\text { Day } \\
1\end{array}$ & $\begin{array}{c}\text { Day } \\
2\end{array}$ & $\begin{array}{c}\text { Day } \\
3\end{array}$ & $\begin{array}{c}\text { Day } \\
5\end{array}$ \\
\hline 5-min intestine handling & 5 & 1 & - & - & - \\
1-hour intestine handling & 2 & 3 & 1 & - & - \\
3-hour intestine handling & - & 2 & 3 & 1 & - \\
Enteroenterostomy & 2 & 2 & - & - & - \\
Gastrojejunostomy & - & - & - & 3 & 2 \\
\hline
\end{tabular}




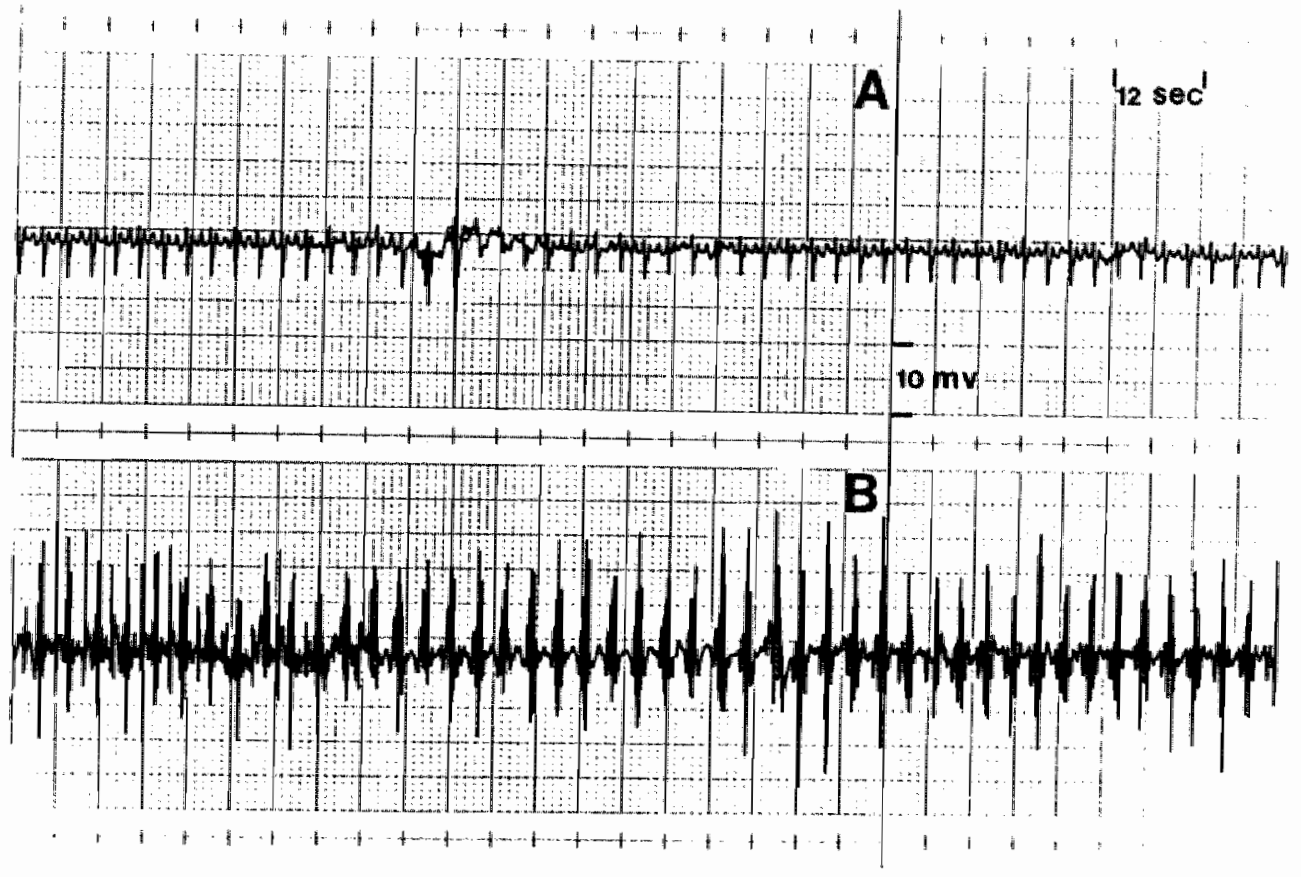

Figure 2. Myoelectric recordings of the jejunum of 2 opossums obtained after laparotomy and before the appearance of the myoelectric migrating complex. Slow waves with only occasional spikes of slow amplitude can be observed in recording $A$. Multiple bursts of spike potentials on each slow wave are shown in recording $B$. 
spike potentials in the sphincter of addi were always present and their frequency was more constant than in the intestine and varied from 0.5 to 2.0 splkes/min. Splke potential amplitude in the sphincter of oddi (10-15 mv) was constant for the same experiment.

\section{Fed Pattexn}

In 8 of 10 experiments, the administration of food into the stomacth abollahed the MMC phases and caused the appearance of a fed pattern within 1 to 3 an. The duration of the fed pattern $(239 \pm 25 \mathrm{mn})$ after the appearance of the MMC was simflar to the control studies $(227 \pm 26$ m $1 \mathrm{n})$.

The fed pattern was absent or delayed $1 \mathrm{n} 2$ animals after infusion of food into the stomach on the first day of the MMC appearance. In one of these animals, the fed pattern was present on the second day of the MMc appearance; however, 1 n the other animal, feeding activity continued to be delayed for 3 subsequent days. Later, a subhepatic abscess was drained from this animal. Interestingly, a nortal MMC 1 in the stomach and smal1 bowel had been observed in this oposum since the fifth postoperative day. Food administration resulted in a fed pattern only in 72 min $1 n$ the proxtmal jejunum (normal, $5 \mathrm{~min}$ ) and 60 min later in the midjejunum (normal, 5-10 min).

The fed pattern did not occur for at least 2 hours 1 n a11 4 experiments in which food was infused before the appearance of the MMC. Vomiting did not occur in these 
a I I I $1 \mathrm{as}$.

\subsection{DISCUSSION}

Developments in electromyographic techniques have allowed a better understanding of the gastrointestinal tract motility. Characteristic paterns of myoelectric actuity occur during fasting and fed states $1 n$ several species $(9,15,16)$. The MMC originates in the stomach and propagates distally to the terminal ileum. It is present during the fasting state and the function of its acitivity front (phase III) is propulsion of gastrointestinal content between meals (17). After feeding, the MMC is substituted by the fed pattern.

Time of appearance of the MMC after abdominal operations has been suggested to correlate with the return of normal gastrointestinal motility $(3,5)$. In the present study, administration of food on the first day that the MMC was observed after the operation usualy resulted in a normal fed patern. In addition, fed patern was not aen when food was infused before the MMC apperance. However. the fed pattern was abent or delayed in 2 animals in which food was given on the first day of MMC appearance. one of the animals later proved to have a subhepatic abscess. These findings suggest that the presence of MMC is necessary to have a normal fed pattern. However, absent or delayed fed pattern may accur in animals that have normal MMC, as in the instance of the opossum with intra-abdominal abscess. 
Time of appearance of the MMC after abdominal operations varied with the type and duration of the surgical procedures. Procedures that severed the upper gastrofintedinal tract d Is rupted the MMC for longer perlods of time. The time of apparance of the MMC was proportional to the duration of the operation.

The results from this study support the view that Intestinal motility is not depressed for prolonged periods of time after abdominal operations. The MMC was observed Wthin 24 hours after the operations in most experiments.

The oposum exhibits a myoelectric activity of the gastrointestinal tract similar to that of humans, dogs, and other animals during both the fasting and fed states $(9,15,16)$. Therefore, $1 t$ is possible that the opossum myoelectric activity during the postoperative period may also be simflar to that of humans. In fact, Rothnie and assoctates described normal gastrointestinal transt of radiopaque material in humans 24 hours after various types af abdominal operations (6). They contend that the sma11 bowel $1 \mathrm{~s}$ capable of mixing and propelitig after surgery and that the absence of postoperative bowel sounds is not due to a lack of lntestinal motility but probably to the absence of content. Carmichael et a1. reported that neither cholecystectomy nor transection and anastomosis of the Intestine had any inhlbitory effects on the myoelectric activity of the small bowel of dogs (5).

The role of analgesics and anesthetics in the 
development of postoperative 1 leus needs to be evaluated. Morphine has been demonstrated to cause constipation, delayed gastric emptying, and a prolonged depression of intestinal propulsion (18). Bueno et al. reported no important change in the intestinal myolectric activity of rats during anesthesia with ethyl ether, pentobarbital, or thiopental (13).

It has been suggested by comblned electromyography and cineradiography that sphincter of odd splke potentials in the opossum are associated with peristaltic contractions of the sphincter of oddi which would have the function of transporting bile and pancreatic julce into the duodenum (19). The frequency of spike potentials in the sphincter of oddi varies with the MMC phases in the duadenum and with the feeding activity state $(11,20)$.

our study showed that the frequency of sphincter of oddi spike potentials was rather constant and low before the MMC appearance in the postoperative period. Correlation between the sphincter of odd1 activity and the MMC phase 1 in the duodenum was retnstated with the MMC fipearance.

The presence of multiple burste of splke potentials on each slow wave of the small bowel abserved postoperatively in most experiments is probably due to thtestine irritation secondary to handling of the small bowel and placement of electrodes. Multiple incoordinate contractions of the intestine were observed during manipulation of the small bowel at the operations. 
We conclude from this study that the return of gastrointestinal motility followlig abdominal aperations depends on the type and duration of the surgical procedure. Intestinal motility is normal within 24 hours following surgery in mast instances. Feeding does not produce a fed pattern in the absence of MMC. Disturbances of the fed pattern may occur in the presence of intra-abdominal sepsis, even in aimals with normal MMC.

\subsection{SUMMARY}

Gastrointestinal myoelectric activity of the opossum, both in fasting and fed states, was studied after abdominal operations. Flve different procedures were performed: a 5-min, a 1-hour, and a 3-hour laparotomy with intestinal handling, enteroenterostomy, and gastrojejunostomy. Electromyographic recordings from the stomach, duodenum, jejunum, Lleum, and sphincter of odd were obtalned from unamesthetized animals. A normal fasting patterm after abdominal operations was observed from immediately after burgery to the fifth postoperative day and depended on the type and duration of the surgical procedure. A fed pattern did not occur $1 \mathrm{n}$ the experiments in which food was instilled before the appearance of the myoelectric migrating complex. A normal fed pattern was observed after the myoelectric migrating complex appearance in all but 2 experiments, ane of which occurred in an antmal th an intra-abdominal abscess. 


\subsection{REFERENCES}

1. Tinckler LF. Surgery and instestinal motility. Brit I Surg $52: 140-150,1965$.

2. Elis H. Acute intestinal obstruction: general considerations. In Maingot R, editar. Abdominal Operations. New York, Appleton-Century-crofts, 1980, pp. $1998-1999$.

3. Morris IR, Darby CF, Hammond $P$, Taylor I. Changes in small bowel myoelectrical activity following laparotomy. Br J Surg $70: 547-552,1983$.

4. Baker LW, Webster DR. Postoperative $\mathbb{1}$, Westinal motility. Br J Surg $55: 374-378,1968$.

5. Carmichae1 MJ, Heisbrodt NW, Copeland EM. Effect of abdominal surgery on intestinal myoelectric activity $1 \mathrm{n}$ the dog. Am J Surg, 133:34-40, 1977 .

6. Rothnie NG, Harper RAK, Catchpole BN. Early postoperative gastrointestinal activity. Lancet 2:64$68,1963$.

7. Dahlgren 5 , Selking 0 . Postoperative motility af the sma11 intestine. Ups J Med Sci 77:202-210,1972.

B. Szurszewski JH. A migrating electric camplex of the cantne small intestine. Am J Physiol 217:1757-1763, 1969.

9. Sarna $S$, Stoddard $C$, Belbeck L, McWade D. Intribic nervous control of migrating myoelectric complexes. Am J Physio1 241:G16-G23, 1981.

10. Eeckhout $C$, De Wever I, Peeters T, Hellemans J, 
Vantrappen G. Role of gatrin and insulin in postprandial disruption of migrating complex in dogs. Am I Phys $101235:$ E666-2669, 1978 .

11. Honda R, Tooul1 J, Dodds WJ, Sarna $s$, Hogan WJ, Itoh $Z$. Relationship of sphincter of oddi spike bursts to gastrolntestinal myolectric activity in conscious opossums. J CIIn Invest 69:770-778, 1982.

12. Smith J, Ke11y KA, Welshilboun RM. Pathophysiology of postoperat1ve 11 eus. Arch Surg $112: 203-209,1977$.

13. Bueno L, Ferre JP, Ruckebusch Y. Effects of anesthesia and surglcal procedures on fotestinal myoelectutc activity in rats. Am J DIg D1s 23:690-695, 1978 .

14. Code CF, Marlett IA. The Interdigestive myoelectric complex of the stomach and small bowel of dogs. J Phystol (London) 246:289-309, 1975 .

15. McCoy EJ, Baker RD. Effect of feeding on electrical activity of dog's smali intestine. Am J Physiol $214: 1291-1295,1968$.

16. De Wever I, Eeckhout $C$, Vantrappen $G$, He1lemans J. Disruptive effect of test meals on itcerdigestive motor complex In dogs. Am J Phys 101 235:E661-E665, 1978 .

17. Code CF, Schlegel JF. The gastrointestinal Interdigestive housekeeper: motor correlates of : hte Interdlgestive myoelectric complex of the dog. In proceedings of the Fourth International sympositu in Gastrolntestinal Motility. Vancouver, Mitcheld Press, $1974, \mathrm{pp} \cdot 631-634$. 
18. Willams EMV, Stretten DHP. The action of morphine, pethidine and amidame upon the intestinal motility of conscious dogs. Br J Pharmacol $5: 584-590,1950$.

19. Toouli J, Honda R, Dodds WJ, Hogan WJ, Sarna S, Egde MS, Arndorfer RC. Manometric, electric and flow properties of the opossum sphincter of oddi. Dig Dis Sci $25: 719,1980$ *

20. Coelho JCU, Moody FG, Senninger $N$. A new method for correlating pancreatic and biliary duct pressures and sphincter of oddi electromyography. Surgery $97: 3.42-349$, 1985. 


\section{EFFECT OF ALCOHOL UPON MYOELECTRIC ACTIVITY OF THE GASTROINTESTINAL TRACT AND PANCREATIC AND BILIARY DUCT PRESSURES}

\subsection{INTRODUCTION}

Acohol 1 s responsible for two-thirds of the instances of pancreatitio in charity hospitals and for one-third in private hospltals (1). The mechanism by which alcohol produces damage to the pancreas remalns unknown. Some athore suggest that alcohol may induce spasm of the sphincter of odd and, thereby, produce an increase in the pancreatic duct presise $(2,3)$. This intraductal pressure elevation could disrupt pancreatic ductules leading to liberation and activation of pancreatic enzymes causing autodigestion and inflamation of the pancreas.

Recent developments in electrophysiologle techniques have allowed a more direct evaluation of the dynamics of the shincter of odd1 $(4,5)$. However the effect of alcohol upon e lectromyography of the sphincter of oddi has not been systemetcally evaluated. We have developed a method that allows sinultaneous measurements of pancreatic and biliary pressures and recording of the sphincter of oddi myoelectric activity. Thts method allows pressure recording for several weeks and avoids interference with the flow of bile and pancreatic juice into the duodenum. The present 
investigation was done to evaluate the effect of alcohol upon myoelectric activity of the gastrolntestinal tract and upon pancreatic and biliary duct pressures.

\subsection{MATERIAL AND METHODS}

Twelve opossum we $1 \mathrm{ghing} 3.0$ to $4.5 \mathrm{~kg}$ were fasted overnight and then anesthetized with intraperitoneal administration of $25 \mathrm{mg} / \mathrm{kg}$ of sodium pentobarbita1. Upper midine laparotomy was performed.

The sphincter of oddi of the opossum is mostly extraduodenal and measures 2 to $3 \mathrm{~cm}$ in length. The maln pancreatic duct foins the common duct at the proximal portion of the sphincter of oddi to form a common channel.

The main pancreatic duct was identifled in the head of the pancreas and catheterized with a $P E-50$ polyethylene $T$ tube. A PE-50 polyethylene tube was placed in the common duct through a small bile duct that connected the right lateral lobule of the liver to the comon duct. This method allowed pressure recordings for several weeks with no Interference of sphincter of odd function or the flow of bile or pancreatic juice into the duodenum.

Six pairs of bipolar extracellular electrodes were implanted in the antrum, duodenum and shincter of odd t two in each site. In the antrum, the electrode pairs were placed 4 and $3 \mathrm{~cm}$ proximal to the pylorus. In the duodenum, the electrodes were fixed at $2 \mathrm{~cm}$ proximal and $2 \mathrm{~cm} d 1 \mathrm{ctal}$ to the sphincter of oddi-duodenal junction. Sphincter of odd 
electrodes were placed 1 and 2 cm proximal to the sphincter of oddu-duodenal function. The electrodes conststed of stranded siver-plated copper wire with teflon (polytetrafluoroethylene) insulation of 36 AWG (American Wre Gauge) size.

A gastrostomy and duodenostomy were performed with sllastic tublig $4 \mathrm{~cm}$ proximal and $2 \mathrm{~cm}$ distal to the pylorus, respectively. The four tubes (biliary, pancreatic, gastrostomy, and duodenostomy) and the electrode wires were previously passed through a subcutaneous tunel from the back of the opossum to the abdomen. The wires were soldered to a female socket prior to the operation. The socket and the tubes were stitched to the skin of the back of the anima1.

An elght channel Gould 2800 s instrument (Gould Inc., Recording Systems Division, Cleveland, ohio) was used to record the electromyographic activities and pressures. A male cocket connected to the recording ingtrument through 1solation preamplifiers wa plugged into the back socket of the opossum for each recording session. Electromyographic recordings were made using a paper speed of $1 \mathrm{~mm} / \mathrm{sec}, 10 \mathrm{w}$ frequency cut-off filter of $1 \mathrm{~Hz}$, high frequency cut-off of $10 \mathrm{~Hz}$ and over-all gensitivity of $100 \mathrm{~m}$.

The pancreatic and billary catheters were attached to Gould P23 pressure transducers (Gould Statham Instruments, Inc., Hato Rey, Puerto Rico) which were infused with water at a constant rate of $0.04 \mathrm{~m} 1 / \mathrm{m} 1 \mathrm{n}$. An Arndorfer hydraulic 
capillary infusion system (Arndorfer Medical Speciallties, Inc., Greendale, Wisconsin) was used to admindster the mater. The low frequency cut-off filter was positioned at direct current offset and the high frequency cut-off filter was set at $10 \mathrm{~Hz}$ or at mean (M) position. In order to elinfute the pressure secondary to the resistance to water flow, catheters equal to those placed in the pancreatic and blliary ducts were perfused with water t a flow rate of $0.04 \mathrm{ml} / \mathrm{min}$. The tip of each external catheter was placed at the same height as the Internal catheters while the opossum was on its abdomen.

The pressure recorded from the external catheters was considered to be zero level. The sensitivity of the pressure recording system was tested by occluding the tip of each catheter for two seconds. This caused an Increase in pressure of at least $20 \mathrm{~mm}$.

Recordings were begun seven to ten days after the operation. All studies were performed on conacious, fasted opossums. During each recording sesslon, at least one normal migrating myoelectric complex (MMC) was recotaed as control. Ethanol at concentrations of 10,20 or $40 \%$ and 1 in volumes of 1 or $2 \mathrm{~m} 1 / \mathrm{kg}$ was then administered $1 \mathrm{nto}$ the stomach ( 20 experiments) or into the duodenum ( 45 experiments).

Bolus alcohol instiliations were performed during phame I of the MMC in 55 experiments and during phase II in ten experiments. Recordings were continued for one or two additional MMCs. Sodium chloride solution (154 mEq/1) or 
distlled water. was also lnfued at volumes of 1 or $2 \mathrm{ml} / \mathrm{kg}$ through the gastrostomy or duodenostomy tubing (ten expertments). In ten ather experiments, alcohol was Instiled for a second or third time during the same or subsequent MMC.

The myoelectric activity of the stomach and duodenum was divided into four phases (6). In phase I, occasionaz or no spike potentials are observed. During phase II, the splke potentils are trregular and increase in frequency and Intensity throughout the phase. Phase III 1 s characterized by action potentials of high amplitude that are superimposed on 90 to $100 \%$ of the s10\% waves. During phase IV, the frequency and intensity of splke potentials subside quickly to qulescence in phase I, therefore beginning a new cycle.

The sphincter of oddi of the opossun exhibits cyclic changes 1 in the frequency of spike potentials that correlate with the MMC cycle in the duodenum and therefore, myoelectric activity of the spincter of oddi was also divided Into phases I, II, III and IV. The number of slow waves with spike potentials was determined for each of the MMC phases. The data were analyzed statstically by means of the student's two-talled, palred test.

\subsection{RESULTS}

The contral MMC phases of the sphincter of oddi and duodenum are hown in Figure 1. Instillation of alcohol caused a characteristic myoelectic activity sequence 


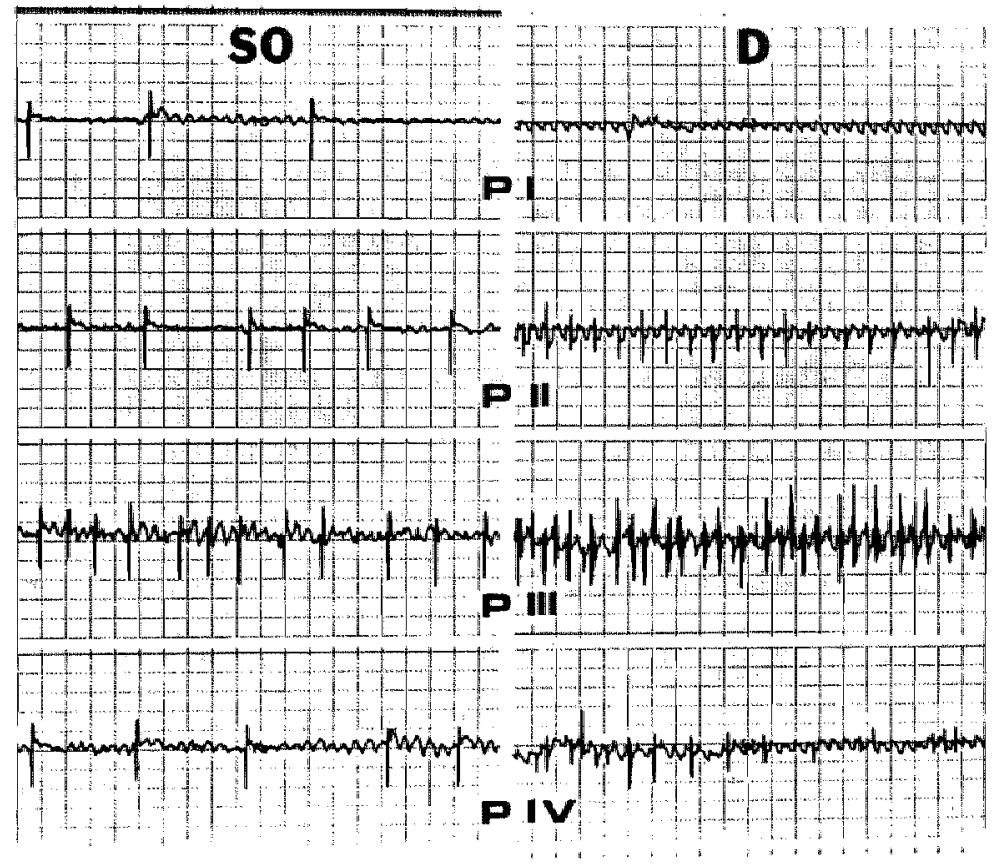

Figure 1. Myoelectric migrating complex phases (P) of the sphincter of oddi (SO) and duodenum (D). 
(Figure 2). In the duodenum, a minute burst of spike activity $(10 / \mathrm{m} 1 \mathrm{n}) \mathrm{g}$ followed by five to ten minutes of absent or occasional spikes. A vigorous phase III-1ike activity ( 16 spike bursts/min) then ensued in 59 instances (91\%). F1na11y, a new MC with (nine 1 nstances) or without phase. I (47 instances) occurred. In six studies ( $9 \%$ ), the Intial burst of spike activity was followed by phase II of a new MMC whout arly appearance of phase III-Iike activity.

A significant increase in the numbr of splke potentials occurred for Is to 20 minutes in the sphincter of odd in all instances $(7.4 \mathrm{splke}$ bursts/min). The two largest increases in the frequency of sphincter of oddi action potentials occurred in the first minute after alcohol tnstilation $(8.2$ spike bursts/min) and simultaneaus wh phase III-11ke activity in the duodenum (8.1 spike bursts/min). This sequence of changes in the duadenum and sphincter of oddi myoelectric activity occurred after instillation of alcohol into elther the stomach or duodenum. The appearance of spike activity in the antrum was varlable, depending upon the location of alcohol Instillation. It was observed Immediately after gastric adminitation and six to elght minutes after duodenal 1nstilation. The Initial burst of spike activity observed in the duodenum and sphincter of oddi after duodenal adminigtration of alcohol was not seen in the antrum.

Appearance of phase III-1tke activity was independent 


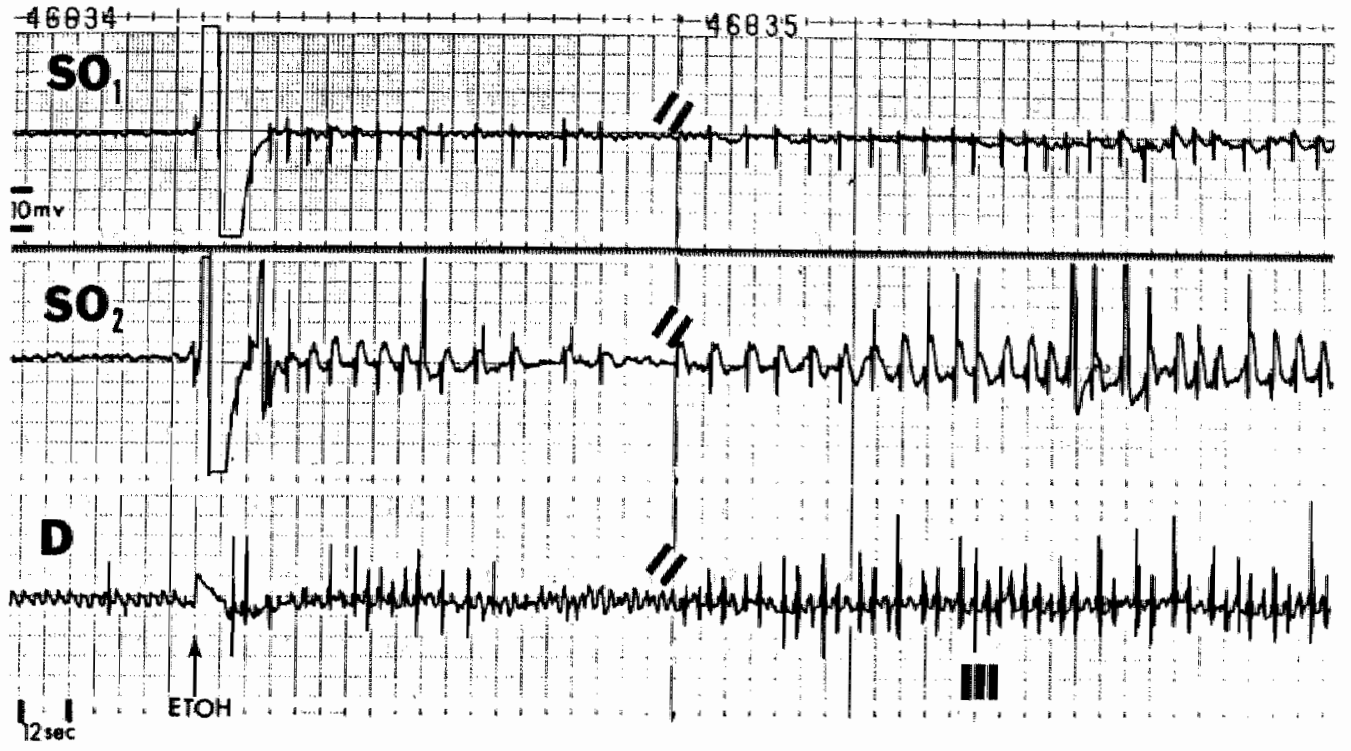

Figure 2. Effect of alcohol on myoelectric activity of the proximal ( $\mathrm{SO}_{1}$ ) and distal ( $\mathrm{SO}_{2}$ ) sphincter of oddi and duodenum (D). Phase III-Iike activity (III) can be seen eight minutes after 20 per cent alcohol administration (EToH) into the duodenum. A five minute recording period was deleted $(1,1)$ 
of the dosage and concentration of the alcohol administered and of the MMC phase that alcohol was 1 nstilled. The comparison between the MMC that preceded alcohol adminiotration and the MMC that followed phase III-1ike activity 19 glven in Table 1 . Phase $I$ was not observed 1 n the MMC after alcohol insitiliation in $84 \%$ of the experiments. Administration of isotontc sodiun chloride solution or distiled water did not alter the normal pattern of the MMC.

A second or third instillation of alcohol caused a transient increase in the number of spike potentlals in the duodenum and antrum in elght of ten experiments $(80 \%)$, but no subsequent phase III-11ke activity was observed. Phase III-11ke activity appeared after additional alcohol administration in only two experiments (20\%). However, there was a marked subsequent increase 1 in the splke burst activity of the sphincter of oddi in all instances (7.3 spike burstg $(\mathrm{m} i \mathrm{n})$.

Two types of pressure changes in the pancreatlc and bl11ary. ducts were recorded. First, pressure osctiletion of 1 to $3 \mathrm{mmHg}$ were observed with resplratory movements. These pressure variations could be eliminated from the recordings by turning the high frequency cut-off fliter knob to the $M$ position. Second, there was a temporary elevation of pancreatic and billary pressures of 1 to 3 mag simultaneous with each sphincter of oddi spike potential.

There was an increase in the number of pressure 
Table 1

Myoelectric Activity of the Antrum, Duodenum and Sphincter of Oddi

Myoelectric migrating complex phase

No. of spike potentials (spikes/min)

$\begin{array}{cccc}\text { I } & \text { II } & \text { III } & \text { IV } \\ & & & \\ 0 & 1.9 \pm 0.6 & 3.3 \pm 0.8 & 1.5 \pm 0.3 \\ 0 & 6.1 \pm 2.3 & 15.5 \pm 1.0 & 5.9 \pm 2.3 \\ 2.8 \pm 1.1 & 4.6 \pm 0.9 & 5.8 \pm 0.5 & 3.2 \pm 0.9 \\ 20.2 \pm 4.8 & 50.8 \pm 8.1 & 8.0 \pm 0.7 & 4.9 \pm 0.6\end{array}$

Control MMC

Antrum

$\begin{array}{cccc}\text { I } & \text { II } & \text { III } & \text { IV } \\ & & & \\ 0 & 1.9 \pm 0.6 & 3.3 \pm 0.8 & 1.5 \pm 0.3 \\ 0 & 6.1 \pm 2.3 & 15.5 \pm 1.0 & 5.9 \pm 2.3 \\ 2.8 \pm 1.1 & 4.6 \pm 0.9 & 5.8 \pm 0.5 & 3.2 \pm 0.9 \\ 20.2 \pm 4.8 & 50.8 \pm 8.1 & 8.0 \pm 0.7 & 4.9 \pm 0.6\end{array}$

Duodenum

Sphincter of Oddi

Duration (min)

$\begin{array}{lrrr}\S & 2.2 \pm 0.9^{*} & 3.2 \pm 0.9 & 1.4^{ \pm} \pm .5 \\ \S & 6.1 \pm 1.9 & 15.2 \pm 1.1 & 4.3 \pm 1.9^{* *} \\ \S & 4.8 \pm 1.2 & 6.2 \pm 0.7 & 2.8 \pm 1.1 \\ \S & 54.1 \pm 6.5 & 6.4 \pm 0.6 & 4.2 \pm 0.9\end{array}$

MMC after phase III-like activity

Antrum

Duodenum

Sphincter of Oddi

Duration (min) 
elevetions related to sphincter of oddi splke-burst potentials after alcohol administration, but baseline pressures remained constant. The mean pancreatic and billary baseline pressures before alcohol lnstillation were $15.0 \pm$ 3.8 and $14.0 \pm 3.6 \mathrm{mmHg}$, respectively; after ethanol administration, they were $17.0 \pm 2.7$ and $14.0 \pm 2.8$ mo Hg.

\subsection{DISCUSSION}

The MMC 1 s a spectfic pattern of myoelectric activity of the gastrointestinel tract that was first described in fasted dogs in 1969 (7). It is observed only during the fasting gate in some pecies and during fasting and fed states in others. Human belngs, dogs and opossums are Included in the first group and sheep and cattle are in the second group $(5,8)$. It has been shown that the MMC Is composed of four phases which propagate caudad from the stomach to lleum and recur cyclicly (6). The frequency of splke potentials increases from phase I through phase III, then decreases during phase IV to begin a new myoelectric $\operatorname{complex}$

The results of our study and those of another study have demonstrated that the sphincter of oddi of a fasting opossum exhibits cyclic changes in the number of spike potentials that correlate with the MMC in the duodenum (5). However, the number and intensity of splke potentials in the sphincter of oddi are different from those of the duodenum.

The function of recurrent MMC in the gastrointestinal 
tract is unknown. It has been demonstrated by cineradiography that the activity front of each complex is associated with propagated contraction wose function is propulsion of gastrofntestinal content between meals (9). It also has been suggested by combined electromyography and cineradiography that sphincter of oddi spike potentials in opossums are associated with peristaltic contractions of the sphincter of oddi which would have the function of transporting bile from the sphincter of oddi lnto the duodenum $(10)$.

While an association between alcoholisu and pancreatitis is well established, little is known about the pathogenesis of alcoholic pancreatits. It has been suggested that alcohol may cause irritation and spasm of the sphincter of odd1 $(2,3)$. An increase in pancreatic pressure might rupture pancreatic ducts, thereby liberating proteolytic enzymes and that might autodigest the pancreas. Unfortunately, this attractive hypothesis has, to date, no scientific validity. spasm of the sphincter of oddi has been detected by indirect methods, such as duct pressure measurement and evaluation of the volute of pancreatic secretion in the duodenum. However, the results of these studies have been controversial $(11-14)$.

Electromyographic studies provide a more direct evaluation of sphincter of oddi activity. our expertmental model combines recording of sphincter of oddi myoelectric activity and measurement of pancreatic and blilary duct 
pressure under circumstances that minfmally disturb the normal pancreatobl11ary physlologic characteristics.

Systematic electromyographic evaluation of the Influence of alcohol on the sphincter of oddi has not been previously reported. An lncrease in the number and amplitude of spike potentials in the sphincter of oddi in a rabbit after alcohol adminlstration has been described, but the Influence of the phases of the MMC was not accounted for (1.15)

The results of our study have demonstrated that gastric or duodenal Instilition of alcohol during phase I or II of the MMG causes a phase III-11ke activity in the antrum, duodenum and sphincter of oddi la five to ten minutes. This phase III-11ke activity was similar to the normal MMC phase III 1 duration and number and amplitude of spike potentials. Subsequent alcohol administration in the same or following MMC produced a dramatic increase in the sphincter of odd splke potentials without causing phase III-1Ike activity in the duodenum.

The results of previous reports suggest that MMC gastrolntestinal tract activity is coordinated by motilin since the MMC phase correlates with cyclic changes of the plasma motilin (16). The peak of motilin was shown to occur concurrently with phase III in the duodenum. The occurrence of premature phase III after administration of morphine sulfate intravenously has recently been observed (17). However, administration of morphine sulfate during the 
inftal $20 \%$ of the MMC cycle did not begin premature phase II, even at supramaximal dosesi. As the remalnder of the MMC cycle progressed, premature phase III was initiated with diminishing doses of morphine.

Alcohol, as used herein, induced phase III-1ike activity independent of the MMC phase $1 \mathrm{n}$ which alcohol was instilled. The average amount of alcohol administered was comparable with a $70 \mathrm{~kg}$ person arinking $15 \mathrm{~g}$ of ethanol. Therefore, it is possible that repetitive 1 icreases 1 in the myoelectric activity of the sphincter of oddi that may occur wth chronic ingestion of alcohol moy be an important contributory factor in the pathogenesis of alcoholic pancreatitis.

There was an 1 ncrease in the number of pressure elevations related to sphincter of oddi phase III-Iike activity after alcohol instilation, but baseline pressure remained constant. The pancreatic and biliary preseures were also not 1 ncreased during normal phase III. On the contrary, billary and pancreatic pressure elevations fer alcohol administration in the dog has been described (18). Theae conflicting results may be related to different recording techniques and species used.

We conclude that gastric and duodenal Instiliation of alcohol causes a dramatic increase in the number of splke potentials in the antrum, duodenum and sphincter of oddi and the onset of phase III-1ike activity. Subsequent micohol administration in sequence evoked intense spike potentials 
In the spincter of oddi without causing phase III-1ike activity in the antrum and duodenum. These alcohol-related myolectric disturbances may contribute to abnormal function of the ampulia of Vater. There was no change in the baseline presure after alcohol adrinistration.

\subsection{SUMMARY}

Myoeletric activity of the antrum, duodenum and sphlncter of odd was recorded from 12 conscious opossums. The comon duct and the pancreatic duct were cannulated for pressure measurement. Recordings were made in the fasted state and after gastric or duodenal admintstration of ethenol. Alcohol was instilled during phase I (55 experiments) or phase II (ten experiments) of the migrating myoelectric complex. Administration of alcohol caused the appearance of phase III-1 the activity in five to ten minutes In $91 \%$ of the expertinents.

Pancreatic duct and comon duct pressure oscillations. occurred synchronousy with resplratory movements and with sphincter of oddi spike potentials. There was an increase in the number of pressure elevations related to the increase in splincter of oddi spike potentials after alcohol admistration; however, baseline pressures remalned constant. It 1s comeluded that the administration of alcohol Into the stomach or duodenum causes the appearance of phase III-11ke activity and that there is no change in the baseline pressure afer the Instillation of alcohol. 


\subsection{REFERENCES}

1. Silen W. Pancreas. In Schwartz SI, edtor principles of Surgery. New York, McGraw-H11, 1979, pp. 1353-1379.

2. Schapiro H, Wrublet LF, Britt LG. The posstble mechantsm of alcohol in the production of acute pancreatits. Surgery $60: 1108-1111,1966$.

3. Strum WB, Spiro HM. Chronic pancreatitis. Ann Intern Med $74: 264-277,1971$.

4. Becker JM, Moody FG, Zinsmelster AR. Wfiect of gastrolntestinal hormones on the biliary sphincter of the opossum. Gastroenterology $82: 1300-1307,1982$.

5. Honda $R$, Tooul1 J, Dodds WJ, Sarna $S$, Hogan WJ, Itoh $Z$. Relationship of sphincter of oddi spike bursts to gastraintestinal myoelectric activity in conscious opossums. J C1in Invest. 69:770-778, 1982 .

6. Code CF, Marlett JA. The Interdigestive myoelectric complex of the stomach and small bowel of dogs. J Physiol (London) $246: 289-309,1975$.

7. Szurzewsk1 JH. A migrating ellectic complex of the canine sma11 Lntestine. Am J physiol 217:1757-1763, 1969.

8. De Hever I, Eeckhout $C$, Vantrappen $G$, Hellemans J. Disruptive effect of test meals on interdigestive motor complex in dogs. Am J Physiol 235:E661-E665, 1978.

9. Code CF, Schlegel. JF. The gatrolntestinal interdigestive housekeeper: motor correlates of the interdigestive myoelectric complex of the dog. 
Proceedings of the Fourth International symposidm in Gastrointestinal Motility. Vancouver, Mitchell Press, 1974, pp. 631-634.

10. Tooul1 $J$, Honda $R$, Dodds WJ, Hogan WJ, Sarna $S$, Egide MS, Arndorfer RC. Manometric, electric and flow properties of the opossum sphincter of Oddi. Dig Dis Se1 $25: 719,1980$.

11. Madding GF, Tuel1er EE, Kennedy PA. Oral and Intravenous administration of alcohol and the pancreas. JAMA $205: 106,1968$.

12. Mott C, Sarles H, Tiscornia O, Gullo L. Inhibitory action of alcohol on human exocrine pancreatic secretion. D1g D1s 17:902-910, 1972 .

13. Tiscornia OM, Gullo L, Sarles H. Effects of Intragastric and intraduodenal ethanol on canine exocrine pancreatic secretion. Digestion 10:52-60, 1974 .

14. Tiscornia 0, Gulio L, Sarles H. The inhibition of cantre exocrthe pancreatic secretion by intravenous ethanol. Gastroenterology $62: 866,1972$.

15. Sarles JC, Midejean A, Devaux MA. Electromyography of the sphincter of Oddi. Am J Gastroenterol 63:221-231, 1975 .

16. Takahash1 I, Honda R, Dodds WJ. Effect of motilin on the opossum upper gastrolntestinal tract and sphincter of Odd1. Am J Phys101 245:G476-G481, 1983 .

17. Sarna $S$, Northcott $P$, Belbeck L. Mechanism of cycling 
of migrating myoelectric complexes; effect of morphine. Am J Phys101 242:G588-G595, 1982 .

18. Menguy $R$, Hallenbeck G, Boliman J, Grindlay J. Intraductal pressures and sphincteric reststance in canine pancreatic and biliary ducts after various stimu11. Surg Gyneco1 obstet 106:306-320, 1958 . 


\section{SPHINCTER OF ODDI AND GASTROINTESTINAL MOTILITY DISTURBANCES FOLLOWING ALCOHOL ADMINISTRATION IN THE OPOSSUM}

\subsection{INTRODUCTION}

Sarszewskl and others have described a characteristic pattern of myoelectric activity, referred to as the migrating myoelectric complex (MMC), which is present during the fasting state and propagates down the gastrointestinal tract cyclically from the stomach to the ileum $(1,2,3)$. After feeding, the MMC is abolished and replaced with a feeding activity pattern in several species, including man, dog and apossum.

We have demonstrated previously that instiliation of alcohol at concentrations of 10,20 , and $40 \%$ into the stomach or into the duodenum causes the appearance of intense spike potentials in the sphincter of oddi and duodenum simflar in frequency, duration, and aplitude to those observed in phase III of the MMC (4). There was an Increase in the frequency of pressure elewations in the pancreatic duct and comon blle duct related to the increase In sphincter of odd splke potentials following alcohol administration; however, the baseline pressures remained constant. Our objective in the present study is to evaluate the mechanism by which alcohol stimulates the motility of the sphincter of odd and duodenum. The effect of alcohol on 
the gastric, duodenal, and jejunal mucosa of opossums that were subjected to gastrojejunostomy with duodenal exclusion were assessed to determine whether alcohol stimulates the motility of the sphincter of oddi and duodenum by direct contact with the duodenal mucosa or not. The concentration of plasma motilin was also determined during the normal MMC phases and during phase III-like activity caused by alcohol.

\subsection{MATERIAL AN METHODS}

Seven opossums of either sex weighing 2.5 to $3.5 \mathrm{~kg}$ were subjected to an upper midline laparotomy following intraperitomea 1 administration of 25 mg of sodium pentobarbital per $\mathrm{kg}$. The gatroduodenal junction was severed and a gatrojejunostomy with closure of the duodenal stump was performed (Figure 1).

Silastic catheters were placed into the stomach, duodenal stump, mid-jejunum, and jugular vein. Seven pairs of blpolar extraceliular electrodes were implanted in the sphincter of oddi, gastric antrum, duodenum, proxima 1 jejunum, mid-jejunum, terminal Jejunum, and termital 11 eum. The electrodes consisted of stranded siver-plated copper wire with tefion insulation of 36 AWG ale (Micro Measurement Co., Romulus, Michigan). The wires were placed in the muscular layer of the gastrointestinal tract and sphincter of oddl through a 25 -gauge hypodermic needle and the end was tied off. The catheters and the wires were passed through a subcutaneoug tunne1 to the back of the 


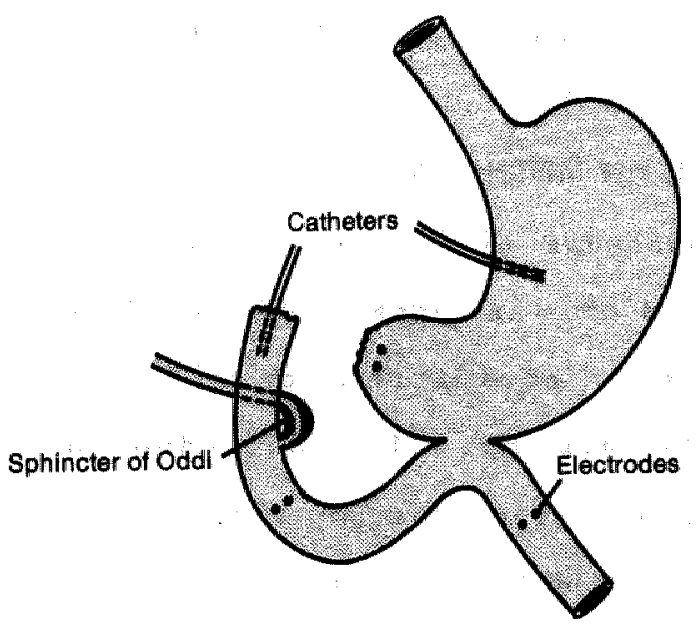

Figure 1. Schematic diagram of the opossum preparation showing the gastrojejunostomy, the electrodes, and the gastric and duodenal stump catheters. 
animal. The wires were previously soldered to a female socket. The catheters and the socket were stitched to the skin.

Experiments were begun seven to ten days after the operation and were performed on a we, nonmedicated animals. Electromyographic activities were recorded on an eight-channel Gould 2800 s instrument Gould Inc., Recording Systems Division, Cleveland, ohio). For each recording session, a male socket connected to the recording system was plugged into the animal socket.

Bolus infusions of a $20 \%$ solution of ethanol in a volume of $2 \mathrm{ml} / \mathrm{kg}$ of body weight were glven $1 \mathrm{nto}$ the stomach ( 30 experiments), duodenal stump (30 experiments), jejunum (ten experiments) and intravenousiy (40 experiments) 20 minutes after the beginning of phase $I$ of the MMC in the duodenum. Each experiment lncluded recording of the MMC in which alcohol was instilled and the MMC preceding 1 .

The following solutions were also administered into the duodenum of three additional opossums at a volume of 2 milkg, nine experiments of each: sodium chlorlde (154 mEq/11tex), $20 \%$ glucase (18ocaloric to $20 \%$ ethanol; 0.8 Ca $1 / \mathrm{m} 1 \mathrm{n}$ ) and $32 \%$ glycerol (1so-osmolar to $20 \%$ ethanol; 5.8 molar/1iter). Alcohol blood level wa determined before and following duodenal and intravenous infuston of ethanol on different days (elght experiments of each). The blood was drawn during the appearance of phase III-11ke activity following infusion of alcohol into the duodenum or 20 
mutes ater 1 nteavenous adminlstration of alcohol. Alcohol wa determined by a DuPont Automatic Cinical Analyzer (DuPont Co., W11mington, Delaware) that employed a modifled alcohol dehydrogenase enzymatic procedure.

Plama motilin concentration was determined in five other opossums. In these studies, 5 ml samples of venous blood were obtalned from the jugular catheter during phases I, II, and III of the control MMC and during phase III-1ike activity that followed duodenal instilation of alcohol, 16 samples of each. The samples were drawn ten minutes after the begining of phases I and II and to minutes after the beginning of phases III and III-like activity. The plasma was separated by refrigerated centrifugation for radiolmmunasay of motilin. The red blood cells with equal volume of normal saline solution were returmed to the anima1s. Motilin assays were performed in Dr. W1111am Y. Chey's laboratory in Rochester, New York by a method described previously (5).

The MMC was divided into four phases as described by Code and Marlett (6). The frequency of slow waves ith spike potentials was determined for each MMC phase and following acohol instilation. The data were analyzed statistically by theans of analys is of variance.

\subsection{RESULTS}

Control Migrating Myoelectric Complex

The frequency of slow waves was $3.5 \pm 0.2 / \mathrm{min}$ (mean \pm 
ISD) in the antrum, $19 \pm 0.3 / \mathrm{min}$ in the sphincter of odd and duodenum, $18 \pm 0.3 / \mathrm{m} 1 \mathrm{n}$ in the proximal jejunum, and $14 \pm$ $0.4 / \mathrm{min}$ in the terminal Hleum. The frequency of slow waves with spike potentials in the sphincter of oddi, antrum, duodenum, proximal jejunum, and terminal lieum and the duration of each MMC phase in the duodenum are shown in Table $\mathbb{1}$.

No spike potentials were seen in the antrum and small intestine during phase I. However, splkes were always present in the sphincter of oddi. In all sites, the frequency of spike potentials lncreased throughout phase II to reach a maximum during phase III and then decreased rapidly during phase IV to start a new MMC. Even though the gastroduodenal junction was severed, the activity front of the MMC (phase III) was seen first in the duodenum, and then migrated to the efferent loop of the gastrojejunostomy and to the terminal ileum.

Myoelectric Activity Following Alcohol Adrinistration

Intraduodenal administration of ethol provoked a minute of spike potentials $(10 / \mathrm{m} / \mathrm{n})$ in the duodenum that was followed by four to eight minutes of no spike activity. After this period, phase III-1ike activity occurred in 26 experlments (87\%). This vigorous spike activity stitar to phase III of the MMC in frequency (16 bursts of spikes/min), duration $(6-8 \mathrm{~min})$, and ampltude $(10-15 \mathrm{mV})$ of the bursts of spike potentials. A significant increase in the number of spike potentials ( 7.2 bursts of gpikes/min) 
Table 1

Myoelectric Activity of the Sphincter of Oddi and Gastrolntestinal Tract During Fasting

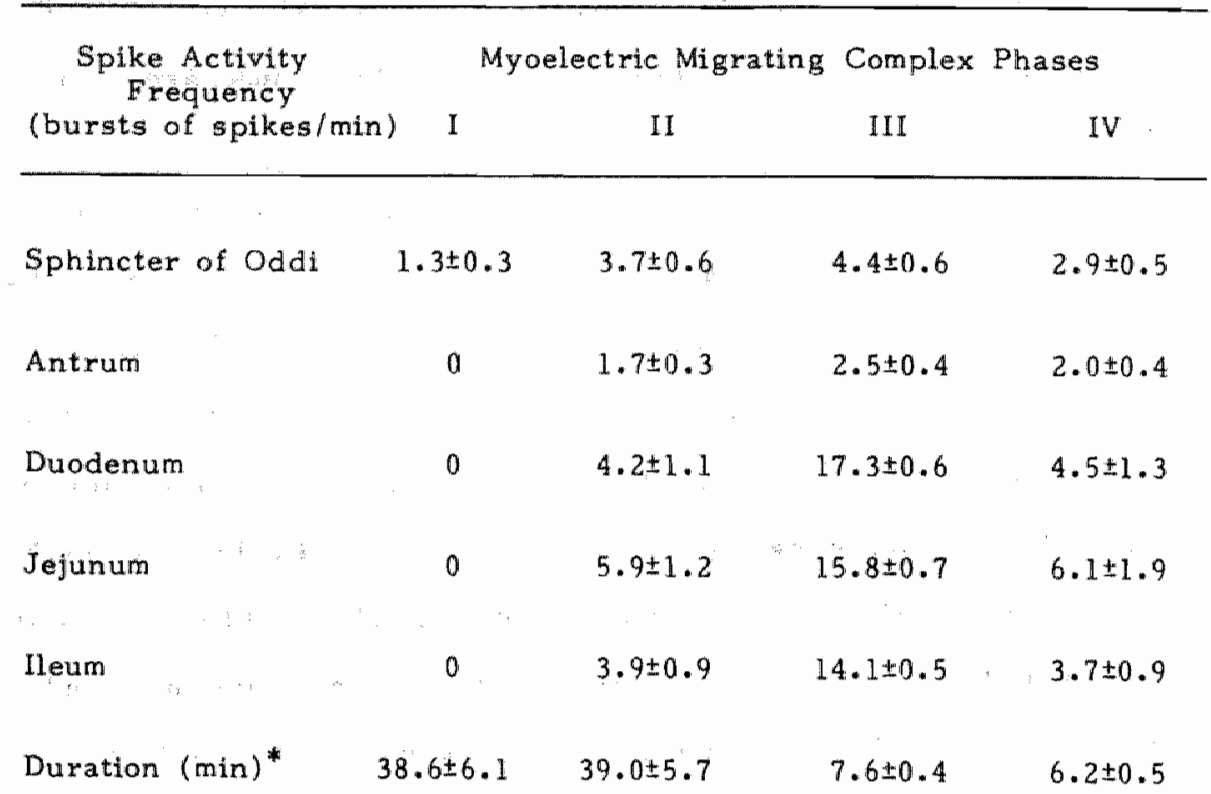

* Duration of each phase in the duodenum 
occurred in all studies for 15 to 20 minutes in the sphincter of oddi. The two largest Increases were observed immedately after alcohol administration (8.1 bursts of spikes/min). Only occacional spike potentials were observed In the antrum following instillation of alcohol into the duodenum .

Instillation of alcohol into the stomach resulted in phase III-11ke activity in six to eight minutes 1 in 20 expertments $(67 \%$ ) (Figure 2). A regular phase $T(60 \%$ or phase II $(40 \%)$ of the MMC then followed. The duration of phases II $(42.4 \pm 8.2 \mathrm{~m}$ In) (mean +1 SD), III $(7.4 \pm 0.3)$, and IV $(5.8 \pm 0.6)$ following alcohol instilation was similar to the control phases II $(39.0 \pm 5.7)$, III $(7.6 \pm$ $0.4)$, and $I N(6.2 \pm 0.5)$

Moderate splke activity (s1x bursts of splkes/min) was observed in the jejunum for one to two minutes after administration of alcohol thto the mid-jejunum, but no change in spike activity occurred 1 in the sphincter of odd and duodenum.

Intravenous infusion of alcohol caused phase III-1ike activity in the sphincter of oddi and duodenum in nine experiments (22\%). This vigorous spike activity was observed 15 to 20 minutes after admintstration of alcohol and occurred in only one animal. No change in spike activity of the sphincter of oddi and gastrolnteatinal tract followed intravenous infusion of alcohol in the other stx andials.

Phase III-11ke activity always migrated distaily to the 


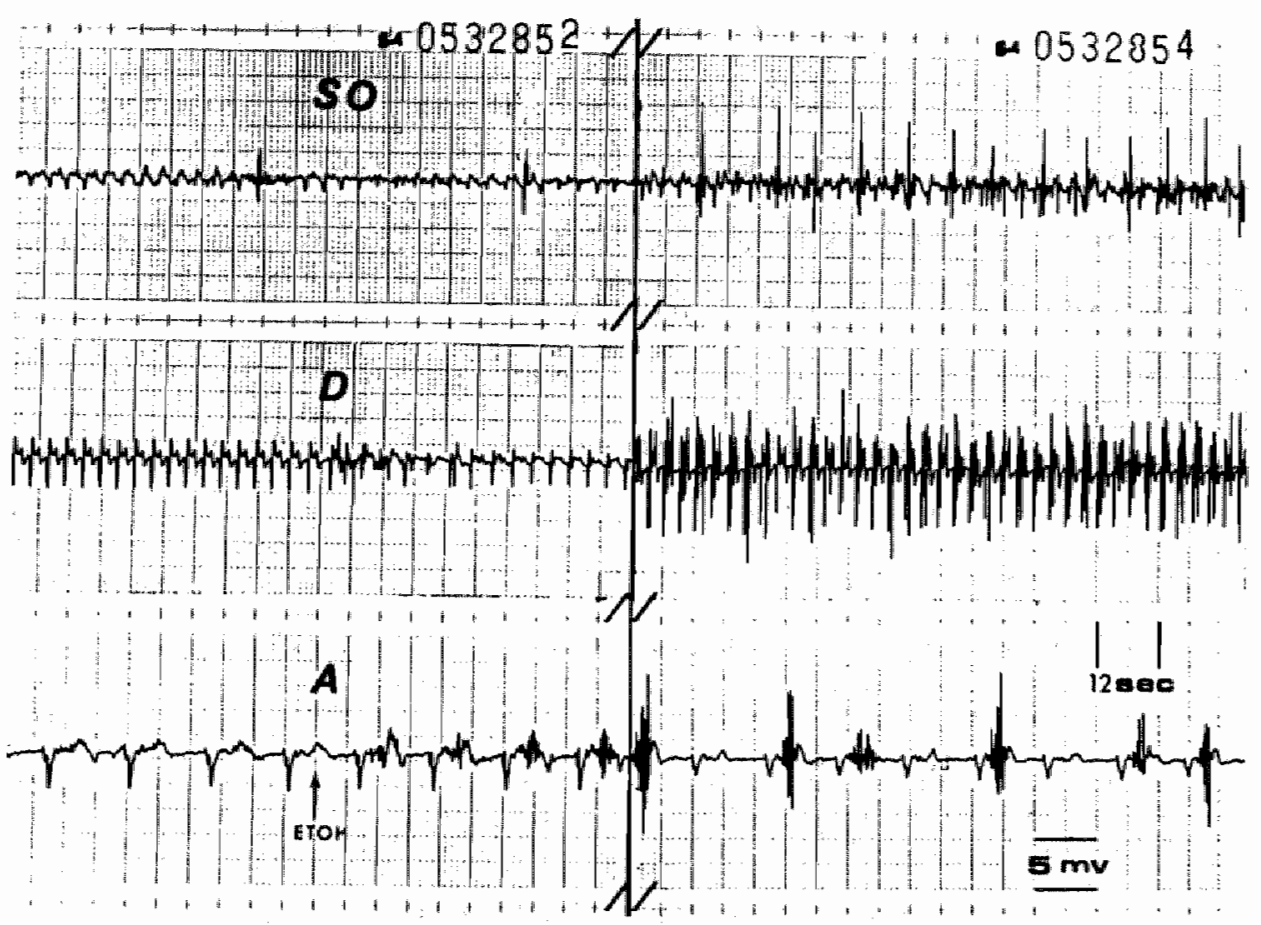

Figure 2. Electromyographic recording of the sphincter of Oddi (SO), duodenum (D), and antrum (A) during phase $I$ of the migrating myoelectric complex of an opossum with gastrojejunostomy and duodenal exclusion. A 208 solution of ethanol in volume of $2 \mathrm{ml} / \mathrm{kg}$ infused into the stomach (ETOH) caused immediate spike activity in the antrum. Intense spike activity was also observed in the sphincter of oddi and duodenum in ten minutes. A six-minute recording period was deleted from the figure $V A$. 
proximal jejunum where it was seen 15 to 20 minutes after the regular phase III. Only one activity front was observed in the distal jejunum and lleum.

Adninistration of solutions of sodium chloride and glucose caused no or occasianal bursts of spike potentials in the duodeaum and sphincter of oddi. Glycerol instillation provoked immediate, intense bursts of splke potentials in the duodenum (12/min), sphincter of oddi ( $8 / \mathrm{min})$ and proximal jefunum (11/min) for two to six minutes. This Initial period of spike activity was not followed by phase III-11ke activity. A normal phase I or II of the MMC ensued. Alcohol blood level after duodenal and intravenous instillation of ethanol was $45 \pm 29$ and $190 \pm 17 \mathrm{mg} / \mathrm{dl}$. respectively. No phase III-11ke activity occurred in the eight experiments im which alcohol was administered intravenously. The ethanol level before admintstration of alcohol was always below $10 \mathrm{mg} / \mathrm{dl}$, which is the lowest value determined by the method employed.

\section{Plasma Motilin Concentration}

The peak of plasma moti11n level observed during the control MMCs occurred during phase III $(35.6 \pm 4.7 \mathrm{pM} / \mathrm{mI}$; mean $\pm 1 S E)$, which was signiffcantly greater than the concentration obtained during phase II $(20.6 \pm 5.1)$ $(p<0.05)$, but not different from the values obtained during phase I $(30.5 \pm 7.6)$. There was no difference in the concentration of plasma motilin abtalned during the phase III-11ke activity $(41.5 \pm 4.6)$ and phase III of the MMC 
$(35.6 \pm 4.7)$

\subsection{DISCUSSION}

The effect of alcohol on the sphincter of oddi has been subjected to several studies. It has been suggested that alcohol may cause spasm of the sphincter of oddi and Increase pancreatic pressure, which might rupture pancreatic ducts and cause liberation of proteolytic enzymes and pancreatitis $(7,8)$. However, the matility of the sphincter of oddi following gastroduodenal infuston of alcohol has been evaluated only by indirect methods, such as pancreatic duct pressure measurements and determination of the volume of pancreatic Juice in the duodenum $(9-12)$.

Recently, electromyography has been employed to study the motility of the sphincter of oddi and gastrolntestinal tract $(13,14)$. The sphincter of oddi in the opossum exhiblted spontaneous splke potentials which propagated from the proximal to the distal portion of the sphincter. The myoelectric activity of the sphincter of 0dd1 is independent from that of the duodenum $(13,14)$; however, the frequency of bursts of spike potentials in the sphincter of odd correlates th the phases of the MMC In the duodenum. Both sphincter of odd and duodenum frequencles of bursts of spikes 1ncrease from phase I through phase III and then decrease rapldy during phase IV to start a new MMC.

We have demonstrated in a previous study that Instilation of alcohol into the stomach or into the 
duodenum of the opossum causes a dramatic increase in the frequency of bursts of spike potentials in the sphincter of odd and duadenum (4). In order to further evaluate the mechanism by which alcohol stimulates the motility of the sphincter of oddi and duodenum, ethanol was instilled on the gastric, duodenal, and jejunal mucosa or administered intravenously in opossums subjected to gastrojejunostomy with duodenal exclusion.

Instillation of alcohol into the stomach or duodenum caused both an initial burst of spike potentials and phase III-1ike activity in eight to ten minutes in the sphincter of oddi and duadenum. Gastrojejunostomy with duodenal exclusion impeded direct contact of alcohol on the duodenal mucosa after administration of ethanol into the stomach and therefore, only a direct irritative effect on the sphincter of odd and duodenum does not explain the appearance of phase III-11ke activity. In addition, administration of hyperosmolar substance (glycerol) into the duodenum caused only the lintial intense bursts of splke potentials in the duodenum and sphincter of odd, probably due to a direct irritative effect, but not phase III-1ike activity. The delay in appearance of phase III-11ke activity following alcohol. instillation suggests that a humoral substance that may be released from the upper gastrointestinal tract mucosa is responsible for this myaelectric disturbance.

Since the level of plasma motilin has been demonetrated to correlate with the MMC phases $(5,15)$, we have evaluated 
the relationship of plasma motilin concentration with phase III-1ike activity caused by instillation of alcohol into the upper gastolntestinal tract. The concentration of plasma mot11in was elevated during phase III-1ike activity and it Was simflar to the normal phase III of the MMC. This suggests that the phase III-11ke activity produced by administration of ethanol may be caused by the release of motilin from the upper gastrointestinal tract. The concentration of motilin during phase I was not Lgnificantly different from that seen during phase III, probably because the blood samples were obtalned only ten minutes after the beginning of phase $I, 1 . e .$, when the motilin concentration was still elevated following the peak during phage III.

Infusion of alcohol into the mid-jejunum caused no change in spike activity of the sphincter of oddi and duodenum. In this instance, only a moderate spike activity was observed in the jejunum for one to two minutes. Intravenous admintstration of ethanol likewise did not change the pattern of splke activity of the sphincter of Odd and gastrolntestinal tract except in one animal. In addition, the occurrence of phase. III-like activity did not correlate wh the alcohol blood level.

We conclude from this study that instillation of alcohol into the stomach or duodenum praduces intense bursts of spike potentials in the sphincter of addi and duodenum. There 1 s no correlation between alcohol blood levels and 
accurance of this intense spike activity. The increase in motilin plasma, level. following instillation of alcohol suggests that phase III-like activity produced by instilation of alcohol may be caused by the release of motilin from the upper gastrointestinal tract. The relationship between pancreatitis and the repetitive accurrence of vigorous spike activity in the sphincter of oddi and duodenum following chronic ingestion of alcohol needs to be evaluated.

\subsection{SUMMARY}

Myoelectric activity of the gastrofntestinal tract and sphtacter of oddi was recorded in seven awake opossums. The animals were subjected to gastrojejunostomy with duodenal exclusion to study the effect of alcohol on the gastric, duodenal, and jejuna 1 . mucosa. The response to intravenous Infusion was also evaluated. Radiolmmunoassay of motilin was performed in five other opossums durting phases I, II, and II of the control migrating myoelectric complex (MMC) and during the phase III-11ke. activity following admintstration of alcohol. Phase III-like activity wes observed following infuston of alcohol linto the duodenum in 26 studies ( $87 \%)$, into the stomach in $20 \%$ (67\%), and intravenousiy in nine $(22 \%)$. Alcohol blood level after duodenal and 1 ntravenou instillation of ethanol was 45 and 190 mg/dl respectively (eight experiments of each). There was no difference 1 n the concentration of plasma motilin obtained daring phase 
III-11ke act1v1ty (41.5 $44.6 \mathrm{pM} / \mathrm{mI})$ and phase III of the MMC $(35.6 \pm 4.7)$. We conclude that instilation of alcohol 1nto the stomach or duodenum produces intense bursts of spike potentials in the sphincter of oddi and duadenum. There $1 \mathrm{~s}$ no correlation between alcohol blood levels and occurrence of this intense spike activity.

\subsection{REFERENCES}

1. Summers RW, He1m J, Christensen J. Intestinal propulston in the dog. Its relation to food intake and the migratory myoelectric complex. Gastroenterology $70: 753-758,1976$.

2. Szurgzewski JH. A migrating electic complex of the canine sma11 1ntestine. Am $J$ Phystol 217:1757-1763, 1969.

3. Rees WDW, Malagelada J-R, Mi11er LJ, Go VLW. Human interdigestive and postprandial motor and gastrofitestinal hormone paterns. Dig Dis Sci $27: 321-329,1982$.

4. Coelho JCU, Moody EG, Senninger N, Welsbrodt NW. Effect of aliohol upon myoelectric activity of the gastrointestinal tract and pancreatic and biliary duct pressures. Surg Gynecol obstet $160: 528-533,1985$.

5. Lee KY, chey WY, Ta1 H-H, YafHma H. Radiolmmunoassay of motilin: validation and studies on the relationship between plasma motilin and interdigestive myoelectric activity of the duodenum of the dog. Am $J$ DIg Dis 
$23: 789-795,1978$

6. Code CF, Marlett JA. The interdigestive myoelectric complex of the stomach and small bowel of dogs. J Physiol (London) 246:289-309, 1975 .

7. Schapiro H. Wruble LF, Britt LG. The possible mechanism of alcohol in the production of acute pancreatitis. Surgery $60: 1108-1111,1966$.

8. Strum WB, Spiro HM. Chronic pacreatitis. Ann Intern Med $74: 264-277,1971$.

9. Madding GF, Tueller EE, Kennedy PA. OraI and Intravenous administration of alcohol and the pancreas. JAMA $205: 106,1968$.

10. Menguy RB, Hallenbeck GA, Boliman JL, Grindlay JH. Intraductal pressures and sphincteric resistance in canine pancreatic and biliary ducto after various sttmuli. Surg Gynecol Obstet $106: 306-320,1958$.

11. Mote C, Sarles H, Tiscornia o, Gulio L. Inhibitory action of alcohol on human exocrine pacreatic secretion. D1g Dis Sc1 17:902-910, 1972 .

12. Tiscornia oM, Gullo L, Sarles H. Effects of Intragastric and intraduodenal ethanol on cantne exocrine pancreatic secretion. Digestion 10:52-60, 1974.

13. Coelho JCU, Moody FG, Senninger N. A new method for correlating pancreatic and biliary duct pressures and sphincter of oddi electrodyography. Surgery $97: 342-349$, 1985. 
14. Honda R, Tooull J, Dodds WJ, Sarna $\mathrm{S}$, Hogan WJ, Itoh Z. Relationship of sphincter of oddi splke bursts to gastrolintestinal moelectric activity in conscious opossums. J C11n Invest $69: 770-778,1982$.

15. Takahashi I, Honda R, Dodds HJ. Effect of motilin on the opossum upper gastrointestinal tract and sphincter of Ddd1. Am J Physiol $245: 6476-485,1983$. 


\section{EFFECT OF 16,16 DIMETHYL PROSTAGLANDIN $E_{2}$ ON THE MYOELECTRIC ACTIVITY OF THE GASTROINTESTINAL TRACT OF THE OPOSSUM}

\subsection{INTRODUCTION}

prostaglandins are substamices derived from unsaturated fitty-acids which are widely distributed ln several human tissues, including the gastrointestinal tract (1). The role of prostaglandins under physiological and pathological conditions in the gastrointestinal tract is currently under extensive evaluation. Prostaglandins have been shown to produce important disturbances in the motility of the gastrointestinal tract $(1-3)$. The effects are varlable and depend on the type of prostaglandins, the dose, the spectes, and the muscle layer studied (3-5). Prostaglandin $E_{2}$ and its methylated derivative, $16,16-d i m e t h y 1$ prostaglandin $E_{2}$ $\left(16,16-\mathrm{dm} P \mathrm{PE}_{2}\right)$, cause diarhea in several species including $\operatorname{man}(2,6)$.

It has been suggested that the mechanism by which prostaglandins cause diarrhea is due to changes 1 th the gastrolntestinal motlity and/or in the transport of water and electrolytes across the intestinal mucosa $(6,7)$. The effect of $16,16-\mathrm{dm} \mathrm{FGE}_{2}$ on the migrating myoelectric complex in vivo has not been evaluated. Our abjective in the present study is to assess the effect of 16,16-dm PGE and indomethacin, an inhibitor of prostaglandin synthesis, on 
the moelectric activity of the gastrolntestinal tract and sphincter of oddi in the opossum.

\subsection{MATERIAL AND METHODS}

Seven opossums of elther sex weighing 2.6 to $3.5 \mathrm{~kg}$ were fasted overnight and then anesthetized with 1ntraperitoneal administration of 25 mg of sodium pentobarbital per kg. Upper midilne laparotomy was prerformed.

Seven pairs of blpolar extracellular electrodes were implanted in the mucular layer of the sphincter of oddi, distal gastric atrum, duodenum, proximal jejunum, midjejunum, terminal jejunum, and terminal ileum. The electrodes consisted of stranded silver-plated copper wire Wth teflon insulation of 36 AWG (American Wire Gauge) size. The other end of the wres was previousiy soldered to a female socket.

Following abdominal waj.l closing, a silatic catheter was Inserted Into the jugular vein. The catheter and the wretwe passed through a subcutaneous tunnel to the animal's back and stitched to the skin.

Wlectromyographic recordings were started seven to ten days after the operation and were performed on conscious opossums fasted for 12 hours. For each recording session, a male socket which was connected to an eight-channel Gould 2800 instrument (Gould Inc., Recording systems Division, Cleveland, otio) was plugged into the opossum socket. 
Following recording of at least one control migrating myoelectrie complex (MMC), 16,16-dm PGE, (Upjohn, Kalamazoo, Michigan) or indomethacin (Sigma Chemical Co., St. Louls, Missouri) was infused intravenously. In order to obtain a stock solution, 16,16-dm $\mathrm{PGE}_{2}$ was dissolved in absolute ethanol, separated in small aliquots af $20 \mu_{g} / m 1$, and frozen. For each experiment, the stock solution was diluted with 0.9 sodium chloride solution. Indomethacin solution was freshly prepared for each experiment by dissolving it in $5 \%$ sodium carbonate solution.

The $16,16-d m \mathbb{P G E}_{2}$ was administered contimuously for one complete MMC cycle in the duodenum at a rate of $0.1 \mathrm{~m} 1 / \mathrm{min}$ employing a Harvard pump. A total of ten experiments of each of the following doses of 16,16-dm $P G E_{2}$ was performed: 0.1 , 1,2 and $5 \mu \mathrm{g} / \mathrm{kg} / \mathrm{h}$. Bolus $1 \mathrm{nfusion}$ of $2 \mu \mathrm{g} / \mathrm{kg} / \mathrm{h}$ of $16,16-\mathrm{dm}$ $\mathrm{PGE}_{2}$ was also studied (ten experiments). In ten other experiments, indomethacin at a dose of $10 \mathrm{mg} / \mathrm{kg}$, was infused as a bolus. All infustions were started at the beginning of phase $I$ of the MMC in the duodenum. Following administration of each substance, at least two additonal Mucs were recorded.

Each recording session lasted flue to eight hours. For analysis of the myoelectric recordings, the tracing were divided into two-minute intervals and the average frequency of slow waves with superimposed splke potentials for each phase of the MMC was determined. The MMC was divided into four phases as described by Code and Marlett (8). Honda et 
a1. and our group have shown that there is a temporal correlation between the MMC phases in the duodenum and sphincter of odd $(9,10)$. All phases in the sphincter of Ddd1 start almost simultaneously ith the MMC phases in the proximal duodenal. Therefore, the moelectric activity of the ghincter of oddl was also divided into four phases. The duration of each MMC was determined by measuring the time 1nterval between two consecutive phase: IIIs in the duodenum. The progression velocity of phase III was calculated by determining the time interval for a phase III to migrate from the duodenum to the terminal ileum. The data were analyzed statistically by means of the student two-tailed test. Determination of dose dependency was made by Iinear regression analysis. In the text, averaged values are given as mean \pm ISD.

\subsection{RESULTS}

The frequency of slow wawes with superimposed bursts of splke 1n a 11 recording stes increased from phase I of the MMC to reach the maximurn in phase III, then 1 t decreased rapidly during phase IV to start a new MMC cycle. The frequency of slow: waves with superimposed spike potentials In the antion, duodenum, and sphincter of odd for each control MMC phase in the duodenum is shown in Table 1.

Continuous infusion of $16,16-\mathrm{dm} \mathrm{PGE}_{2}$ caused a reduction of the duration of the MMC cycle and an increase of the velocity of phase III algration from the duodenum to the 
Myoelectrical Activity of the Antrum, Duodenum, and Sphincter of Oddi.

Bursts of Spikes/Min

Myoelectric Migrating Complex (MMC) Phase

I $\mathbb{I I}$ III IV

Control MMC

$\begin{array}{lcccc}\text { Antrum } & 0 & 1.9 \pm 0.2 & 3.0 \pm 0.2 & 1.2 \pm 0.3 \\ \text { Duodenum } & 0 & 6.2 \pm 0.7 & 17.1 \pm 0.7 & 4.6 \pm 0.9 \\ \text { Sphincter of Oddi } & 2.6 \pm 0.6 & 4.7 \pm 0.6 & 5.3 \pm 0.7 & 3.0 \pm 0.6 \\ \text { Duration (min) } & 52.3 \pm 9.0^{*} & 26.9 \pm 5.2^{*} & 7.5 \pm 0.5 & 4.0 \pm 0.4\end{array}$

MMC During Infusion

of $16,16-\mathrm{dm} P \mathrm{PE}_{2}$ at $2 \mu \mathrm{g} / \mathrm{kg} / \mathrm{h}$

Antrum

0

$2.0 \pm 0.3$

$3.0 \pm 0.2$

$1.5 \pm 0.4$

Duodenum

0

$6.6 \pm 0.8 \quad 16.6 \pm 0.8$

$5.1 \pm 0.8$

Sphincter of Oddi

$2.8 \pm 0.6$

$4.8 \pm 0.5$

$5.6 \pm 0.6$

$2.9 \pm 0.5$

Duration $(\min )^{t}$

$14.9 \pm 3.2$

$13.9 \pm 3.0$

$7.2 \pm 0.4$

$3.8 \pm 0.4$

t Duration of each phase in the duodenum.

* This value is significantly greater than the corresponding value in the same column below at the 18 level, $\mathrm{p}<0.01$. 
tertinal lleu (Figure 1). The che changes were dose-dependent (Table 2). The duration of the MMC cycle varied from $74.2 \pm$ 11.4 min during infusion of $16,16-\mathrm{dm} \mathrm{PGE}_{2}$ at $0.1 \mathrm{Hg} / \mathrm{kg} / \mathrm{h}$ to $37.6 \pm 6.4$ min at $5.0 \mu g / \mathrm{kg} / \mathrm{h}$ correlation coeffictent $=$ 0.77; p(o.01). The time interval for phase III to migrate from the duodenum to the terminal 1leum varied from $64.4 \pm$ 12.7 during infusion of $16,16-\mathrm{dm} P \mathrm{PE}_{2}$ at $0.1 \mu \mathrm{g} / \mathrm{kg} / \mathrm{h}$ to 34.7 +6.0 at $5.0 \mu g / \mathrm{kg} / \mathrm{h}$ (correlation coefficlent $=0.69 ;$ $\mathrm{p}(0.01)$

The frequencies of slow waves th bursts of spikes in the antrum, duodenum, and sphincter of oddl during infusion of $16,16-\mathrm{dm} P \mathrm{PE}_{2}$ at $2 \mu \mathrm{g} / \mathrm{kg} / \mathrm{h}$ is shown $1 \mathrm{n}$ Table 1 and they were not signiflcantly different from those of the control MMC phases. "The time reduction of the MMC cycle was due to a shortening of the duration of both phase $I$ and II. Phase III, observed during infusion of $16,16-\mathrm{dm}$ PGE 2 , was stmilar to that of the control MMC in duration (6 to 8 min), amplitude ( 7 to $10 \mathrm{mV})$, and frequency of bursts of spike potentials (17/min in the duodenum). There was no difference in the frequency of phase III migration to the terminal 1. Leum between the contro1 MMCs ( $89 \%)$ and during infuston of $16,16-\mathrm{dm} \mathrm{PGE}_{2}(93 \%)$

The duration of the next MMC cycle following administration of $16,16-\mathrm{dm} \mathrm{PGE}_{2}$ at $1.0(69.5 \pm 12.3 \mathrm{~min})$, $2.0(67.4 \pm 5.4 \mathrm{~min})$, and $5.0 \mu \mathrm{g} / \mathrm{kg} / \mathrm{h}(56.0 \pm 10.1 \mathrm{~min})$ was signiflcantly smaller than that of the control MMC $(90.7 \pm$ 15.0 min). There was no significant difference between the 
Bursts of

Spikes/min

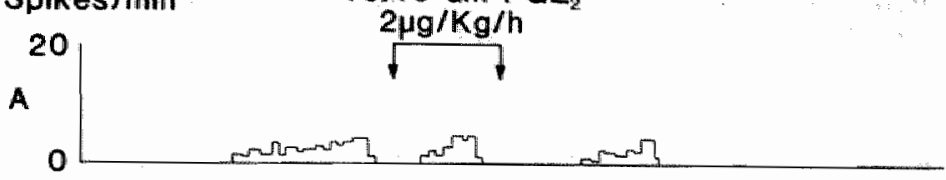

so
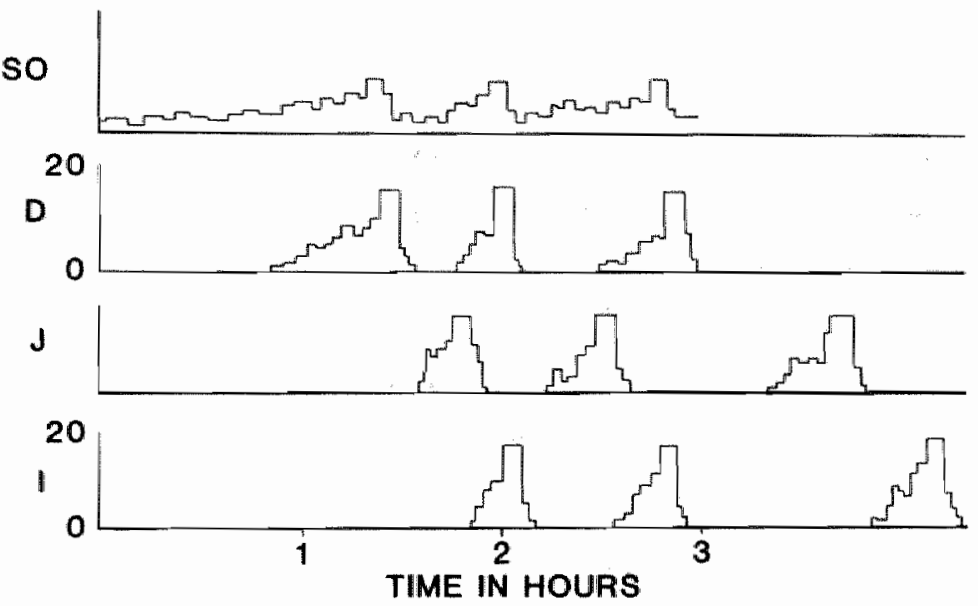

Figure 1. Histograms of sphincter of oddi and gastrointestinal tract myoelectric activity in a fasted opossum. Electrodes are positioned in the gastric antrum (A), sphincter of oddi (SO), duodenum (D), distal jejunum (J), and distal ileum (I). Infusion of 16,16 -dimethyl prostaglandin $\mathrm{E}_{2}$ at a dose of $2 \mu \mathrm{g} / \mathrm{kg} / \mathrm{h}$ reduced the duration of the MMC cycle and increased the velocity of propagation of phase III from the stomach to the ileum. 
TABLE 2

Migrating Mycelectric Complex Cycle Duration and Velocity

of Propagation of Phase III During Infusion

of 16,16-Dimethyl Prostaglandin $E_{2}$

$\begin{array}{ccc}\text { Dose of Prostaglandin } & \text { MMC Duration } & \text { Velacity of Propagation } \\ (\mu \mathrm{g} / \mathrm{kg} / \mathrm{h}) & (\mathrm{min}) & \text { (min) }\end{array}$

$\begin{array}{ccc}0.1 & 74.2 \pm 11.4 & 64.4 \pm 12.7 \\ 1.0 & 56.0 \pm 10.1 & 49.2 \pm 8.8 \\ 2.0 & 47.0 \pm 4.3 & 39.8 \pm 4.9 \\ 5.0 & 37.6 \pm 6.4 & 34.7 \pm 6.0 \\ \text { Control } & 90.7 \pm 15.0 & 79.3 \pm 15.0\end{array}$


duration of the control MMC cycle and that followig infustan of $16,16-\mathrm{dm} P \mathrm{PGE}_{2}$ at $0.1 \mathrm{\mu g} / \mathrm{kg} / \mathrm{h}(91.5 \pm 15.6 \mathrm{~min})$.

Balus infuston of $16,16-\mathrm{dm} \quad \mathrm{PGE}_{2}$ at $2 \mu \mathrm{g} / \mathrm{kg}$ caused intense splke activity for two to four minutes in all recording sites simultaneously. The frequency of slow waves with bursts of spikes was 2 bursts of splkes/min in the antrum, 8 bursts of spikes/min in the sphincter of oddi, 17 bursts of spikes/min in the duodenum, 15 bursts of spikes/min in the distal jejunum, and 14 bursts of spikes/min in the terminal lieum. The phase III continued its migration down to the terminal ileum but at a higher velocity. The time tnterval for phase III to migrate from the duodenum to the terminal ileum was $37.4 \pm 4.7 \mathrm{~min}$.

Diarrhea was observed in eight experiments, six following infusion of $16,16-\mathrm{dm} \mathrm{PGE}_{2}$ at $5, \mu \mathrm{g} / \mathrm{kg} / \mathrm{h}$ and two after infuston at $2 \mu g / \mathrm{kg} / \mathrm{h}$. Diarrhea was deflned as any bowel movenent of liquid content that accurred during or within two hours of the experiment. There mas no significant difference in MMC cycle duration between the MMC following Indomethacin administration ( $84.2 \pm 12.3$ min) and control $\operatorname{MCs}(90.0 \pm 11.0 \mathrm{~m} 1 \mathrm{n})$

\subsection{DISCUSSION}

Prostaglandins have been fmplicted a a possible cause of diarrhea in several clintcal stuations, including bacterial infections, colonic and thyroid cancerg, irrtcable colon syndrome, food intolerance, and following radiotherapy 
(11,12). Diarrbea has been observed following administration of: prostaglandin E $(2,6,13)$. The mechanism of diarrhea asoclated with prostaglandins 1 stil not clear. Changes 1n gastolntestinal motility as well as water and electrolyt1c lntetinal transport have been suggested as the cause of prostaglandin-1nduced diarchea $(2,6,7)$.

In the present study, we evaluate the effect of a methylated synthetic prostaglandin $E_{2}, 16,16-d i m e t h y l$ prostaglandin, on the electromyographic activity of the gastrolntestinal tract of the apossum. This animal exhibits gut myoelectric activity ofmilar to that of humans and it usually lies quietly for many hours without the need of restraints, sedatives, or anesthetics. Continuous administration of $16,16-d n \mathrm{PGE}_{2}$ produced a dose-dependent Increase in the frequency of MMCs and in the velocity of propagation of phase III from the duodenum to the terminal 1leum. Since the activity front of each MMC (phase III) is assoclated with peristaltic contractions of the small bowel whose function 1 s propulsion of gastointestinal contents, an lincrease $1 \mathrm{n}$ the frequency and velocity of propagation of phase III may increase the delivery of gut contents into the colon and so contribute to diarhea.

Mathias et al. reported that infusion of prostaglandin $\mathbb{F}_{2}$ alpha 1 into rabbit 11 eal 100 ps produced a highly organized myoelectric pattern defined as migrating action potential complex. This myoelectric pattern was simflar to that observed In animals that developed diarhea secondary to 
administration of cholera toxin (14).

Ruwart et al. observed an increase in the small intestine transit of a radiolsotopic marker following intravenous administration of $16,16-d m P_{2}$ in rats (15). An increase in lleal flow of a nonaborbable marker during administration of both prostaglandin $E_{2}$ and $F_{2}$ was also reported by Milton-Thompson et al. in man (7). However, Ronturek reported a prolongation of the MMC cycle duration following continuous intravenous infusion of prostaglandin $\mathrm{E}_{2}$ in dogs (5). These different results may be related to the use of different antmal species.

Prostaglandin $E_{2}$ has also been demonstrated to stimulate the motility of the lsolated human stomach (12). The gastric emptying rate of test meal marker is increased following administration of $16,16-\mathrm{dm} \mathrm{PGE}_{2}$ (3). In our study, a bolus administration of high doses of 16,16-dm PGE interrupted the MMC temporarily and increased the spike activity of the antrum of the stomach as well as of the small bowel and sphincter of oddi. Continuous infusion of 16,16-dm $\mathrm{PGE}_{2}$ also increased the motility of the antrun, but in an organized fashion. In this situation, the increase in spike activity of the antrum was associated with al precocious appearance of phase III of the MMC $1 \mathrm{n}$ the upper gastrointestinal tract, which migrated distally to the terminal ileum at a higher velocity than in the control MMCs .

The physiologic role of prostaglandins in modulating 
the motilty of the gastolntestinal tract is controversial (16). The observations that prostaglandin $E_{2}$ is produced in the 1 intestine and that administration of prostaglandins and 1 nhd b t t ors

of prostaglandin gynthesis

change gatrolntestinal motility suggest that endogenous prostaglandin synthesis may have a role in regulating 1.ntestimal mot11ty $(15,17,18)$. Several authors have reported an increase in the motility of the gastrointestinal tract followlig admintetration of prostaglandin inhibitors both 1n w1vo and in v1tro $(\mathbb{1} 9,20)$. However, other authars abserved a decrease in activity of the small intestine in guinea-p1g 11 eum and human small intestine following administration of asplrin and 1 ndomethacin $(5,18)$. Eorosuska et a1. reported that application of aspirin, indomethacin and suprofen to the intestinal serosa did not affect peristalsis in the small intestine of the mouse (21). We have observed no change in either the electromyographic activity of the antrum, small bowe1, or sphincter of odd of the fasted opossum following intravenous administration of 1ndomethacin. This finding does not eliminate the possibility that prostaglandin may have a role in regulating the gastrointestinal tract motility.

Honda et al. and our group have demonstrated that athough the myoelectric activity of the sphincter of odd Is Independent from that of the duodenum, the frequency of bursts of spike potentials in the sphincter of odd correlates with the MMC phases in the duodenum $(9,10)$. 
Continuous infusion of $16,16-\mathrm{dn} \mathrm{PGE}_{2}$ did not terminate the correlation between the spike activity of the sphincter of oddi with the shortened MMC phases of the duodenum.

It is concluded from this study that continuous infusion of $16,16-\mathrm{dm} P \mathrm{PGE}_{2}$ Increases the frequency of MMCs and the welocity of propagation of the activity front of the MMC from the antrum to the terminal 11 eum in the opossum. These changes in gastraintestinal motility may be 1 mportant contributory factors in the etlopathogenesis of prostaglandin-1nduced diarrhea.

\subsection{SUMMARY}

Myoelectric recordings of the opossum gastrolntestinal tract were performed during continuous infusion of 16,16-dimethyl prostaglandin $E_{2}$ at $0.1,1,2$ and $5 \mu \mathrm{g} / \mathrm{kg} / \mathrm{h}$. Prostaglandin causes a dose-dependent reduction of the duration of the MMC cycle and an increase in the velocity of phase III migration from the duodenum to the terminal 11eum. The time reduction of the MMC cycle was due to a shortening of the duration of both phase I and II. Bolus tnfusion of 16,16-dimethy1 prostaglandin caused intense sptke activity for two to four minutes in all recording sites simultaneously. Administration of indomethacin did not change the myoelectric activity of the gastrolntestinal tract. Diarrhea was observed in eight expertments. These changes in gastrointestinal motility may be linotiant contributory factors in the etiopathogenesis of 
prostaglandin-tiduced diarrhea.

\subsection{AEFERENCES}

1. Bennete $A$, Hensby CN, sanger GJ, stanford IF. Metabolites of arachidonic acid formed by human gatrolntestinal tissue and thelr actions on the muscle layers. Br J Pharmaco1 $74: 435-444,1981$.

2. Horton EW, Main IHM, Thompson CJ, Wright PM. Effect of orally administered prostaglandin, $E_{1}$ on gastric secretion and gastrolntestinal motility in man. Gut $9: 655-658,1968$.

3. Nylander B, Mattsion 0 . Effect of $16,16-d i m e t h y 1$ PGE $_{2}$ on gastric emptying and intestinal transit of a barlum-food test meal in man. Scand J Gastroenterol $10: 289-292,1975$

4. Sanders KM. Endogenous prostaglandin E and contractile activity of isolated lieal smooth muscle. Am: J Physiol $234: E 209-E 212,1978$.

5. Konturek SJ, Thor P, Pawlik W, Gutaw P, Dembinsk1 A. Rolle of prostaglandins in the myolectric, motor and metabolic activity of the small intestime in the dog. In Wenbeck M, editor. Moti11ty of the Digestive Tract. New York, Raven Press, 1982, pp. 437-444.

6. Rask-Madsen J, Bukhave $K$. Prostaglandins and chronte diarrhea: clinical aspects. Scand J Gastroenterol $($ supp1 53) $14: 73-78,1979$.

7. Milton-Thompson GJ, Cumings JH, Newman A, Billings, JA, 
Misiewicz JJ. Colontc and small intestinel response to intravenous prostaglandin $\mathbb{F}_{2}$ and $E_{2}$ in man. Gut $16: 42-46,1975$

B. Code CF, Marlett JA. The interdigestive myoelectric complex of the stomach and small bowel of dogs. I Physiol (London) 246:289-309, 1975 .

9. Honda R, Toouli J, Dodds WJ, Sarna S, Hogan WJ, Itoh Z. Relationship of sphincter of oddi spike bursts to gastrointestinal myoelectric activity ln consclous opossums. J Clin Invest $68: 770-778,1982$.

10. Coelho JcU, Moody FG, Senninger N. A new method for correlating pancreatic and biliary duct pressures and sphincter of oddi electromyography. Surgery $97: 342-349$, 1985.

11. Williams ED, Karim SMM, Sandier M Prostaglandin secretion by medullary carcinom of the thyroid. Lancet $1: 22-26,1968$

12. Bennett $A$, Bertaccinl $G$, Corazziari E. Mediators and drugs in gastrolntegtinal motility II. NeW York, springer-Verlag, 1982 .

13. Dajani Sz, Rogue EAW, Bertermann RE. Effects of prostaglandins, diphenoxylate and morphine on intestinal motility invivo. Eur J pharmacol $34: 105-113,1975$.

14. Mathias JR, Carlson GM, Bertiger 6 , Martin JL, Cohen $s$. Migrating action potential complex of cholera: a possible prostaglandin-induced response. Am $J$ phystol 
$232: \mathbb{E} 59-\mathbb{E} 534,1977$

15. Ruwart MJ, K1epper MS, Rush RD. Prostaglandin tetmulation of gastrolntestinal transt in postoperative. 11eus rats. Prostagladins 19:415-427, 1980

16. Bennete A. The role of prostaglandins in gatrolntegtinal tone and motility. In Bertaccini I, Samulsson B, Velo GP, editors. Prostaglandins and Thromboxones. New York, Plenun Press, 1977, pp. $275-285$

17. Ekelund $K$, Johangson $C$, Nylander B. Effects of 16,16 dimethyl prostaglandin $\mathrm{E}_{2}$ on food-stimulated pancreatic secretion. and output of bile in man. scand J Gastroentero1 $12: 457-460,1977$.

18. Bennett A, Eley KG, Stockley HL. Inhibition of peribalsis in guinea-p1g; isolated. 1leum and colon by drugs that block prostaglandin synthesis. Br J Pharmacol $57: 335-340,1976$.

19. Sanders KM, Ross G. Effects of endogenous prostaglandin E on Intestinal woti11ty. Am J Phys101 234:E204-E208, 1978.

20. Koch KL, Dwyer. Andomethacin-1nduced spiking activity in rabbit lleum: $1 \mathrm{n}$ vivo interactions of prostaglandins and cholinergic neurotranomistion. In Roman c, editor. Gastrolntestinal Motility. Boston, MTP Press, Ltd, $1983, \mathrm{pp} \cdot 357-363$.

21. Boroswsk A, Mackowlak: J, Wisniewsk1, A. 
Prostaglandins/PGS/ and peristalsis. Prostaglandins and Medicine 6:13-16, 1981 . 


\section{SEROTONIN INCREASES THE VELOCITY OF PROPAGATION AND FREQUENCY OF THE MIGRATING MYOELECTRIC COMPLEXES}

\subsection{INTRODUCTION}

The matn source of s-hydroxytryptame (serotontn) in mamals, 1ncluding humans, is the enterochromaffin cells and enterochromaffin-like cells in the gastrointestinal tract (1). The physlological role of this amine in the motility of the gatrointestinal tract is still controversial $(1,2)$. It has been suggested that the elevated production of serotonin by carcinold tumors is responstbie for the increased motility of the intestine and the diarrhea observed in this condition $(3,4)$.

The most comon techniques employed to evaluate the effect of serotonin on gastrolntestinal tract motility have been determinations of contractions of nuscle strips in vitro, Intraluminal pressures, extraluninal contractile forces, and movements of radiopaque substances (5-9). Recent developments in electromyagraphy have allowed a more detalled evaluation of the gastrointestinal tract motility. Several antmals, Including man, opossum, and dog exhibit a characteristic fasting motility pattern of the gastrolntestinal tract that has been termed the migrating 
myoelectric complex (MMC) which periodically propagates down the digestive tract form the stomach to the terminal ileum $(10,11)$. Ruckebusch and Bardon have evaluated the effect of bolus administration of serotonim on the MMC in the stomach and duadenum of sheep (12). Our objective in the present study is to assess the effect of both continuous and bolus administration of serotonin on the myoelectric activity of the gastrointestinal tract and sphincter of oddi of the opossum.

\subsection{MATERIAL AND METHODS}

Under sodium pentobarbital anesthesia that as administered. Intrapertitoneally at a dose of $25 \mathrm{mg} / \mathrm{kg}$, seven fasted opossums were subjected to an upper midline 1aparotomy.

Bipolar electrodes of silver-plated copper ires of 36 AWG size were implanted 10 the muscular layer of the sphincter of odd and gastrolutestinal tract through a 25 gauge hypodermic needle. The wire was loosely tied off and the free end was trimmed. A total of seven pass of electrodes were placed, one in the sphincter of oddi, one In the distal antrum, one in the duodenum (two centimeters didtal to the sphincter of oddi-duodenal junction), and four at equidistant intervals from the proximal jejunum to the distal. ileum. 
Allastic catheter was placed into the jugular wein. The catheter and the wires were brought subcutaneously to the interscapular reglon. The wires were prevtousiy soldered to a female socket. The socket and the catheter were attahed to the sk1n.

Experiments were started seven to ten days after the operation. The animals were fasted for 12 to 15 hours before each study. Myolectric activity was recorded on an elght-channel Gould 2800S Instrument (Gould, Inc., Recording systems Division, Cileveland, ohio) using a paper speed of 1 $\mathrm{mm} / \mathrm{s}$, low frequency cut-off fliter of $1 \mathrm{~Hz}$, high frequency cut-off 11 ter of $10 \mathrm{~Hz}$, and an overall sensitivity of 25 or $50 \mathrm{mV}$. A male sacket connected to the recording instrument was plugged linto the opossum's back socket for each recording session. No anesthetics or sedatives were administered to the animals.

After one to three spontaneously occurring MMCs had been recorded, $0.01,0.1,0.2,0.5$, or $1.0 \mathrm{mg} / \mathrm{kg} / \mathrm{h}$ of serotonin creatinine sulfate (sigma Chemical co., St. Louls, Missuil) was admintstered intravenously at a continuous rate of $0.2 \mathrm{ml} / \mathrm{mIn}$ employling a Harvard pump. A total of ten studies was obtalned for each dose. The infusion was started at the beginning of phase I of the MMC in the duodenum and was continued for the time period of one MMC cycle. Finally, the next MMC following termination of the serotonin infusion was a 1 so recorded.

In additional experiments, bolus intravenous infusions 
of methysergide maleate (Batch 78001, sandoz Pharmaceuticals, East Hanover, New Jersey) at a dose of 1 mg/kg were given alone (ten studies) at the beginnlng of phase I of the MMC in the duadenum or preceding infusion of serotonin at $1 \mathrm{mg} / \mathrm{kg} / \mathrm{h}$ (ten studies).

Finally, bolus infusion of serotonin at $0.2 \mathrm{mg} / \mathrm{kg}$ was also performed at the beginning of phase I of the MMC $1 \mathrm{n}$ the duodenum in ten other studies.

The different phases of the MMC were identified using the criteria of code and Marlett (11). The progression velocity of phase III was calculated by determining the time interval for a phase III to migrate from the duodenum to the terminal ileum. The recordings were divided into two-minute intervals and the average frequency of slow waves wh superimposed spike potentials for each phase of the MMC was determined. The data were analyzed statistically by means of the student two-tailed test. Determination of dose dependency was made by linear regression analysis. The average MMC cycle duration was ploted agatiot the Logarithmic serotonin concentration. In the text, averaged values are given as mean $\# 1 \mathrm{SD}$.

\subsection{RESULTS}

sllow waves occurred at a rate of $3.3 / \mathrm{min}$ in the antrum, $18 / \mathrm{min}$ in the duodenum and sphincter of odd, and $15 / m i n$ in the terminal tleum. The average duration of the MMC in the dudodenum was $93.7 \pm 15.8$ min and the time 
Interval for a phase III to migrate from the duodenum to the terminal 11eum $84.3 \pm 12.6 \mathrm{~min}$.

Honda et al and our group have demonstrated previously that, although the frequency of splke potentials 1 different in the sphincter of oddi and duodenum, there is a temporal correlation between the MMC phases in the sphincter of odd1 and duodenum $(13,14)$. All phases in the sphincter of Oddi started almost simultaneousiy with the MMC phases in the proximal duodenum. Therefore, the myoelectric activity of the sphincter of oddi was also divided into four phases.

continuaus infusion of serotonin reduced the periodictiy of the MMC. The MMC cycle duration reduction was dose-dependent (correlation coefficient $=0.82 ; \mathrm{p}(0.01)$ and the cycle lenght varted from $90.6 \pm 15.6 \mathrm{~min} . \mathrm{dur} i \mathrm{ng}$ Infustion of serotonin at $0.01 \mathrm{mg} / \mathrm{kg} / \mathrm{h}$ to $36.6 \pm 5.4 \mathrm{~min}$. during Infusion at $1.0 \mathrm{mg} / \mathrm{kg} / \mathrm{h}$ (Figure 1). There was no difference in the MMG cycle duration between the control group $(93.7 \pm 15.8 \mathrm{~min})$ and during infusion of serotonin at $0.01 \mathrm{mg} / \mathrm{kg} / \mathrm{h}(90.6 \pm 15.6 \mathrm{~min})$.

The reduction of the MMC cycle duration was the result of the decrease in time of both phases I and II. Phase III obtained during administration of serotonin was simflar to the control phase III 1 n duration $(6-8$ min), frequency of spike activity ( 18 spikes/min, in the duodenum), and amplitude of the sptke potentials $(10-14$ mV). In addition, the frequency of phase III migration to the terminal ileum during admintstration of serotonin $(86 \%)$ was similar to that 


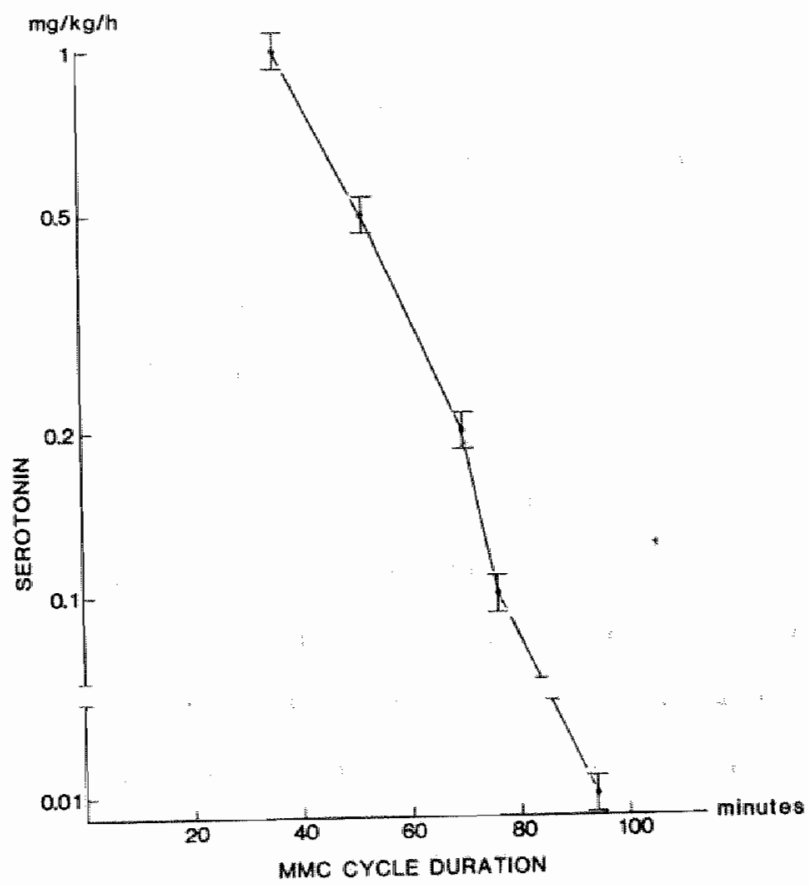

Figure 1. Dose-response relationship of intravenous infusion of serotonin on the MMC cycle duration. 
of the control MMC (91\%). As in the control group, when phase III was seen $1 \mathrm{n}$ the terminal fleum, a new one was beglniting in the duodenum. The time required for a phase III to migrate from the duodenum to the terminal ileum during administration of serotonin at $1 \mathrm{mg} / \mathrm{kg} / \mathrm{h}$ was $35.8 \pm 5.5 \mathrm{~min}$ (F1gure 2).

The average frequency of slow waves with spike potentials in the sphincter of oddi, antrum, and duodenum for each phase of the MMC during the administration of gerotonin at $1 \mathrm{mg} / \mathrm{kg} / \mathrm{h}$ ls shown $1 \mathrm{n}$ Table 1 . There was no slgnificant difference as compared to the MMC preceding the admintstration of serotonin. The duration of the MMC following serotonin infusion was similar to the control, except when the 1 fusulon dose was $1 \mathrm{mg} / \mathrm{kg} / \mathrm{h}$. At this dose, the MMC following seratanin infugton $(76.2 \pm 12.1 \mathrm{~min})$ was shorter than the control $(90.1 \pm 12.9$ min) $(p<0.05)$.

Bolus admintstration of serotonin at $0.2 \mathrm{mg} / \mathrm{kg}$ caused the appeance of intense spike actiulty simultaneously in ald recording sites for a period of $3-5 \mathrm{~min}$. The frequency of bursts of pike potentials was 2 spikes/min in the antrum, 7 splkes/min in the splncter of oddi, 17 splkes/min In the duadenum, and $\mathbb{1} 4$ spikes/min in the 11 inm.

The cycle duration of the two MMCs following administration of methysergide was similar to that of the control MMCs. After administration of methysergide, infusion of serotontn at $1.0 \mathrm{mg} / \mathrm{kg} / \mathrm{h}$ reduced the cycle duration of the MMC to only $71.0 \pm 15.3$ min. This value was 


\section{Bursts of}

Spikes /min

serotonin $1 \mathrm{mg} / \mathrm{kg} / \mathrm{h}$ $\sqrt{ }$

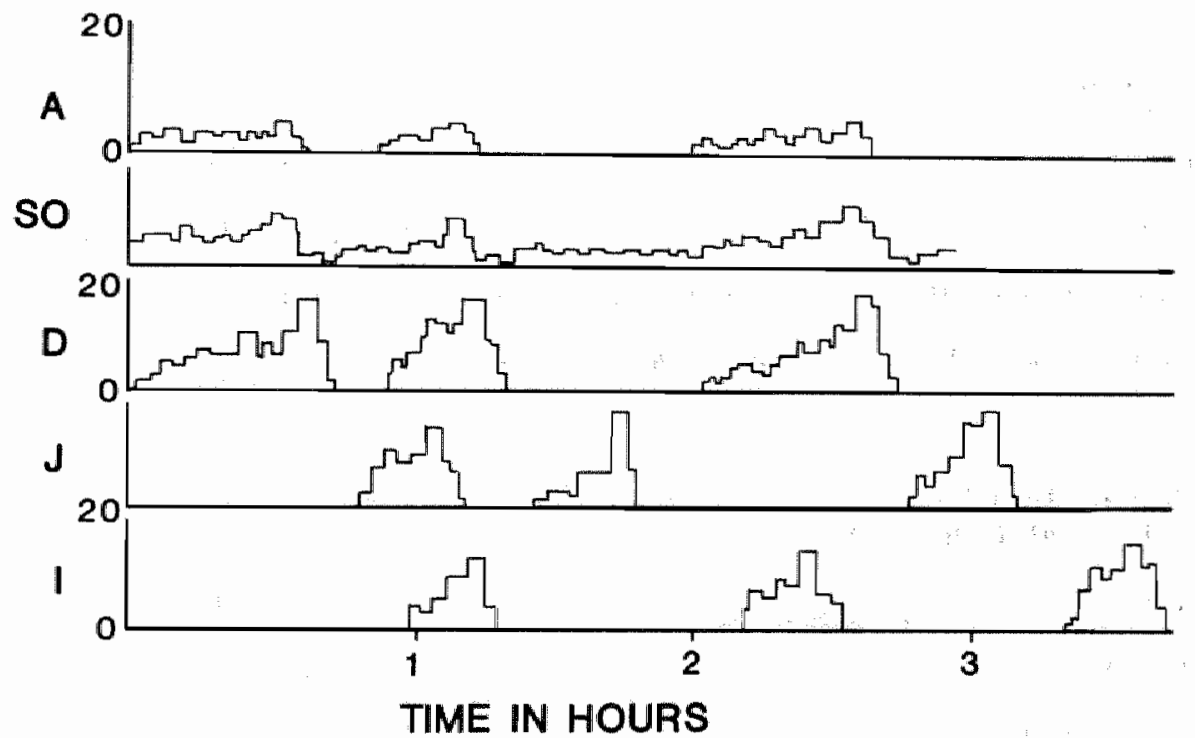

Figure 2. Histograms showing temporal distribution of slow waves with spike potentials in the antrum (A), sphincter of Oddi (SO), duodenum (D), distal jejunum (J), and distal ileum (I) of an opossum. Infusion of serotonin at a dose of $1 \mathrm{mg} / \mathrm{kg} / \mathrm{h}$ reduced the duration of the MMC cycle and increased the velocity of propagation of phase III from the stomach to the ileum. 
Myoelectrical Activity of the Antrum, Duodenum, and Sphincter of Oddi

Control $\mathrm{MMC}^{\dagger}$

Antium

Duodenum

Sphincter of Oddi

Duration $(\min )^{\dagger \dagger}$
0

0

$$
2.8 \pm 0.5
$$

$50.1 \pm 8.2$

$$
1.9 \pm 0.3
$$

$$
3.1 \pm 0.2
$$$$
1.8 \pm 0.2
$$

$$
5.9 \pm 0.8
$$

$16.7 \pm 0.7$

$$
5.3 \pm 0.8
$$

$$
4.3 \pm 0.4
$$

$5.7 \pm 0.4$

$3.2 \pm 0.5$

$31.3 \pm 5.4$

$6.7 \pm 0.4$

$4.1 \pm 0.6$

MMC During Infusion

of Serotonin at $1 \mathrm{mg} / \mathrm{kg} / \mathrm{h}^{\dagger}$

Antrum

Duodenum

Sphincter of Oddi

Duration (min) ${ }^{\dagger \dagger}$

$\begin{array}{crrr}0 & 2.1 \pm 0.3 & 3.1 \pm 0.3 & 2.0 \pm 0.3 \\ 0 & 6.5 \pm 0.7 & 16.5 \pm 0.5 & 4.9 \pm 0.3 \\ 3.0 \pm 0.2 & 4.7 \pm 0.4 & 6.1 \pm 0.3 & 3.0 \pm 0.4 \\ 12.3 \pm 2.9^{*} & 14.5 \pm 3.5^{*} & 6.2 \pm 0.4 & 3.6 \pm 0.5\end{array}$

$\dagger$ Values given as mean \pm 1 S.D.

t† Duration of each phase in the duodenum.

* This value is significantly greater than the corresponding value in the column above at the 18 level, $p<0.01$. 
slgnificantly greater than the MMC duration obtalned during Infusion of serotontm at $1 \mathrm{mg} / \mathrm{kg} / \mathrm{h}$ wh no pritor administration of methysergide $(36.6 \pm 5.4 \mathrm{~min} ; \mathbb{P}<0.01)$.

Diarrhea was observed in four experiments, three in which serotonin was infused at a dose of 1 mg/kg/h and one experiment at a dose of $0.5 \mathrm{mg} / \mathrm{kg} / \mathrm{h}$. Diarrhea was defined as any bowel movement of liquld content that occurred during or within two hours of the experiment.

\subsection{DISCUSSION}

We have employed electromyoraphy to evaluate the effect of 5-hydroxytryptamine on the motility of the gastrointestinal tract. This technique allows one to assess the effects of a substance in animals in vivo for prolonged perlods of time and without the use of sedatives or anesthetics. In addition, the opossum provides fmportant advantages. This animal usually lies quitely for many hours whout the need of restraints and it exhibits a moelectric activity of the gastointestinal tract dillar to man. The sphincter of oddi in this species is extraduodenal and measures $2-3$ cm in length and, therefore, dissection of the pancreas and duodenum is not necessary in order to implant the electrodes.

In our study, continuous intravenous administration of serotonin reduced the cycle duration of the MMc and Increased the velocity of propagation of the phase III. These changes were dose-dependent and were abserved ondy 
With high doseg of serotonfin of $0.1 \mathrm{mg} / \mathrm{kg} / \mathrm{h}$ or more. Infuston at $0.01 \mathrm{mg} / \mathrm{kg} / \mathrm{h}$ had no effect on the motility of the gastrointestinal tract. The changes observed in the motility of the gastrolntestinal tract were not more intense In some speciflc segments of the small bawel as suggested by some authors (17). The changes occurred 1 in all segments of the gastrointestinal tract studied, included the antrum, and were characterized by a continuous and organized increase in the velocity of propagation of the activity front (phase III) of the MMC from the antrum to the terminal ileum.

Bolus infusion of 5-hydroxytryptamine interrupted the MMC temporarily and increased the splke activity of the gastrolntestinal tract in all recording sites simulaneously. This effect was temporary, possibly due to rapld metabolism of serotonin, primarily in the liver and lungs. Ruckebusch and Bardon also described a stimultaneous Increase $1 \mathrm{n}$ the contractile activity of the antrum and duodenum following intravenous bolus admintstration of serotonin 1 in sheep $(12)$. Recordings of the jejunum and 11 eum were not obtalned in their study. on the other hand, these athor observed that intrawenous admindstration of methyserglde, at a dose of $0.1 \mathrm{mg} / \mathrm{kg}$, 1 ncreased the MMC frequency $1 \mathrm{n}$ the antrum and duodenum. The cycle reduction was les prominent following Intraduodenal than intravenous Infugion of methyserglde. We have observed no change of MMC cycle duration following intravenous administration of methysergide. These different results may be related to the 
use of different andul species.

However, evidence has accumulated recently that serotonin stimulates the intestine by acting on receptors on cholinergic neurons and directly on smooth muscle receptors (18). Methysergide is an effective, competitive antagonist af 5-hydroxytryptamine on smooth muscle serotonin receptors but not on serotonin receptors on cholinergic neurous of the sma11 intestine $(18,19)$. Therefore, the partial inhib1tion of the effect of serotonin on the MMC cycle duration by methysergide observed in our study is possibly due to the selective inhibition of methysergide at the smooth muscle receptors but not at the neuroenteric receptors.

serotonin has been demonstrated to stimulate the motility of the stomach and small bowel both 1 in wivo and in vitro In several species including man, dog, cat, and mouse $(5-9,15): \quad$ Adminfstration of large doses of 5-hydroxytryptamine induces diarrhea in mice and other antmals (16). In man, the lncreased production of serotonin by carcinoid tumors has been associted with hypermotility of the small bowe 1 and diarrhea (3). Antiserotonerglc agents may control or alleviate these annoylng sympoms in patients with carcinold tumors.

The mechanism by which serotonin-producing tumors cause diarrhea is not clear. This study suggest that an increase in the velocity of propagation and frequency of the MMC may play an important rale in the production of diarraa, $1 n$ patients with carcinoid syndrome. A comparable patern of 
organized myoelectric activity was observed during experimental studies with roxins and bacterla cultures. Mathla a a foud that infuston of cholera enterotoxin to rabbits Induced a series of organized migrating action potentials complexes in an 1leal loop (20). S1milar abnormal patterns of small bowel motility were observed following admintstration of other agents which induce diarrhea $(21,22)$

The change in frequency of spike potentials in the sphincter of odd1 during infusion of serotonin also correlates with the MC in the duodenum. There was a proportional reduction of the duration of the MMC phases $\mathbb{1}$ n the sphincter of addi, but the frequency for each phase, prior to and during infusion of serotonin, was similar.

We concluded from this study that contrnuous infusion of serotonin in the opossum increases the frequency of MMCs and the velocity of propagation of phase III of the MMC from the antrum to the terminal 1leum. This change in the motility of the gastrolntestinal tract may be responsible for the diarhea assoclated with administration or increased synthesis of serotonin by carcinold tumors.

\subsection{SUMMARY}

The effect of serotonin on the myoelectric activity of the gastrolntestinal tract was evaluated in seven opossums. The following doses of serotonin were admintstered Intravenously at a continuous rate of $0.2 \mathrm{ml} / \mathrm{m}: 0.01,0.1$, 
$0.2,0.5$, and $1.0 \mathrm{mg} / \mathrm{kg} / \mathrm{h}$. Serotonin reduced the perlodelty of the migrating myoelectric complexes. The migrating myoelectric complex cycle duration reduction was dose-dependent (correlation coefflcient $=0.82 ; \mathrm{p}<0.01$ ) and the cycle length varied from $90.6 \pm 15.6$ minutes during infusion of serotonin at $0.01 \mathrm{mg} / \mathrm{kg} / \mathrm{h}$ to $36.6 \pm 5.4$ mutes during infusion at $1.0 \mathrm{mg} / \mathrm{kg} / \mathrm{h}$. The time interval for a phase III to migrate from the duodenum to the terminal 11 eum during administration of serotonin at $1.0 \mathrm{mg} / \mathrm{kg} / \mathrm{h}$ was $35.8 \pm$ 5.5 minutes (control $84.3 \pm 12.6$ minutes; p $(0.01$ ). The cycle duration of the two migrating myoliectric complexes following administration of methysergide at $1.0 \mathrm{mg} / \mathrm{kg}$ was similar to the control migrating myoelectric complexes. Dlarrhea was abserved in four expertments. We concluded that continuous infusion of serotonin in the opossum increases the velocity of propagation of the phase III of the migrating myoelectric complex from the antrum to the terminal 1leum.

\subsection{REFERENCES}

1. Gershon MD. The enteric nervous system. Ann Rev Neurosed $4: 227-272,1981$.

2. Dubois A, Jacobowitz DM. Fallure to demonstrate serotonergic neurons in the myenteric plexus of the rat. Ce11 Tissue Res $150: 493-496,1974$.

3. Engelman $K$, Lovenberg $W$, sfoerdsma A. Inhlbition of seratonin synthesis by para-chlorophenylalamine in 
patients with the carcinold syndrome. N Engl J Med $227: 1103-1108,1967$.

4. Morin LJ, Zuerner RT. Retroperttoneal fibrosis and carcinold tumor. JAMA $216: 1647-1648,1971$.

5. Anderson JJ, Bolt RI, UIIman BM, Bass P. DIfferentil responge to various stimulants in the body and antrum of the cantine stomach. Am J Dig Dis 13:147-156, 1968 .

6. Bulbring E, Crema A. Observations concerning the action of 5-hydroxytryptamine on the peristaltic reflex. Br J Pharmaco1 $13: 444-457,1958$.

7. Ludwick JR, Wiley JN, Bass P. Extraluminal contractile force and electrical activity of reversed canine duodenum. Gastroenterology $54: 41-51,1968$.

8. Mistewicz JJ, Waller SL, ELsner M. Motor responses of human gastrointestinal tract to 5-hydraxytryptame 1n v1vo and in vitro. Gut $7: 208-215,1966$.

9. Prove J, Ehrlein HJ. Effects of 5-hydoxytryptophane and Insulin on gastric motility and emptying in dogs. Q J Exp Phys101 68:209-219, 1983 .

10. Szurszewsk1 JH. A tigrating electric complex of the canine smal1 intestine. Am J Physiol 217:1757-1763, 1969.

11. Code CF, Marlett JA. The interdigestive myoelectric complex of the stomach and small bowel of dogs. J Physiol (London) 246:289-309, 1975 .

12. Ruckebusch $Y$, Bardon $T$. Invalvement of serotonergic mechanisms in inftiation of small intestine cyclic motor 
events. Dig Dis Sci 29:520-527, 1984.

13. Honda R, Tootil J, Dodds WJ, Sarna S, Rogan: WJ, Itoh $\mathbb{Z}$. Relationship of ephincter of odd splke bursts to gastrointestinal myoelectric activity in consclous opossums. J Clin Invest $69: 770-778,1982$.

14. Coelho JCU, Moody FG, Senninger N. A new method for correlating pancreatle and blliary duct pressures and sphincter of odd electromyography. surgery $97: 342-349$, 1985.

15. Hendrix TR, Atkinson M, Clifton JA, Ingelfinger T. The effect of 5-hydroxytryptamine on integtinal motor function in man. Am J Med 23:886-893, 1957 .

16. Woolley DW. Conventent method for assay in vivo of antimetabolites of serotonin. Proc soc Exp Biol Med $98: 367-370,1958$.

17. Garattini S, Valzeld L. Serotonin. NeW York, Elsevier Publishing Co., 1965.

18. Danfel EE. Pharmacology of adrenergic, cholinergic, and arugs acting on other receptors in gastrolntestinal muscle. In Bertaccini G, editor. Mediatoro and Drugs in Gastraintestinal Motility II. New York, Springer-Verlag, $1982, p p \cdot 247-322$.

19. Furness JB, Costa M. On the posslbility that an indoleamines as a neurotransmitter in the gastrointestinal tract. Biochem Pharmacol 28:565-572, 1979.

20. Mathias JR, Carlson GM, Bertiger G, Martin JL, Cohen 5 . 
Migrating action potential complex of cholera: A possible prostaglandin-induced response. Am J phystol $232: 5529-\mathbb{E} 53,1977$.

21. Justus PG, Mathlas JR, Carlson GM, Mortin JL, Formals. The myoelectric activity of the small intestine in response to clastridium diffictle culture filtrates. Gastroenterology $76: 1163,1979$.

22. We1sberg PB, Car1son GM, Cohen $S$ : Effect of Salmone11a typhimurium on myoelectric activity in the rabbit ileum. Gastronterology $74: 47-51,1978$. 


\section{GENERAL DISCUSSION}

The role of the sphincter of oddi in transporting biliopancreatic secretion into the duodenum and as a source of upper abdominal pain, Jaundice, and pancreatits has been controversial. Inttial studies suggested that the transport of bile into the duodenum was dependent only on the rate of pressure of hepatic bile production, the galibladder contraction, and the resistance of the sphincter of Oddi. These studies suggested that the sphincter of oddi remained closed during fasting and that, following a meal, the sphincter relaxed and allowed bile to flow into the duodenum. However, recent stude employtng electromyography, cineradiography, and endoscoplc manometic techniques indicate that this simple concept of motor activity of the sphincter of odd1 is not accurate. The sphincter of odd actually has a more active role. It probably propels pancreatic julce and bile into the duodenum by a milking mechanism and has a major function of coordinating the time and rate of draining these secretions into the duodenum.

Endoscopic continuous pressure recordings of the pancreatic 
and biliary ducte and sphincters in man have shown that the motility of the sphincter of oddi is different from that of the duodenum and that the sphincter of oddi exhibits phasic wave activity that usualiy migrates in an antegrade fashion. The deternimation of the frequency and amplitude of these phasic ?r?rwaves as we 11 as the basal sphincter of oddi pressure has become important clinically in order to recognize patients with billary diskinesia. Phaslc waves and pressure changes in the sphincter of oddi following administration of morphine and cholecystokintin may also be of diagnostic value.

Electromyography has emerged as an important experimental tool used to sudy the motility of the gastrointestinal tract. Recently, electromyography of the gphncter of oddt has also been performed in the rabbit and the opossum. This method allows one to evaluate the effect of several drugs on consclous, nonanesthetized animals over prolonged periods of time. Simultaneous biliary and pancreatic pressure recordings may provide additional Information. In the present thesis, electromyography of the gastrolntestinal tract and sphincter of oddi in the opossum was evaluated in elght experimental studies. Inttally, the experiments were performed under physlologlcall condtions in nommedicated, conscious antmals, both in the fasting and fed states. The effect of gastrointestinal hormones that posibly influence the digestive process was assessed. Motility of the gastrointestinal tract and sphincter of oddi followitg abdominal operations and adminsteration of substances that cause gastrointestinal disturbances was also studied. 
The normal electromyographic patern of the sphineter of Oddi and gastrolntestinal tract was described in chapter 2 . The sphincter of oddi in the opossum generated spontaneous spike potentials which propagated from the proximal to the distal portion of the sphincter. The spike potentials are associated with peristaltic contractions of the sphincter of odd which possibly have the function of transporting bile and pancreatic juice from the sphincter of oddi into the duodenum. This hypothesis has been confirmed by combined electromyographic and cineradiographic studies.

Although the spike actioity in the sphincter of oddi was different from that in the duodenum, the frequency of spike potentials in the sphincter of oddi correlated with the myoelectric migrating complex (MMC) phases in the duodenum. The frequency of sphincter of oddi spike potentiala increased fram phase $I$ to phase II of the MMC and then 1 tecreased rapidly during phase IV to start a new cycle.

A new experimental model whith allowed correlation of pancreatic duct and common duct pressure with the motility of the sphincter of oddu was also described. A temporary elevation of the pancreatic and biliary duct pressures of 1 to 3 umg was observed with each sphincter of odd spike potential in most experiments. There was a variation $1 n$ the number of preasure elevations related to the frequency of splke potentials in the sphincter of oddi during feeding and the four phases of the MMC, but baseline pressure remafned constant. The constant baseline pancreatic and biliary duct pressures during all MMC phases and 
feeding tate sugest that pressure is not the main regulatory mechantom of bile and pancreatic juice flow into the duodenum. It is posalib that the splke potential variation in the sphincter of odd may have an important role in the rate of blliopancreatic secretion into the duodenum.

In Chapter 3, electromyographic recordings were obtained from consclous opossums both in the fasted state and following admintistion of lsocaloric mount of protein, fat, carbohydrate, and a mixture of equal parts of theses three nutrients. A correlation between the frequency of spike poterutis in the spuincter of oddi and the small bowel was observed. The aliments that caused more spike activity in the small bowel were the same ones that increased the frequency of spike potentials in the splincter of oddi.

Fat and mixed food resulted in the greatest incidence of splke activity in the gastrointestinal tract, fallowed by protein. The lowest Incidence of slow waves with splke potentials in the small bowel was observed following feeding of carbohydrates. The lowest spike activity in the sphincter of odd was observed ater carbohydrate feeding. There was no signiflcant difference in the 1 ncidence of splke potentials in the sphincter of oddi following administration of fat, protein, and mixed food. The durtion of the fed pattern was related to the type of food; fat caused the longest duration and the shortest fed pattern was created by ingestion of carbohydrate. A correlation between the duration of the fed pattern and the frequency of splke potentials in the sphincter of odd and gastrolntestinal tract was also 
observed.

In chapter 4, electromyagraphic activities of the sphineter of odd and duodenum and the pancreatic and biliary duct pressures were recorded during continuous infusion of cholecystokinin, pentagastrin, glucagon, secretin, and acetylcholine. Cholecystokinin and pentagastrin increased the frequency of splke potentials in the sphincter of odd and duodenum and, in most instances, interrupted the MMC. The new myolectric activity pattern resembled that of the fed state. GIucagon and secretin inhibited the onset of the MMC and reduced the frequemcy of slow waves with superimposed spike potentials in the sphincter of oddl and duodenum. Although there was variation In the frequency of pressure elevations related to sphincter of oddi spike potentials, the baseline pressure in the comon duct and pancreatic duct remained constant during infusion of the hormones.

Acetylcholine was the substance that caused the greatest increase in the frequency of bursts of splke potentials into the sphincter of oddi and duodenum; amost each sow wave in the sphincter of odd and duodenum was superimposed with sptke potentials. This intense spike activity in the sphincter of odd possibly hamered bile and pancreatic juice refillig of the sphincter and transport into the duodenum. Therefore, both biliary and pancreatic duct pressures increased.

The findings of this study suggest that the pancreatic and biliary duct pressures are maintalned at a canstant level by increasing or decreasing the flow of bllopancreatic secretion 
into the duodenum through changes in the frequency of sphncter of Ddd spike potential. The gastrointestinal hornones may have an important role in regilating the excretion of bile and pancreatic Julce into the duodenum.

In Chapter 5, the effect of abdominal operations on the sphtincter of oddf and gatrolntestinal myoelectric activity was evaluated both in the fasting and fed states. Flve different surglcal procedures were performed: a flve-minute, a one-hour, and a three-hour laparotomy with intestinal handing, enteroenterostomy, and gastrojejunostomy.

Although the time of appearance of the MC following the abdominal operations varied with the type and duration of the surgical procedures, normal myoelectric activity of the gastrointestinal tract was observed within 24 hours after the operations in most experiments. Procedures that severed the upper gastrolintestina1 tract interrupted the MMC for longer perlods of time. The time of appearance of the MMC was proportional to the duration of the operation.

Admintotation of food on the first day that the MMC was observed ater the operation resulted in a normal fed pattern in all but two experiments, one of which occurred in an animal with an intra-abdominal abscess. A fed pattern did not occur when food was Infused before the MMC appearance. These findings suggest that the presence of the MMC is necessary to have a normal fed pattern. However, the fed pattern may be absent or delayed in antmals that have a normal MMC, as in the instance of the opossum wth an intra-abdominal abscess. The results from this study 
support the view that intestinal motllity 1 s not depressed for prolonged periods af time following most abdominal operations.

In Chapter 6, recordings of the electromyogaphic activty of the sphincter of oddi and upper gastrolntestinal tract and pancreatic and biliary duct pressures vere obtalned during administration of ethanol into the stomach or into the duodenum. Instilation of alcohol caused a minute burst of splke activity in the duodenum that was followed by a five- to ten-minute quiescent period. A vigorous phase III-like activity then ensued in most experiments. This phase III-like activity was similar to the normal MMC phase III in duration, frequency, and amplitude of spike potentials.

A significant increase in the frequency of splke potentials occurred for 15 to 20 minutes in the sphincter of oddi 10 all experiments. The two largest increases occurred in the first minute after alcohol instillation and simultaneous with phase III-like activity in the duodenum. There was an increase in the number of pancreatic and blliary pressure elevations related to sphincter of oddi splke-burst potentlals following ethanol 1nstilation, but baseline pressureg remalned contant.

Repetitive myolectric activity distubances of the sphincter of oddi that may occur following chronlc ingestion of alcohol may be an important contributory factor in the pathogenesis of alcoholic pancreatitis.

The mechanism by which alcohol gtimulates the motility of the sphincter of $0 d d i$ and duodenum was evaluated in chapter 7 . Ethanol was infused into the stomach, duodenal stump, fejunum, 
and 1 ntratenougly in apossums that were subjected to gatrojejunstomy with duodemal exclusion. The concenteaton of plasta motilin was a 1 so determined during the normal MMC phases and durlng the phase TII-1 lke activity caused by alcohol.

Instllation of ethanol into the stomach or duadenun catsed phase TII-IIke activity in the sphincter of oddI and upper gastrolntestinal tract $1 \mathrm{n}$ mot experiments. Jejunum or 1ntravenous: infulon of ethanol did not change the motility of the phtncter of oddi. There was no correlation between alcohol blood levels and the appearance of phase III-IIke activity.

The concentration of plasma notilin was elewated during phase III-1Hke activity caused by ethanol and was simllar to that of the normal phase III of the MMC. This suggests that the phase III-11ke activity produced by administration of alcohol may be caused by the release of motilin from the upper gastrointestinal tract.

In Chapter. 8, the electromyogaplc pattern of the gastrolntestinal tract and sphincter of odd was evaluated durlng Intugan of 16,16 d1methyl prostaglandin E, (dmPG,

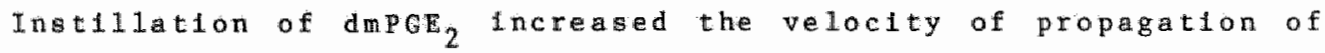
the MMC $1 \mathrm{n}$ the gatrotntegtinal tract from the stomach to the

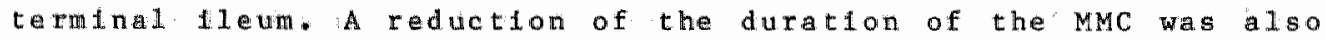
observed. The time reduction of the MMC was due to a shortentng of the durator of both phases: I and II. Phase III was similar to the control in duration, amplitude, and frequency of bursts of splke potentids. The reduction of the MMC was dose-dependent and varied from $37.6 \pm 6.4$ minutes during infusion of dmPGE at 5 
$\mu \mathrm{g} / \mathrm{kg} / \mathrm{h}$ to $74.2 \pm 11.4$ minutes at $0.1 \mu \mathrm{g} / \mathrm{kg} / \mathrm{h}$. Bolus linfusion of ${ }_{\text {dmPGE}}$ caused intense spike activity for tro to four ninutes in al recording sites. Administration of indomethactin did not change the myoelectric activity pattern of the sphincter of oddi and duodenum.

These important changes in the gastrointestinal motfitty my be responsible for the diarrhea that is often observed following administration of dmPGE, during experimental treatment of peptic ulcer disease.

The effect of both continuous and bolus admintstration of serotonin on the myoelectric activity of the gastrolntestinal tract and sphincter of oddi was assessed in chapter 9 . continuous intravenous administration of serotonin increased the veloctty of propagation of the phase III and reduced the duration of the MMC. These changes were dose-dependent and were observed only with high doses of serotonin of $0.1 \mathrm{mg} / \mathrm{kg} / \mathrm{h}$ or more. The changes accurred in a11 segments of the gastrolntestinal tract studid and were characterized by organized increase in the velocity of propagation of the activity front of the MMC from the antrum to the terminal ileutin.

Bolus infusion of serotonim interrupted the MMC temporaridy and increased the frequency of spike potential in all recording sites of the gastrointestinal tract simultaneousiy.

Infusion of methysergide did not change the cycle duration of the MMC. However, administration of methysergide prior to infusion of serotonin partialiy inhibited the effects of serotonin on the MMC cycle duration. 
This partial inhibition is possibly due to the selective Inthition of methysergide on the smooth muscle receptors but not In the newroenteric receptors.

The change in frequency of spike potentials in the sphincter of oddi during infusion of serotonin also correlated with the MMC in the duodenum. This study guggests that an increase in the velocity of propagation and frequency of the MMC may play an Important role in the production of diarrhea in patients with carcinold syndrome.

Several conclustons can be draw from these experimental studies. Although the motility in the sphincter of oddi is different from that in the duodenum, both the sphincter of oddi and duodenum exhibit cyclic changes in the frequency of spike potentials that correlate with the phases of the MMC. The correlation between the frequency of splke potentials in the sphincter of odd and duodenum was observed during fasted and fed states and during administration of all substances evaluated in thls serfes of experiments. The findings that cholecystakinin and pentagatrin stimulate and that glucagon and secretin decrease the frequency of burst of splkes in the sphincter of oddi suggest that these gatrolntestinal hormones may have an important function In controlling the flow of biliopancreatic secretion Into the duodentim. The 1 ntense spike activity that occurred in the splincter of odd following infuston of alcohol may contribute to sphincter of oddi dysfunction. The increase in motilin plasma levels following admintstration of ethanol suggests that phase III-11ke activity produced by instiliation of 
alcohol may be caused by the release of wotilin from the upper gastrolntestinal tract. The increase ln velocity of propagation of phase III of the MMC from the antrum to ther terminal ileum during infusion of serotonin and 16,16 dimethyl prostaglandin E2 may be an important contributory factor in the production of diarrhea in patients with carcinold syndrome or following administration of these two substances. The return of normal gastrolntestinal tract motility following abdominal operationg depends on the type and duration of surglcal procedure. Although intestinal motility is normal within 24 hours following most abdominal. operations, procedures that severed the uper gastrointestinal tract caused the longest disrupton of the intestinal motility.

The application of these conclusions to the clinical situation needs additional. Investigations. other studies demonstrated that the myoelectric activity of the gastrointestinal tract of the man is similar to that of the opossum, both in the fasting and fed. states. Endoscopic manometric studies have also showed that the human sphincter of oddi also exhibits phasic wave contractions that wigrates alstally, suggesting, therefore, a pumping mechanim in the sphincter of oddi, like in the opossum. Further studies are also necessary to evaluate the motility of the sphincter of oddi Eollowing aperations on the sphincter, 1.e., sphincterototom and sphincteroplasty. 


\section{SUMMARY}

In order to study the motility of the gastrointestinal tract and sphincter of oddi, the opossum was employed as an experimental animal. Electromyographic recordings of the gastrointestinal tract and sphincter of oddi were performed in conscious, non-medicated opossums under physiologic conditions and following abdominal operations or administration of several substances. Although the spike activity in the sphincter of oddi was different from that in the duodenum, its frequency correlated with the migrating myoelectric complex (MMC) phases in the duodenum. Temporary elevation of the pancreatio and biliary duct pressures was observed with each sphincter of oddi spike potential in most experiments. There was a variation in the frequency of pressure elevations related to spikeburst potentials during the four phases of the MMC and Feeding, but base-1lne pressures remained constant.

After feeding, the interdigestive phases of the MMC in the sphincter of oddi and duodenum were abolished and substituted by a fed activity pattern. The frequency of spike potentials in the sphincter of oddi and small bowel and the duration of the fed pattern were dependent on the type of food. They were the greatest for fat and mixed food, intermediate for protein, and the lowest for carbohydrate.

Administration of cholecystokinin and pentagastrin abolished the MMC and caused a fed pattern-like activity 
in the sphincter of Oddi and duodenum. Glucagon and secretin reduced the Erequency of spike potentials or inhibited the onset of the MMC. Acetylcholine was the substance that caused the greatest spike activity in the sphincter of oddi and duodenum.

Normal myoelectric activity of the gastrointestinal tract was observed within 24 hours following most abdominal operations and its appearance depended on the type and duration of the surgical procedure. A fed pattern did not occur in the experiments in which food was given before the appearance of the MMC. However, a normal fed pattern was observed on the first aly of the MMC appearance in all but two animals, one of which had an intra-abdominal abscess.

Instillation of alcohol into the stomach or duodenum caused appearance of intense spike activity in the sphincter of oddi and duodenum that was similar to phase III of the MMC in duration, frequency, and amplitude of spike potentials. There was no correlation betwen appearance of phase III-like activity and alcohol blood level. The concentration of plasma motilin was elevated during phase III-like activity and was similar to that of the normal phase III of the MMC. This suggests that administration of alcohol causes phase III-like activity due to the release of motilin from the upper gastrointestinal tract.

Continuous intravenous infusion of 16,16 aimethy 1 prostaglandin $E_{2}$ and serotonin increases the frequency of MMC and the velocity of propagation of phase II of 
the MMC from the antrum to the terminal ileum. The change in frequency of spike potentials in the sphincter of oddi during infusion of 16,16 dimethyl prostaglandin $E$ and serotonin also correlates wh the MMC in the 2

duoderum. These changes in the motility of the gastrointestinal tract may be responsible for the dirchea associated with administration of 16,16 dimethyl prostaglandin $E$ or increased synthesis of serotonin by carcinoid tumors.

It is concluded from these experimental studies that although the motility in the sphincter of oddi is different from that in the duodenum, both the sphincter of oddi and duodenum exhibit cyclic changes in the Erequency of spike potentials that correlate with the phases of the MMC. The correlation between the frequency of spike potentials in the sphincter of Oddi and duodenum was observed during fasted and fed states and during administration of all substances evaluated in this series of experiments. Changes in the motility of the sphincter of oddi following administration of different foods or gastrointestinal hormones may be important in controlling the flow of biliopancreatic secretion into the duodemum. Disturbances in the myoelectric activity of the sphincter of oddi following infusion of alcohol may contribute to sphincter of oddi dysfunction. 


\section{SAMENVATTING}

Ter bestudering van de motiliteit van tractus digestivus in het algemeen en de sphincter van oadin het byzonder worden in dit proefschrift de resultaten beschreven van electromyografische registratie van de tractus digestivus en de sphincter van oddi. De experimenten en registraties werden vericht bij opossums onder fysiologische omstandigheden zonder medicatie na abdominale operaties en na toedienen van verschillende medicamenten. De actie potentialen in de sphincter van oddi verschilden van die in het duodenum, maar de exequentie correleerde met de fasen van het migrerend motorisch complex (MMC) in het duodenum. Tijdens iedere actie potential van de sphincter van oddi werd in de meeste experimenten een tijdelijke verhoging van de druk in de ductus pancreaticus en de ductus choledochus gevonden. Er was een variatie in het aantal drukverhogingen die afhankelijk was van het patroon van het activiteitenfront van actie potentialen gedurende de vier verschillende fasen van het MMC en tijdens voeding, maar de basale drukken bleven onveranderd.

Na voeding verdween het normale fasen patroon van het MMC in de sphincter van oddi en het duodenum. In plats biervan verscheen een voeaingsactiviteitspatroon. De frequentie van de actie potentialen in de sphincter van odall en in de dunne darm en de dur van het bij voeding passend 
activiteitspatroon bleken afhankelijk te zijn van de aard van de voeding. zij waren het grootst na vet en gemengd voedsel, iets minder na het toedienen van eiwitten, en het laagst na koolhydraten.

Toediening van cholecystokinine en pentagastrine gaven aanleiding tot afbraak van het MMC, zowel in de sphincter van oddi als in het duodenum een activiteitspatroon passend bij voeding. Glucagon en secretine gaven een vermindering van het aantal actie potentialen of verhinderden het ontstaan van het MMC. Acetylcholine veroorzakte de grootste electrische activiteit in de sphincter van oddi en het duodenum.

Na een laparotomie keerde de normale electrische activiteit van de darm meestal weer binnen 24 uur terug. Dit was afhankelijk van het type en de duur van de operatie. Na toediening van voedsel verscheen het voedings- activiteitspatroon niet voordat het MMC was terug gekeerd.

Toediening van alcohol in mag en duodenum veroorzakte een verhoging van electrische activiteit en actie potentialen in de sphincter van oddi en het duodenum, gelijk an die van fase III van het MMC, in duur, frequentie en amplitude (van de potentialen). Er was geen correlatie tussen het verschijnen van deze activiteit en de alcohol spiegel in het bloed. De concentratie van het darmhormoon motiline in het plasma was verhoogd tijdens de op fase III gelijkende activiteit en was gelijk aan die tijdens een normale fase III van het MMC. Dit suggereert dat toedienen van 
alcohol een op Ease II gelijkende electrische activiteit veroorzaakt, als gevolg van het vrijkomen van motiline in het bovenste deel van de tractus digestivus. Continue intraveneus toedienen van 16,16 dimety 1 prostaglandine $\mathrm{E}_{2}$ en serotonine leidde tot verhoging van het aantal MMC's en de snelheid van voortgeleiding van fase III $\operatorname{van}$ het MMC van het antrum tot an terminale ileum. De verandering in de erequentie van de actie potentialen in de sphincter van oddi gedurende het toedienen van 16,16 dimetyl prostaglandine en serotonine correllerden ook met het MMC in het duodenum. Deze veranderingen in motiliteit van de tractus digestivus zouden verantwoordelijk kunnen zijn voor de diarrhee die vaak gezien wordt na het toedienen van 16,16 dimetyl. prostaglandine $E$ of bij verhoogde synthese van serotonine bij carcinoid tumoren.

Deze experimentele studies leidden tot de conclusie dat, ondanks het verschil in de motiliteit, de sphincter van oddi en het duodenum, cyclische veranderingen in de frequentie van actie potentialen ondergaan die correleren met de verschillende fasen van het MMC. De correlatie van actie potentialen in de sphincter van oddi en het duodenum werd gevonden gedurende de periode van vasten en na voeding, als ook tijdens het toedienen van de verschillende stoffen die werden onderzocht in deze serie experimenten. Veranderingen in de motiliteit van de sphincter van oddi na het toedienen van verschillende soorten voedsel of gastro-intestinale hormonen kunnen mogelijk een rol spelen in de regulatie 
van de afvloed var gal en pancreas sappen naar het duodenum. De stoornissen in de electrische activiteit van de sphincter van addi na toediening van alcohol zou kunnen bijdragen tot dysfunctie van de sphincter van Oddi. 


\section{PUBLICATIONS OF THE STUDIES PRESENTED IN THIS THESIS}

1. Coelho JCU, Moody, EG, senninger N. A new method for correlating pancreatic and biliary duct pressures and sphincter of oddi electromyography. Surgery $97: 342-349$. 1985 .

2. Coelho JCU, Gouma DJ, Moody FG, Schlegel JF. The effect of feeding on myoelectric activity of the sphincter of oddi and gastrointestinal tract in the opossum. Dig Dis Sci (Ir press).

3. Coelho JCU, Moody FG, Senninger N, Li YF. Effect of gastrointestinal hormones on the sphincter of oddi and duodenum myolectric activity and on pancreatic and biliary pressures in the opossum. Arch surg (In press).

4. Coelho JCU, Gouma DJ, Moody EG, Li YF. Gastrointestinal myoelectric activity following abdominal operations in the opossum. World J Surg $9: 612-618,1985$.

5. Coelho JCU, Moody FG, Senninger N, Weisbrodt NW. Effect of alcohol upon myoelectric activity of the gastrointestinal tract and pancreatic and biliary duct pressures. Surg Gyn abst 160:528-533, 1985.

6. Coelho JCU, Gouma DJ, Moody FG, Senninger N, Li XF, Chey WY. Sphincter of oddi and gastrointestinal motility disturbance following alcohol administration in the opossum. World J Surg (In press). 
7. Coelho JCU, Gouma DJ, Moody FG, Li YF, Schlegel JF. Efect of 16,16 dimethyl prostaglandin $E$ on the myoelectric activity of the gastrointestinal tract of the opossum. Submitted for publication.

8. Coelho JCU, Gouma DJ, Moody FG, Li YF, Weisbrodt NW. Serotonin increases the velocity of propagation and frequency of the migrating myoelectric complexes. Submitted for publication. 


\section{CURFICULUM VITAE}

Julio C.U. Coellho was born on March 22, 1953 in Brazil.

He finished his redical school at the Federal University of Parana, Brazil in 1976. At graduation, he recelved the Prize Hildebrando de Araujo.

He finished his surgical residency at the cilnical Hospital of the Federal university of Paran in 1979 under the direction of the prof. Dr. Giocondo V. Artigas.

He was a Clinical Fellow at the Department of Surgery of the University of Illinois at Chicago for 3 years under the superviston of Prof. Dr. Bernard Sigel and Prof. Dr. Lloyd M. Nyhus. Received Honorable Mention of the Chicago Surgical Society in 1981 and $3 \mathrm{rd}$ Prize of the Sigma Xi Graduate student Research Forum of the University of I11.nols in 1982 .

He joined the Department of surgery of the Federal University of Parana in March, 1982 as Assitant professor and in the same year was promoted to Associate professor.

From August of 1983 up to present, he has been Working at the Department of surgery of the University af Texas as Visiting Assistant professor under the supervision of the Prof. Dr. Frank G. Moody. 